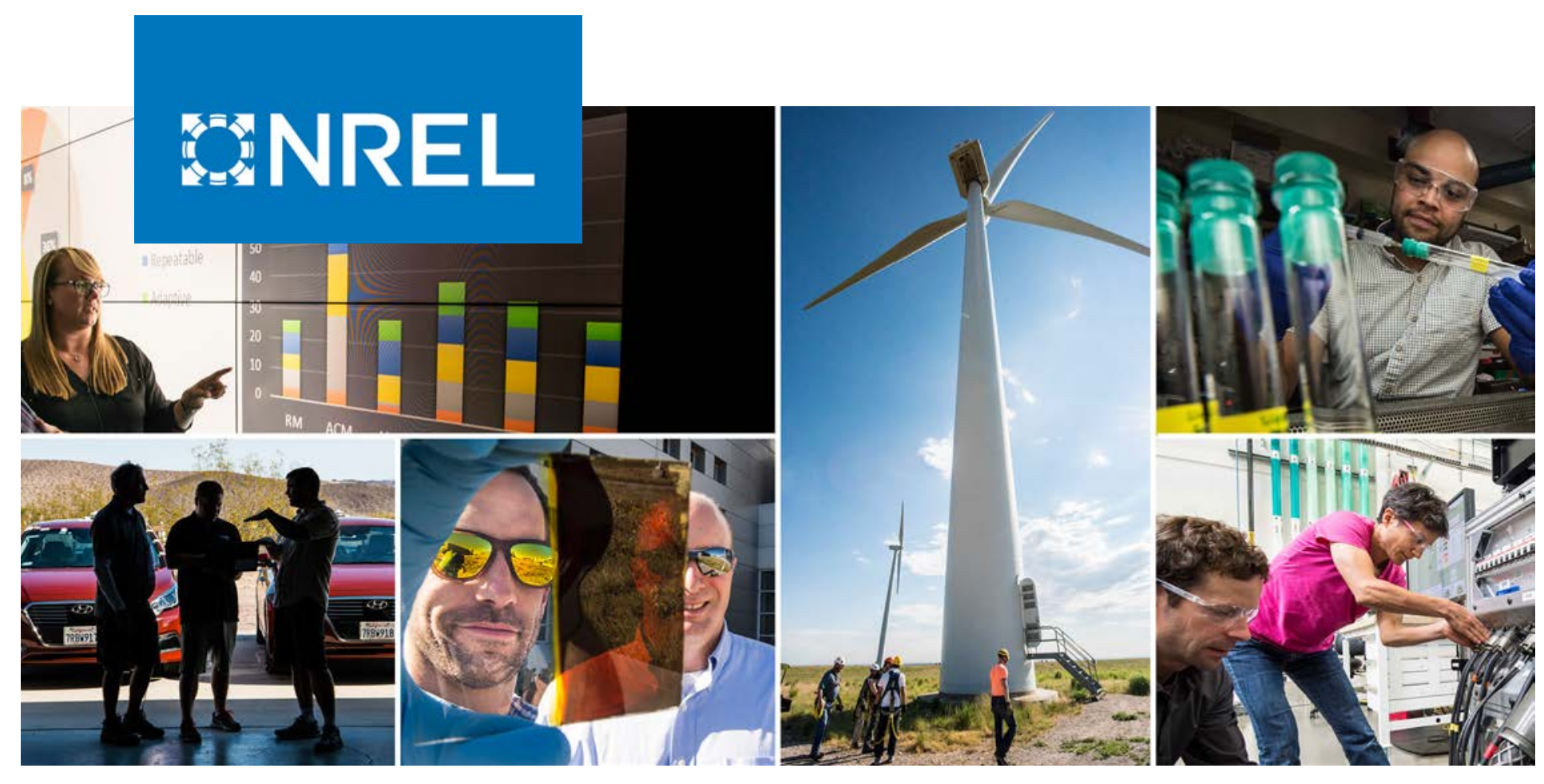

\title{
2017 Cost of Wind Energy Review
}

\author{
Tyler Stehly ${ }^{1}$, Philipp Beiter ${ }^{1}$, Donna Heimiller ${ }^{1}$, \\ and George Scott ${ }^{1}$
}

National Renewable Energy Laboratory

NREL is a national laboratory of the U.S. Department of Energy

Office of Energy Efficiency \& Renewable Energy

Operated by the Alliance for Sustainable Energy, LLC

This report is available at no cost from the National Renewable Energy Laboratory (NREL) at www.nrel.gov/publications.

\section{Technical Report}

NREL/TP-6A20-72167

September 2018 


\title{
GHREL
}

\section{Cost of Wind Energy Review}

\author{
Tyler Stehly ${ }^{1}$, Philipp Beiter ${ }^{1}$, Donna Heimiller ${ }^{1}$, \\ and George Scott ${ }^{1}$
}

National Renewable Energy Laboratory

\section{Suggested Citation}

Stehly, Tyler, Philipp Beiter, Donna Heimiller and George Scott. 2018. 2017 Cost of Wind

Energy Review. Golden, CO: National Renewable Energy Laboratory.

NREL/TP-6A20-72167. https://www.nrel.gov/docs/fy18osti/72167.

NREL is a national laboratory of the U.S. Department of Energy Office of Energy Efficiency \& Renewable Energy Operated by the Alliance for Sustainable Energy, LLC

This report is available at no cost from the National Renewable Energy Laboratory (NREL) at www.nrel.gov/publications.

Contract No. DE-AC36-08GO28308
Technical Report

NREL/TP-6A20-72167

September 2018

National Renewable Energy Laboratory 15013 Denver West Parkway Golden, CO 80401

303-275-3000 • www.nrel.gov 


\section{NOTICE}

This work was authored by the National Renewable Energy Laboratory, operated by Alliance for Sustainable Energy, LLC, for the U.S. Department of Energy (DOE) under Contract No. DE-AC36-08GO28308. Funding provided by the U.S. Department of Energy Office of Energy Efficiency and Renewable Energy Wind Energy Technologies Office. The views expressed herein do not necessarily represent the views of the DOE or the U.S. Government.

This report is available at no cost from the National Renewable Energy Laboratory (NREL) at www.nrel.gov/publications.

U.S. Department of Energy (DOE) reports produced after 1991 and a growing number of pre-1991 documents are available free via www.OSTI.gov.

Cover Photos by Dennis Schroeder: (clockwise, left to right) NREL 51934, NREL 45897, NREL 42160, NREL 45891, NREL 48097, NREL 46526.

NREL prints on paper that contains recycled content. 


\section{Acknowledgments}

This work was supported by the U.S. Department of Energy (DOE) under Contract No. DEAC36-08GO28308 with the National Renewable Energy Laboratory (NREL). Funding for the work was provided by the DOE Office of Energy Efficiency and Renewable Energy Wind Energy Technologies Office (WETO). The authors would like to thank Patrick Gilman (WETO) for supporting this research. Thanks also to Daniel Beals of Allegheny Science and Technology (contractor to WETO) and Richard Tusing (NREL) for providing strategic guidance in the development of this work. Thank you to Ryan Wiser, Mark Bolinger (Lawrence Berkeley National Laboratory), and Ben Hoen (Lawrence Berkeley National Laboratory), and Philipp Beiter (NREL) for their analysis of wind project market data that informed this analysis. Thanks also to Christopher Moné (Senvion) for reviewing prior versions of this manuscript. Finally, thanks to Eric Lantz (NREL) for his technical guidance, contributions, and review of prior versions of this manuscript. Any remaining errors or omissions are the sole responsibility of the authors. 


\section{List of Acronyms}

$\begin{array}{ll}\text { AEP } & \text { annual energy production } \\ \text { ATB } & \text { Annual Technology Baseline } \\ \text { BLS } & \text { Bureau of Labor Statistics } \\ \text { BOS } & \text { balance of system } \\ \text { CapEx } & \text { capital expenditures } \\ \text { Cp } & \text { coefficient of power } \\ \text { CRF } & \text { capital recovery factor } \\ \text { CSM } & \text { Cost and Scaling Model } \\ \text { DOE } & \text { U.S. Department of Energy } \\ \text { FCR } & \text { fixed charge rate } \\ \text { GPRA } & \text { Government Performance and Results Act } \\ \text { GW } & \text { gigawatt } \\ \text { kW } & \text { kilowatt } \\ \text { LCOE } & \text { levelized cost of energy } \\ \text { m } & \text { meter } \\ \text { m/s } & \text { meters per second } \\ \text { MACRS } & \text { Modified Accelerated Cost Recovery System } \\ \text { MW } & \text { megawatt } \\ \text { MWh } & \text { megawatt-hour } \\ \text { NREL } & \text { National Renewable Energy Laboratory } \\ \text { O\&M } & \text { operation and maintenance } \\ \text { OpEx } & \text { operational expenditures } \\ \text { OWDB } & \text { Offshore Wind Database } \\ \text { PTC } & \text { production tax credit } \\ \text { SAM } & \text { System Advisor Model } \\ \text { SCBS } & \text { System Cost Breakdown Structure } \\ \text { TSR } & \text { tip-speed ratio } \\ \text { WACC } & \text { weighted-average cost of capital } \\ \text { yr } & \text { year } \\ & \end{array}$




\section{Executive Summary}

This report uses representative utility-scale projects to estimate the levelized cost of energy (LCOE) for land-based and offshore wind power plants in the United States. Data and results detailed here are derived from 2017 commissioned plants. More specifically, analysis detailed here relies on recent market data and state-of-the-art modeling capabilities to maintain an up-todate understanding of wind energy cost trends and drivers. This annual report represents the seventh installment and is intended to provide insight into current component-level costs as well as a basis for understanding variability in LCOE across the country.

The primary elements of this report include:

- Estimated LCOE for a representative, land-based wind project installed in a moderate wind resource in the United States in 2017

- Estimated LCOE for representative offshore, fixed-bottom, and floating projects, using National Renewable Energy Laboratory (NREL) models and a database informed by projects installed in Europe in 2017 for a representative site on the U.S. North Atlantic Coast

- Sensitivity analyses showing the range of effects that basic LCOE variables could have on the cost of wind energy for land-based and offshore wind power plants

- Updated national supply curves for land-based and offshore wind based on geographically specific wind resource conditions paired with approximate wind turbine size characteristics

- Updated fiscal year 2018 values for land-based and offshore wind used for Government Performance and Results Act (GPRA) reporting and including progress toward established GPRA end-point targets.

\section{Key Inputs and Results}

Throughout this report, the representative land-based and offshore project types are referred to as "reference projects." Table ES1, Table ES2, and Table ES3 summarize the basic LCOE inputs and outputs (including GPRA values) for the reference land-based, fixed-bottom, and floating offshore wind projects, with some additional detail about project capital expenditures (CapEx) and the respective turbine capacity factor associated with the net annual energy production estimate. Unless specifically stated, all data and analysis in the report are in 2017 United States dollars (USD). 
Table ES1. Summary of the Land-Based Reference Project Using 2.32-Megawatt (MW) Turbines

\begin{tabular}{|c|c|c|c|}
\hline & $\begin{array}{c}\text { 2.32-MW Land-Base } \\
\text { Turbine } \\
\text { (\$/kilowatt [kW]) }\end{array}$ & $\begin{array}{l}\text { 2-MW Land-Based } \\
\text { Turbine } \\
\text { (\$/megawatt- } \\
\text { hour [MWh]) } \\
\text { Market }\end{array}$ & $\begin{array}{c}\text { 2.32-MW Land-Based } \\
\text { Turbine } \\
\text { (\$/me gawatt- } \\
\text { hour [MWh]) } \\
\text { GPRA }\end{array}$ \\
\hline Turbine capital cost & 1,094 & 23.8 & 25.8 \\
\hline Balance of system & 360 & 7.8 & 8.5 \\
\hline Financial costs & 157 & 3.4 & 3.7 \\
\hline Capital expenditures (CapEx) & 1,610 & 35.1 & $\mathbf{3 8 . 0}$ \\
\hline Operational expenditures (OpEx; $\$ / k W / y r)$ & 44 & 12.0 & 12.0 \\
\hline Fixed charge rate (FCR; \%) [real] & \multicolumn{2}{|c|}{$7.9 \%$} & $8.6 \%$ \\
\hline Net annual energy production (MWh/MW/yr) & \multicolumn{2}{|c|}{3,633} & 3,633 \\
\hline Net capacity factor (\%) & \multicolumn{2}{|c|}{$41.5 \%$} & $41.5 \%$ \\
\hline TOTAL LCOE (\$/MMh) & \multicolumn{2}{|c|}{47} & $\mathbf{5 0}$ \\
\hline
\end{tabular}

Table ES2. Summary of the Fixed-Bottom Reference Project Using 5.64-MW Turbines

\begin{tabular}{|c|c|c|}
\hline & $\begin{array}{l}\text { 5.64-MW Offs hore } \\
\text { Turbine } \\
\text { (\$/kW) }\end{array}$ & $\begin{array}{c}\text { 5.64-MW Offs hore } \\
\text { Turbine } \\
\text { (\$/MWh) } \\
\text { Market }\end{array}$ \\
\hline Turbine capital cost & 1,557 & 29.2 \\
\hline Balance of system & 2,289 & 43.0 \\
\hline Financial costs & 690 & 13.0 \\
\hline CapEx & 4,536 & 85.2 \\
\hline OpEx $(\$ / k W / y r)$ & 144 & 38.5 \\
\hline Fixed charge rate (real) [\%] & \multicolumn{2}{|c|}{$7.0 \%$} \\
\hline Net annual energy production (MWh/MW/yr) & \multicolumn{2}{|c|}{3,741} \\
\hline Net capacity factor $(\%)$ & \multicolumn{2}{|c|}{$42.7 \%$} \\
\hline Total LCOE (\$/MWh) & \multicolumn{2}{|c|}{124} \\
\hline
\end{tabular}

Note: The market FCR and the GPRA FCR are equivalent for the offshore fixed-bottom reference project; therefore, we do not include an additional column to report the GPRA values. Also, the capacity-weighted average turbine rating for this analysis was based on data contained in NREL's offshore wind database (OWDB) as of May 2018. The capacity-weighted average turbine rating in the 2017 Offshore Wind Technologies Market Update (Beiter et al. 2018) presents a different turbine rating because it was based on updated data in the OWDB after May 2018. The difference in turbine rating is anticipated to have a minor impact on the LCOE results for fixed-bottom and floating offshore wind. 
Table ES3. Summary of the Floating Offshore Reference Project Using 5.64-MW Turbines

\begin{tabular}{|c|c|c|}
\hline & $\begin{array}{c}\text { 5.64-MW Offs hore } \\
\text { Turbine } \\
(\$ / k W)\end{array}$ & $\begin{array}{c}\text { 5.64-MW Offshore } \\
\text { Turbine } \\
\text { (\$/MWh) } \\
\text { Market }\end{array}$ \\
\hline Turbine capital cost & 1,521 & 33.3 \\
\hline Balance of system & 3,318 & 72.6 \\
\hline Financial costs & 766 & 16.8 \\
\hline CapEx & 5,605 & 122.6 \\
\hline OpEx (\$/kW/yr) & 86 & 23.0 \\
\hline Fixed charge rate (real) [\%] & \multicolumn{2}{|c|}{$8.2 \%$} \\
\hline Net annual energy production (MWh/MW/yr) & \multicolumn{2}{|c|}{3,732} \\
\hline Net capacity factor $(\%)$ & \multicolumn{2}{|c|}{$42.6 \%$} \\
\hline Total LCOE (\$/MWh) & \multicolumn{2}{|c|}{146} \\
\hline
\end{tabular}

Note: GPRA values are not reported for floating technology; hence, they are not included for the floating offshore reference project.

Installed land-based wind project data and costs are primarily obtained from Wiser and Bolinger (2018). These data are supplemented with outputs from NREL's cost models for wind turbine and balance-of-system components. The offshore reference project data are estimated from installed 2017 global offshore projects, data collected from U.S.-proposed projects, and market data from the existing international offshore wind industry. The assumed wind resource regime and geospatial power plant characteristics (e.g., water depth and distance from shore) for the offshore reference plant are comparable to sites on the U.S. North Atlantic Coast (i.e., 30-meter water depth, 30 kilometers from onshore interconnection, and 30 kilometers from installation and the operation and maintenance port).

The three major component cost categories and many subcategories are represented in Figure ES1, Figure ES2, and Figure ES3, including wind turbine (e.g., wind turbine components), balance of system (e.g., development, electrical infrastructure, assembly, and installation), and financial costs (e.g., insurance and construction financing). The majority of the land-based project CapEx (68\%) is in the turbine itself, whereas the turbine makes up 34\% of the fixedbottom offshore and $27 \%$ of the floating offshore reference project CapEx. 


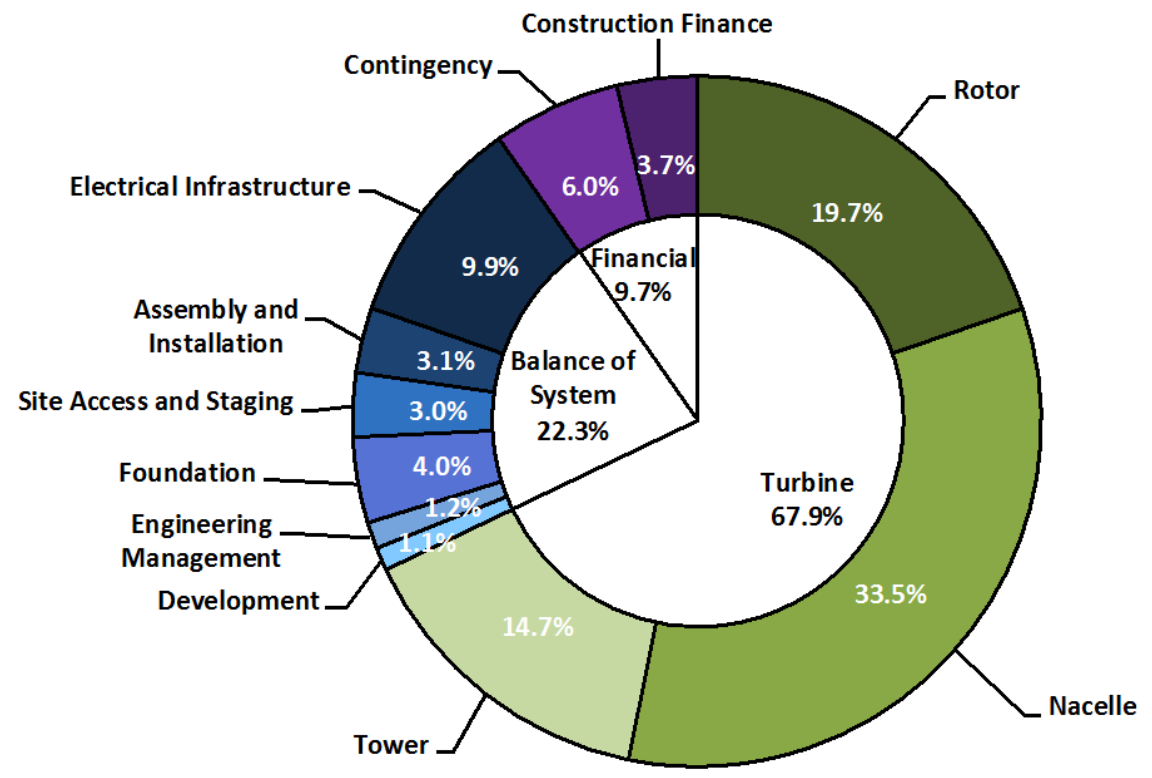

Figure ES1. CapEx for the land-based reference wind power plant project Source: NREL

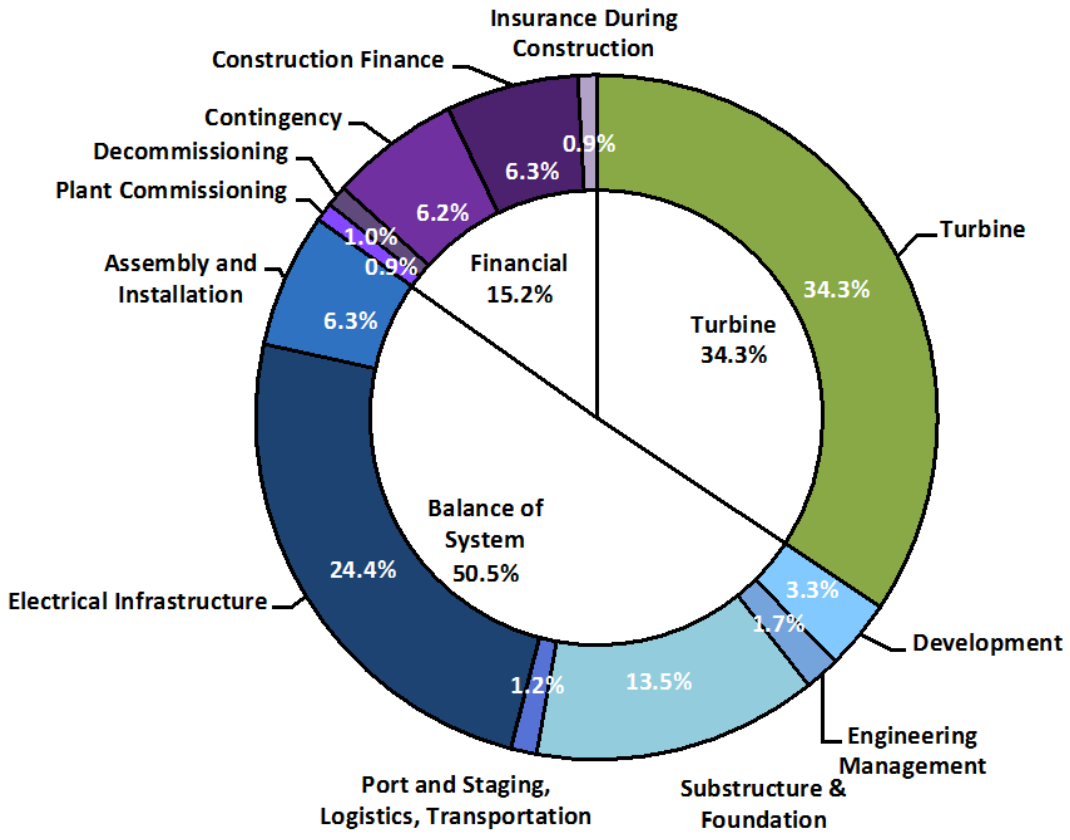

Figure ES2. CapEx for the fixed-bottom offshore reference wind power plant project Source: NREL 


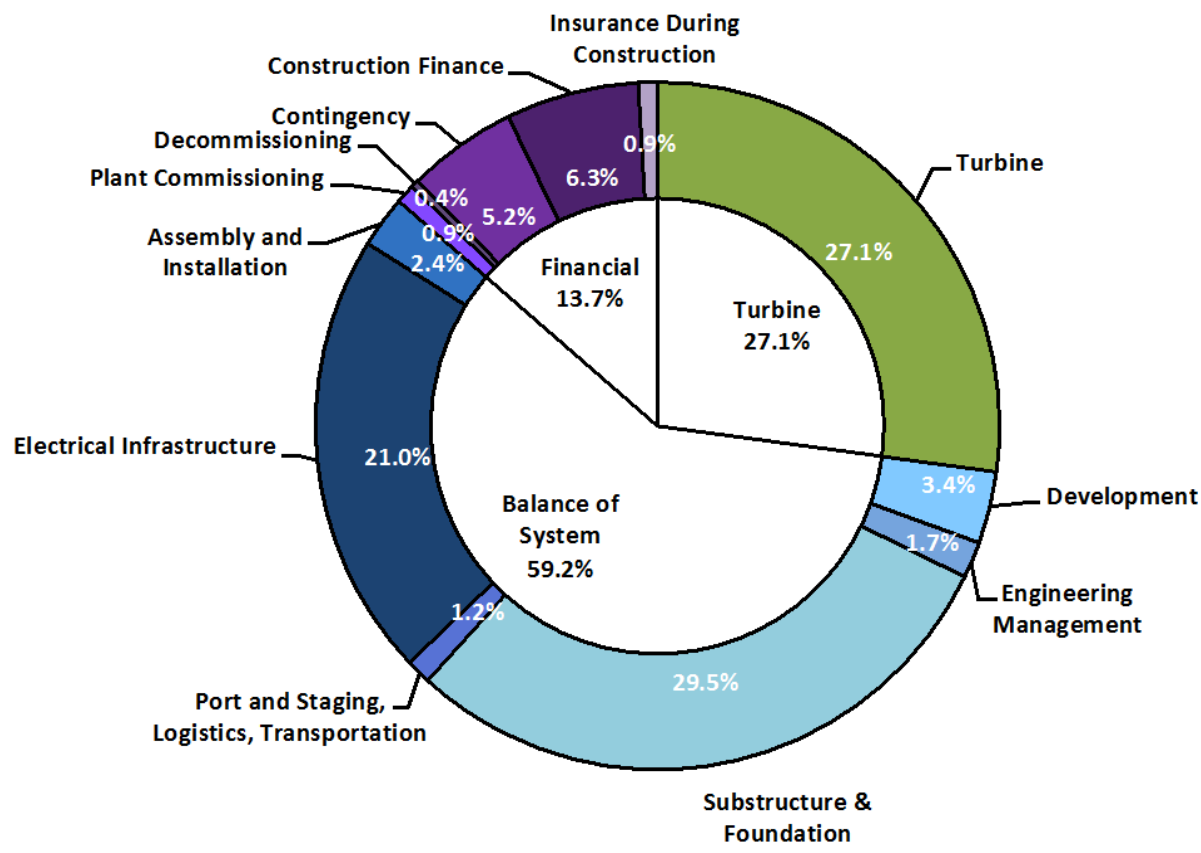

Figure ES3. CapEx for the floating offshore reference wind power plant project Source: NREL

Figure ES4, Figure ES5, and Figure ES6 define the LCOE associated with the land-based and offshore reference power plants and provide a range of independent, single-variable sensitivities showing how specific variables affect cost and performance. More specifically, these figures show the effect that CapEx, OpEx, net capacity factor, nominal discount rate, and project design life ${ }^{1}$ have on the LCOE for both land-based and offshore wind projects. Reference project values of \$47/MWh for land-based wind, \$124/MWh for fixed-bottom offshore wind, and \$146/MWh for floating offshore wind rely on inputs summarized in Table ES1 through Table ES3 and are identified by the vertical white line in those figures. The figures also show sensitivity ranges pulled from representative industry data contained in the 2017 Wind Technologies Market Report (Wiser and Bolinger 2018) for the LCOE inputs and the resulting calculated impacts on LCOE. Clearly, the ranges for land-based and offshore wind LCOE inputs vary significantly (note the different axes in these figures). More detailed descriptions of the ranges and assumptions are included in the body of the report.

\footnotetext{
${ }^{1}$ Project design life refers to the time in which the wind power plant is expected to operate (not referring to the turbine’s design life for engineering or certification purposes).
} 


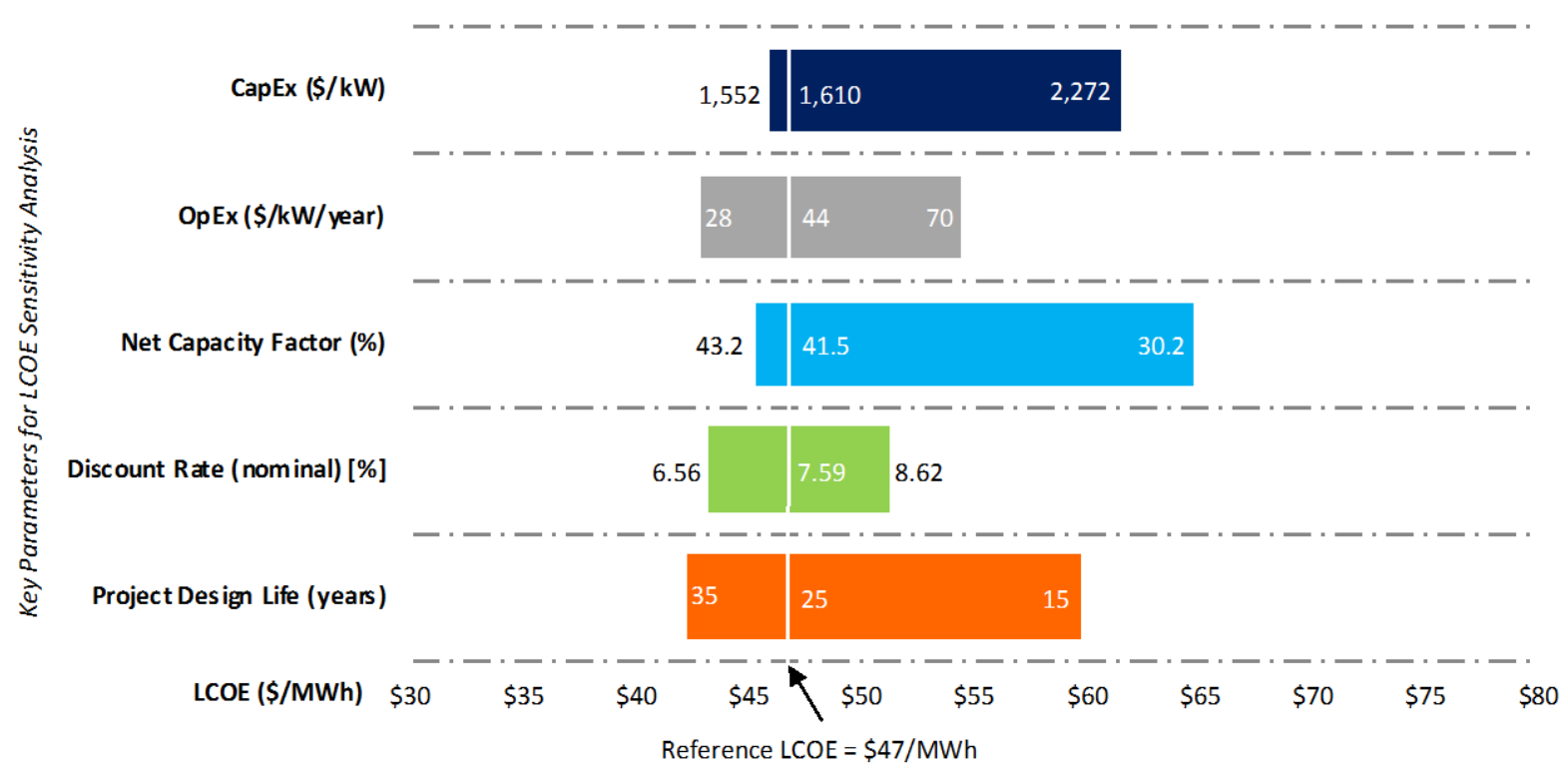

Figure ES4. Land-based wind power plant assumptions and ranges for key LCOE input parameters

Source: NREL

Note: The reference LCOE represents the estimated LCOE for the NREL reference project. Changes in LCOE for a single variable can be understood by moving to the left or right along a specific variable. Values on the $\mathrm{x}$-axis indicate how the LCOE will change as a given variable is altered, assuming that all others are constant. For example, as capacity factor decreases toward $30 \%$, the LCOE shown on the x-axis will increase accordingly to approximately $\$ 65 / \mathrm{MWh}$. Or, as the operational life for the reference project moves toward 35 years, the period in which a project achieves the requisite cash flow it needs to recover its initial CapEx and meet investors' internal rate of return threshold is assumed to be 35 years; therefore, the resulting LCOE decreases to nearly $\$ 42 / \mathrm{MWh}$. 


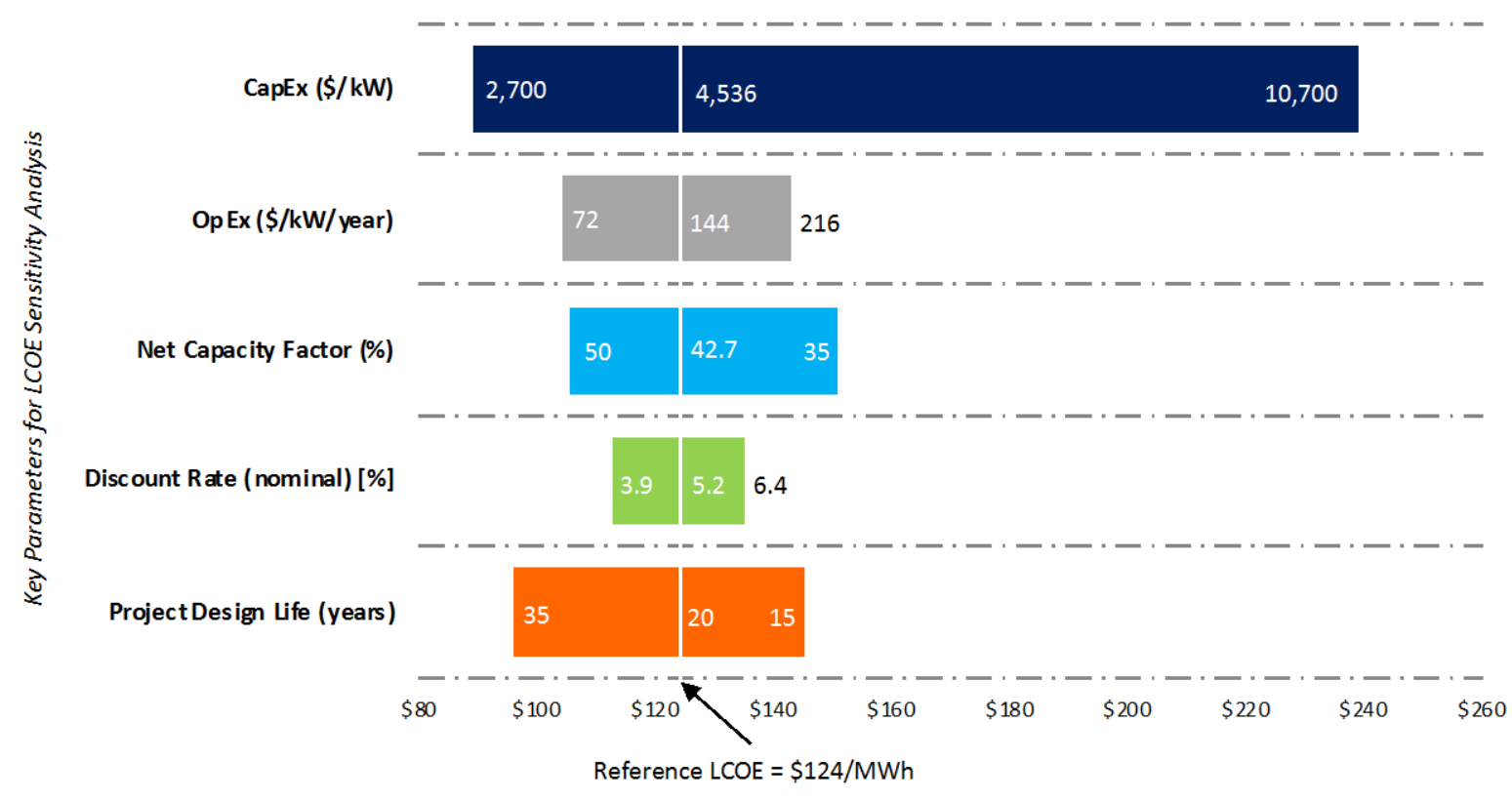

Figure ES5. Fixed-bottom offshore wind power plant assumption and ranges for key LCOE input parameters

Source: NREL

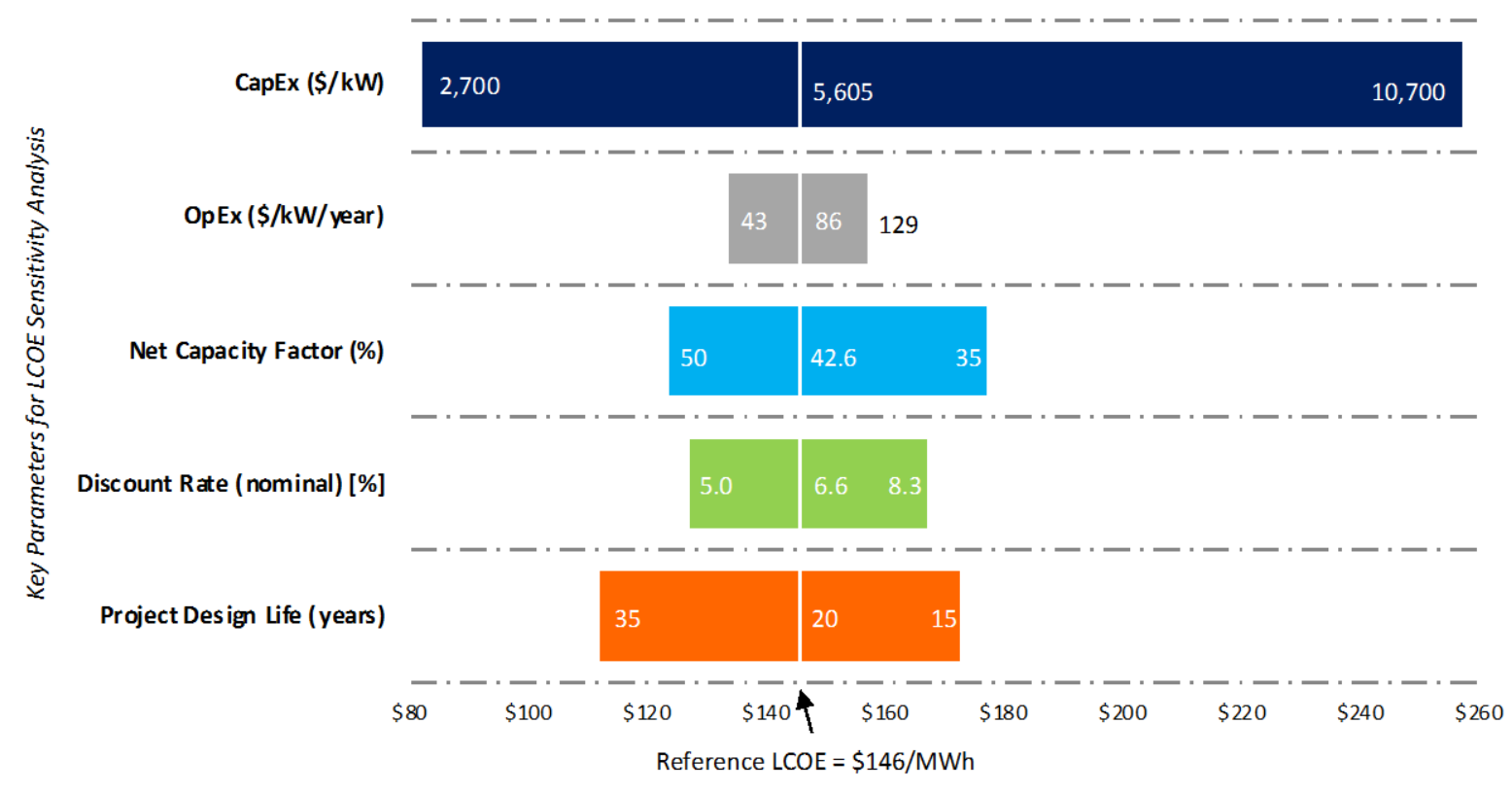

Figure ES6. Floating offshore wind power plant assumptions and ranges for key LCOE input parameters

Source: NREL 
From the data provided earlier as well as the full body of work detailed in this report, the authors derived the following key conclusions:

- Land-based wind power plant LCOE estimates continue to show a downward trend from the 2010 Cost of Wind Energy Review (Tegen et al. 2012) to the 2017 review. The reference project LCOE for land-based installations was observed to be $\$ 47 / \mathrm{MWh},{ }^{2}$ with a range of land-based estimates from the single-variable sensitivity analysis covering \$42-\$65/MWh. ${ }^{3}$

- Offshore wind power plant LCOE estimates continue to decrease. The fixed-bottom reference project offshore estimate is $\$ 124 / \mathrm{MWh}$, and the floating substructure reference project estimate is $\$ 146 / \mathrm{MWh}$. These two reference projects give a single-variable sensitivity range of $\$ 82-\$ 257 /$ MWh. This range is caused by the large variation in CapEx $(\$ 2,700-\$ 10,700 /$ kilowatts), which is partially a function of water depth and distance from shore, reported by project developers. More recent European project bids or "strike prices" suggest that costs for offshore wind could fall further in the coming years. ${ }^{4}$

- Sensitivity analyses show that LCOE can vary widely based on changes in any one of several key factors; however, the variable with the most dramatic effect on LCOE is net capacity factor, followed by project design life, then CapEx for land-based projects, and CapEx followed by project design life and net capacity factor for offshore projects.

\footnotetext{
${ }^{2}$ As the production tax credit ramps down and expires permanently over the next few years, it is likely that wind project weighted-average cost of capital or discount rate will be reduced as leverage increases and tax equity is replaced with cheaper debt.

${ }^{3}$ LCOE estimates reflect a cost to a wind power plant developer and are not directly comparable with power purchase agreements that reflect sale of electricity.

${ }^{4}$ Additional information on the recent European strike prices can be found in the 2016 Offshore Wind Technologies Market Report (Musial et al. 2017).
} 


\section{Table of Contents}

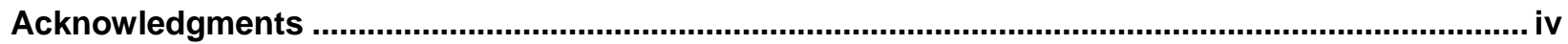

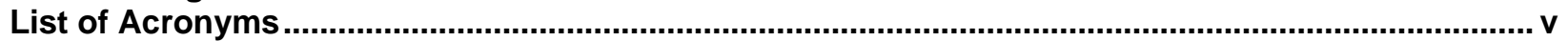

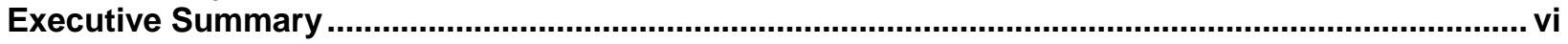

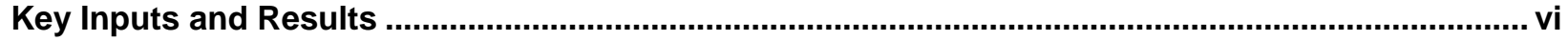

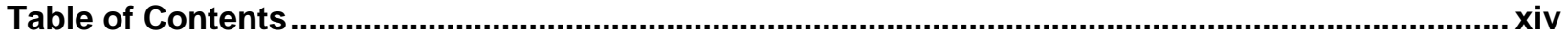

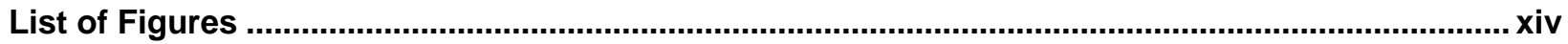

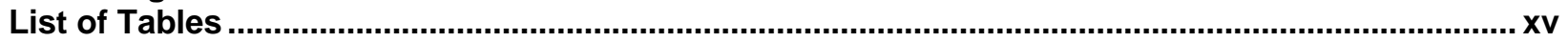

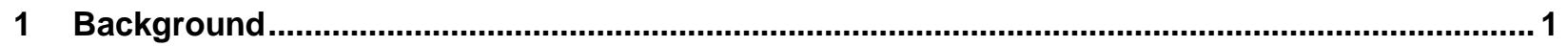

2 U.S. Department of Energy Goals and Reporting Requirements ............................................. 3

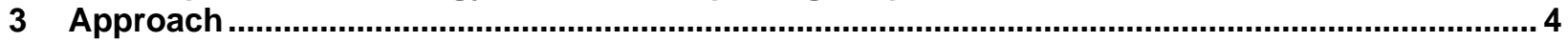

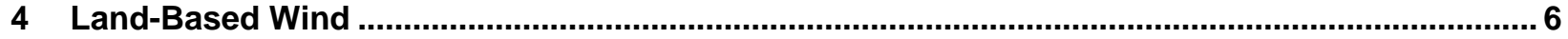

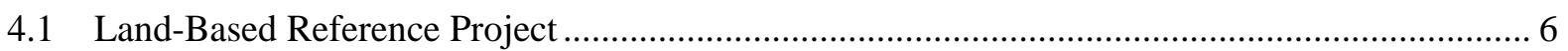

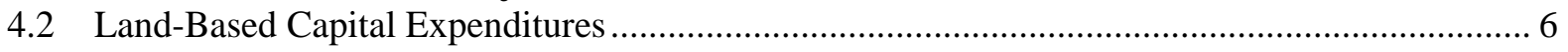

4.3 Land-Based Technology Characteristics and Annual Energy Production .................................... 8

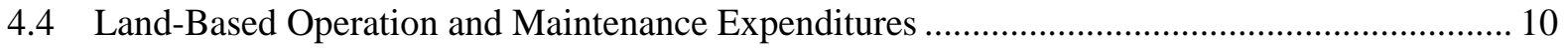

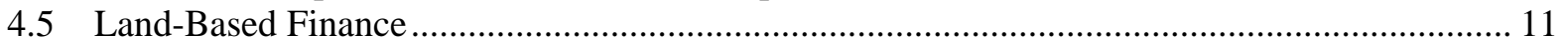

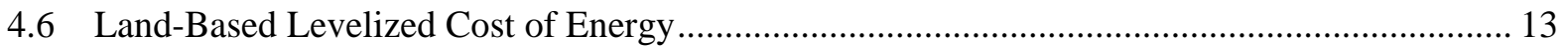

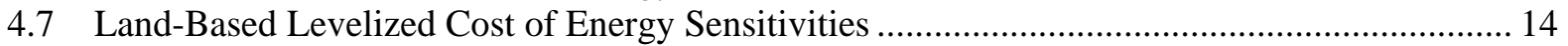

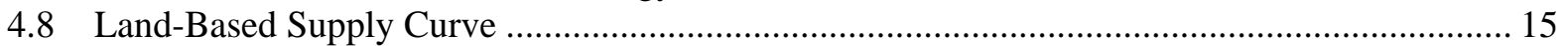

4.9 Land-Based Discussion of Results in Context of DOE Goals ............................................... 16

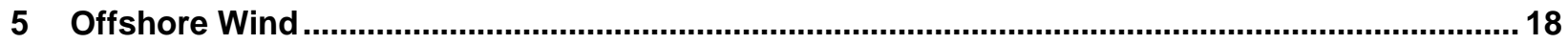

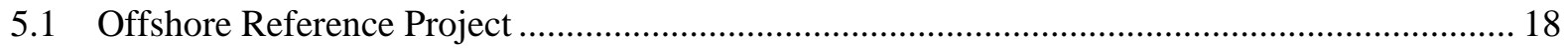

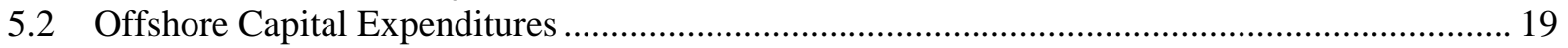

5.3 Offshore Technology Characteristics and Annual Energy Production ...................................... 23

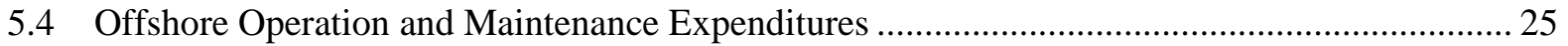

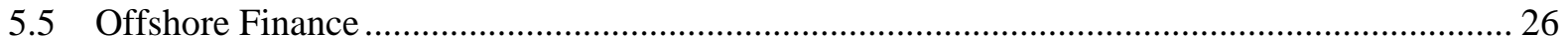

5.6 Offshore Reference Project Levelized Cost of Energy ......................................................... 27

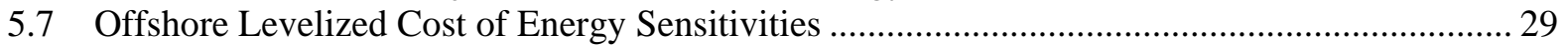

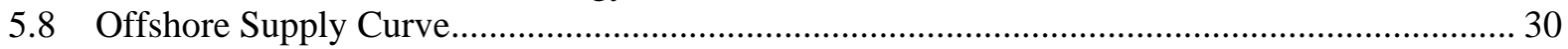

5.9 Offshore Discussion of Results in Context of DOE Goals...................................................... 31

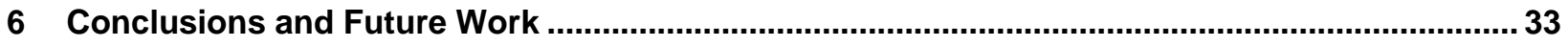

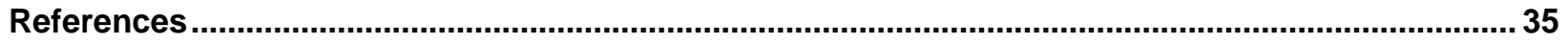

Appendix A. Land-Based Wind 30-Year Financial Life Sensitivity .................................................. 38

Appendix B. Offshore Wind 25- and 30-Year Financial Life Sensitivity ........................................... 39

Appendix C. Summary of Assumptions for 2017 Reference Projects.............................................. 40

\section{List of Figures}

Figure ES1. CapEx for the land-based reference wind power plant project....................................... ix

Figure ES2. CapEx for the fixed-bottom offshore reference wind power plant project ..................... ix

Figure ES3. CapEx for the floating offshore reference wind power plant project ............................

Figure ES4. Land-based wind power plant assumptions and ranges for key LCOE input

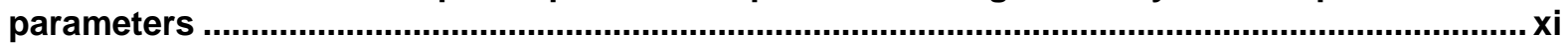

Figure ES5. Fixed-bottom offshore wind power plant assumption and ranges for key LCOE input

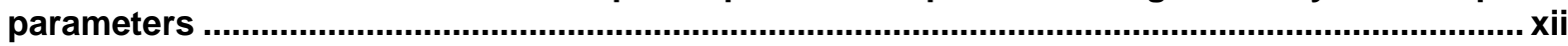

Figure ES6. Floating offshore wind power plant assumptions and ranges for key LCOE input

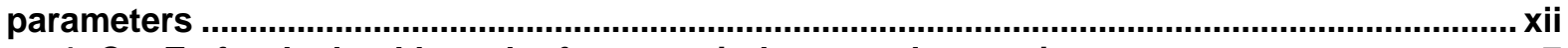

Figure 1. CapEx for the land-based reference wind power plant project........................................... 7

Figure 2. Component-level cost breakdown for the 2017 land-based wind reference project .........14

Figure 3. Sensitivity of land-based wind LCOE to key input parameters ..........................................15

Figure 4. National land-based wind resource supply curve with 2017 U.S. installed projects......... 16

Figure 5. Land-based wind GPRA cost trajectories for LCOE ...................................................... 17

\section{xiv}

This report is available at no cost from the National Renewable Energy Laboratory (NREL) at www.nrel.gov/publications. 
Figure 6. Capital expenditures for the fixed-bottom offshore wind reference project .....................20

Figure 7. Capital expenditures for the floating offshore wind reference project .............................. 22

Figure 8. Component-level cost breakdown for the 2017 fixed-bottom offshore wind reference

project.

Figure 9. Component-level cost breakdown for the 2017 floating offshore wind reference project 29

Figure 10. Sensitivity of fixed-bottom offshore wind LCOE to key input parameters ....................... 29

Figure 11. Sensitivity of floating offshore wind LCOE to key input parameters ..............................30

Figure 12. National fixed-bottom and floating offshore wind supply curve .................................... 31

Figure 13. Fixed-bottom wind GPRA cost trajectories for LCOE..................................................... 32

\section{List of Tables}

Table ES1. Summary of the Land-Based Reference Project Using 2.32-Megawatt (MW) Turbines . vii

Table ES2. Summary of the Fixed-Bottom Reference Project Using 5.64-MW Turbines .................. vii

Table ES3. Summary of the Floating Offshore Reference Project Using 5.64-MW Turbines........... viii

Table 1. Summary of Land-Based and Offshore Fixed-Bottom Wind GPRA Cost Trajectories for

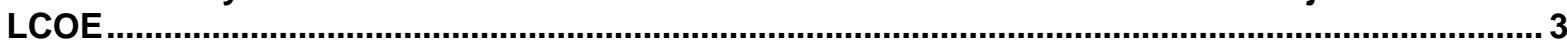

Table 2. Land-Based Reference Project Parameters..................................................................... 6

Table 3. Land-Based CapEx and LCOE Breakdown .............................................................. 8

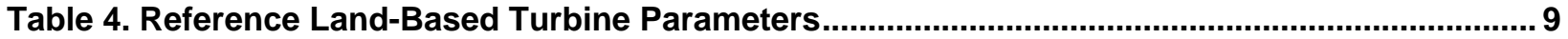

Table 5. Reference Land-Based Wind Resource Assumptions ...................................................... 9

Table 6. Reference Land-Based Wind Losses and Availability Assumptions.................................... 10

Table 7. Reference Land-Based Wind Plant AEP and Capacity Factor Summary ............................. 10

Table 8. Land-Based Wind Reference Project OpEx ........................................................................ 11

Table 9. Summary of Land-Based Reference Project Economic Evaluation Metrics ........................ 13

Table 10. Summary of Inputs and Reference Project LCOE for 2017 Land-Based Installations ...... 14

Table 11. Offshore Reference Project Parameters (Fixed-Bottom and Floating Substructures) ..... 19

Table 12. Fixed-Bottom Offshore CapEx and LCOE Breakdown .....................................................2 21

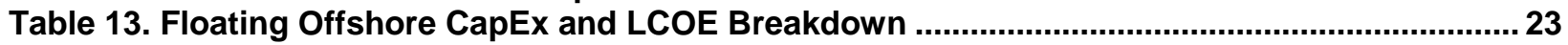

Table 14. Reference Offshore Turbine Parameter Input Assumptions ............................................. 24

Table 15. Reference Offshore Wind Resource Input Assumptions .................................................. 24

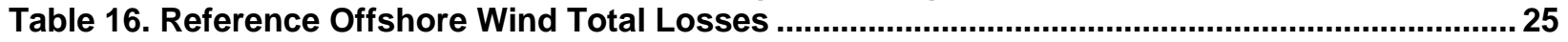

Table 17. Reference Offshore Wind Net Annual Energy Production ..................................................25

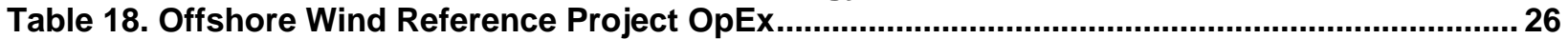

Table 19. Summary of Offshore Reference Project Economic Evaluation Metrics.......................... 27

Table 20. Fixed-Bottom Offshore Wind LCOE and Reference Projects Cost Breakdown................. 27

Table 21. Floating Offshore Wind LCOE and Reference Projects Cost Breakdown .......................... 28

Table 22. Range of LCOE for U.S. Land-Based and Offshore Wind in 2017 ..................................... 33

Table A1. Summary of Offshore Capital Recovery Factor, Fixed Charge Rate, and Levelized Cost of Energy for 30-Year Useful Life ........................................................................................ 38

Table B1. Summary of Offshore Capital Recovery Factor, Fixed Charge Rate, and Levelized Cost

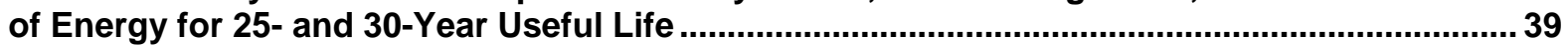

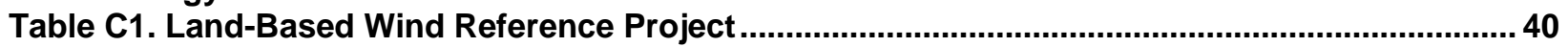

Table C2. Fixed-Bottom Offshore Wind Reference Project ........................................................... 42

Table C3. Floating Offshore Wind Reference Project …............................................................ 44 


\section{Background}

This report estimates the levelized cost of energy (LCOE) for land-based and offshore wind projects in the United States. LCOE is a metric used to assess the cost of electricity generation and the total power-plant-level impact from technology design changes, and can be used to compare costs of all types of generation. The specific LCOE method applied in this analysis is described in A Manual for the Economic Evaluation of Energy Efficiency and Renewable Energy Technologies (Short et al. 1995).

This report provides an update to the 2016 Cost of Wind Energy Review (Stehly et al. 2017) and a look at the 2017 wind industry LCOE, turbine costs, financing, and market conditions. More specifically, this 2017 report includes:

- Estimated LCOE for a representative, land-based wind project installed in a moderate wind resource in the United States in 2017

- Estimated LCOE for representative offshore (fixed-bottom and floating projects) using National Renewable Energy Laboratory (NREL) models and a database informed by projects installed in Europe for a representative site on the U.S. North Atlantic Coast

- Sensitivity analyses showing the range of effects that basic LCOE variables could have on the cost of wind energy for land-based and offshore wind power plants

- Updates to the national supply curves for land-based and offshore wind based on geographically specific wind resource conditions paired with approximate wind turbine size characteristics

- Projected land-based and offshore wind cost trajectories from 2017 through 2030 used for U.S. Department of Energy (DOE) annual wind power LCOE reporting as required by the Government Performance and Results Act (GPRA).

This report addresses a number of assumptions and cost variables, but does not include the full spectrum of drivers that affect wind energy prices. For example, it does not consider policy incentives (such as the production tax credit [PTC]), factors from underlying economic conditions (such as an economic recession), the cost of building long-haul interstate transmission, or potential grid integration costs. These important variables can have an impact by increasing or decreasing project costs or delaying projects. Nevertheless, their exclusion is consistent with past economic analyses conducted by NREL (Stehly et al. 2017), as LCOE is not traditionally defined as a measure of all societal costs and benefits associated with power generation resources.

The standard Annual Technology Baseline (ATB) LCOE equation (NREL's Annual Technology Baseline and Standard Scenarios web page) can be simplified for each technology. For wind, the following equation is used to calculate LCOE:

$$
\mathrm{LCOE}=\frac{(\mathrm{CapEx} \times \mathrm{FCR})+\mathrm{OpEx}}{\left(\mathrm{AEP}_{\text {net }} / 1,000\right)}
$$

where 
LCOE = levelized cost of energy (\$/megawatt-hour [MWh])

FCR $=$ fixed charge rate $(\%)$

CapEx = capital expenditures $(\$ /$ kilowatt $[\mathrm{kW}])$

AEP net $=$ net average annual energy production $(\mathrm{MWh} /$ megawatt $[\mathrm{MW}] /$ year [yr])

OpEx = operational expenditures $(\$ / \mathrm{kW} / \mathrm{yr})$.

The first three basic inputs into the LCOE equation—capital expenditures (CapEx), operational expenditures (OpEx), and annual energy production (AEP) — enable this equation to capture system-level impacts from design changes (e.g., larger rotors or taller wind turbine towers). The fourth basic input—a fixed charge rate (FCR) — represents the amount of revenue required to pay the annual carrying charges as applied to the CapEx on that investment during the expected project economic life. All analysis and LCOE results are in 2017 U.S. dollars (USD) throughout this report unless otherwise noted. The following sections define the approach to calculating the LCOE following the respective NREL system cost breakdown structures (SCBSs) to organize data. This report also describes each component of the LCOE equation (such as CapEx, OpEx, AEP, and FCR), the market context, and a range of data for typical U.S. wind projects in 2017. 


\section{U.S. Department of Energy Goals and Reporting Requirements}

In 2015, the Wind Energy Technologies Office updated their official GPRA levelized cost of energy end point targets. These updates were implemented to keep performance measures up to date and reduce the impact of inflation on LCOE for land-based and offshore wind projects. The GPRA targets are based on trajectories for land-based and fixed-bottom offshore ${ }^{5}$ wind projects that span from the current year to 2030. A summary of the GPRA targets is shown in Table 1. It is required that each year the actual costs for land-based and fixed-bottom wind LCOE be reported against the GPRA targets. This report provides the cost data to DOE to meet the annual reporting requirement required by the GPRA. The assumptions and calculations for land-based wind and fixed-bottom offshore wind projects used in GPRA reporting are presented in more detail in Section 4.9 and Section 5.9, respectively.

Table 1. Summary of Land-Based and Offshore Fixed-Bottom Wind GPRA Cost Trajectories for LCOE

\begin{tabular}{|lcccc|}
\hline & 2018 & 2020 & 2025 & 2030 \\
\hline Land-based LCOE $(2015 \$ / M W h)$ & 54 & 52 & 42 & 31 \\
\hline Offshore fixed-bottom LCOE $(2015 \$ / M W h)$ & 165 & 149 & 121 & 93 \\
\hline
\end{tabular}

Note: The GPRA levelized cost of energy targets were rebaselined in 2015 and are therefore reported in 2015 USD.

${ }^{5}$ The GPRA does not require reporting costs for floating offshore wind. 


\section{Approach}

This 2017 Cost of Wind Energy Review applies a similar approach as the past cost of wind energy review reports (Tegen et al. 2012, 2013); (Moné et al. 2015a, 2015b, 2017); (Stehly et al. 2017). The analysis uses a number of data sources and models to estimate the cost of wind energy. All models and data have, at some point, been tested, documented, and verified within NREL, other national laboratories, universities, and industry to ensure that the methodology and tools are as accurate as possible. The land-based wind data utilize the annually released Wind Technologies Market Report authored by Lawrence Berkeley National Laboratory. Specific to the 2017 Cost of Wind Energy Review, the data come from Wiser and Bolinger (2018). The market data supporting the offshore wind analysis are limited to international projects and proposed U.S. projects and stored in NREL's offshore wind database ${ }^{6}$ (OWDB) of global offshore projects. Given the market and model data available, the general approach to estimating the levelized cost of wind energy includes:

- Evaluating market conditions and data for projects that have been installed in the United States in a given year to understand total land-based CapEx, AEP, operating costs, and representative turbine technology. Representative turbine characteristics (i.e., rating, rotor diameter, and hub height) are taken as market averages. Accordingly, LCOE estimates reflect average empirical conditions to the extent possible.

- Evaluating market conditions and data for projects that have been installed in Europe and Asia when considering offshore wind technology in a given year to understand total CapEx, OpEx, and representative turbine technology. AEP and balance-of-system (BOS) costs are modeled using the specified U.S. North Atlantic site conditions. The primary sources for these data are NREL's OWDB and the 2017 Offshore Wind Technologies Market Update (Beiter et al. 2018).

- Supplementing available market data with modeled data based on a representative or reference project that reflects technology and project parameters for a given year. The following suite of NREL models are used to complete the LCOE analysis:

o The 2015 Cost and Scaling Model $^{7}$ (CSM) to estimate land-based wind turbine component costs using scaling relationships at the component level (e.g., blade, hub, generator, and tower) that reflect the component-specific and often nonlinear relationships between size and cost

o The Land-Based Wind Balance of System (BOS) Model ${ }^{8}$ to estimate all other components of the wind power plant other than the turbine's tower and rotor nacelle assembly using scaling relationships based on empirical data obtained from a land-based wind developer and wind industry stakeholders

o The NREL Offshore Wind Cost Model (Beiter et al. 2016) to estimate offshore turbine costs using scaling relationships from collected global offshore wind industry empirical data and to estimate offshore wind power plant losses and availability

\footnotetext{
${ }^{6}$ NREL's offshore wind database is used as an internal reference and is not published publicly.

${ }^{7}$ NREL's 2015 Cost and Scaling Model is used as an internal reference and is not published publicly.

${ }^{8}$ NREL's Land-Based Wind Balance of System Model is used as an internal reference and is not released publicly.
} 
o The System Advisor Model (SAM) (NREL 2010) to estimate net energy production for land-based wind and the NREL Offshore Wind Cost Model to estimate net energy production for offshore wind power plants based on turbine rated capacity, rotor diameter, hub height, and a representative wind resource

- Combining the market data and modeled data described earlier to estimate the primary elements necessary to calculate LCOE (i.e., CapEx, OpEx, AEP, and FCR) and provide details about wind technology costs and performance that are aligned with market data but reported at a more detailed resolution. Unless specifically stated, all data and analysis used in this report are in 2017 USD, taking into account changes resulting from inflation from previous reports. 


\section{Land-Based Wind}

The turbine characteristics used in the land-based wind reference project were derived from DOE's 2017 Wind Technologies Market Report (Wiser and Bolinger 2018). Reference project wind turbine and component costs are based on a hypothetical wind turbine that comprises the average parameters — nameplate capacity, rotor diameter, and hub height —of turbines that were installed in the United States in 2017. This type of turbine rests on a standard spread-foot foundation design and incorporates a three-stage planetary/helical gearbox feeding a high-speed asynchronous generator. The 2017 reference project wind regime is intended to reflect an average wind power class 4 (NREL's Renewable Resource Data Center web page) wind resource site that is consistent with prior versions of this report and a typical plant size of $200 \mathrm{MW}$.

\subsection{Land-Based Reference Project}

The land-based reference project is intended to be representative of a wind site found in the interior region of the United States. The wind power plant specific to this analysis consists of 87 wind turbines each rated at 2.32 MW (based on the average turbine size installed in the United States in 2017), equating to a 200-MW wind power plant capacity. Further detail on the turbine parameters are summarized in Table 4 in Section 4.3.1. The wind power plant layout is roughly placed in a grid layout at an elevation around 450 meters (m) above sea level. The wind power plant is assumed to be operating for 25 years with no catastrophic operation and maintenance (O\&M) events. These reference project parameters are summarized in Table 2.

Table 2. Land-Based Reference Project Parameters

\begin{tabular}{|lc|}
\hline \multicolumn{2}{|c|}{ Project Parameters } \\
\hline Turbine rated power (MW) & 2.32 \\
\hline Number of turbines & 87 \\
\hline Wind plant capacity (MW) & 200 \\
\hline Elevation above sea level (m) & 450 \\
\hline Project design life (years) & 25 \\
\hline
\end{tabular}

Note: Project design life refers to the time in which the wind power plant is expected to operate (not referring to the turbine’s design life for engineering or certification purposes).

\subsection{Land-Based Capital Expenditures}

The weighted-average CapEx data are published annually by DOE (Wiser and Bolinger 2018). The NREL 2015 CSM is used to determine the component cost breakdown given the total CapEx cost estimates reported by Wiser and Bolinger (2018). The NREL 2015 CSM uses curve fits from commercial turbine component design and cost data while providing the ability to adjust inputs such as overhead, profit, and transportation. Figure 1 illustrates the breakdown of CapEx for the NREL land-based reference project. In the figure, the CapEx component percentages highlighted in shades of green capture the turbine capital cost, the percentages highlighted in blue capture the BOS share of capital costs, and the components highlighted in purple capture the financial CapEx. For information on the assumptions and inclusions of the individual components, see the 2013 Cost of Wind Energy Review (Moné et al. 2015a). Some costs, such as transportation, are rolled up into higher categories (such as nacelle and blades), as the specific 
data are difficult to obtain based on a theoretical reference site and an unspecified turbine manufacturer.

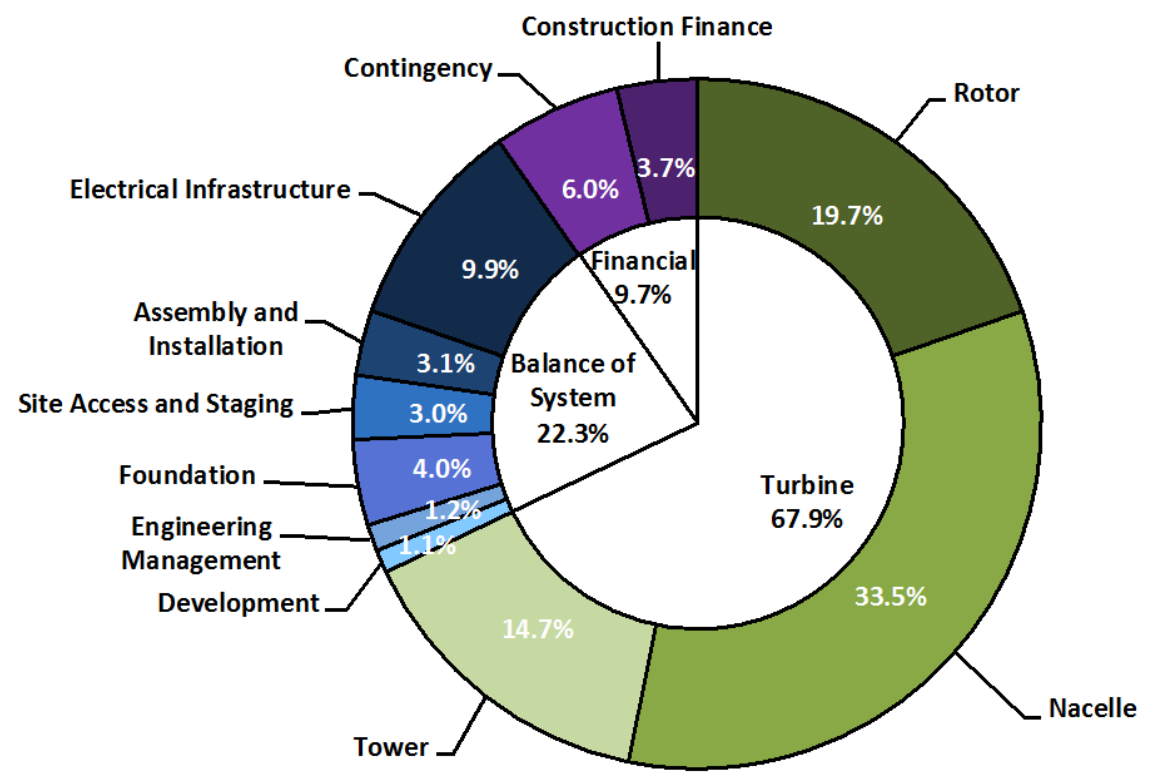

Figure 1. CapEx for the land-based reference wind power plant project Source: NREL

Table 3 summarizes the costs for the reference project's individual components (including their contribution to LCOE). In Table 3, two columns presenting LCOE contributions are included. One shows LCOE contributions for 2017 specific installations using market averages, referred to as the "Market" case and the other is presenting the LCOE contributions to inform GPRA reporting, referred to as the "GPRA" case. The primary difference between the two different scenarios (i.e., GPRA case and Market case) is a difference in financial assumptions. More details on the financial assumptions are provided in Section 4.5. 
Table 3. Land-Based CapEx and LCOE Breakdown

\begin{tabular}{|c|c|c|c|}
\hline & $\begin{array}{c}\text { 2.32-MW Land-Based } \\
\text { Turbine } \\
\text { (\$/kilowatt [kW]) } \\
\text { Market }\end{array}$ & $\begin{array}{c}\text { 2.32-MW Land-Based } \\
\text { Turbine } \\
\text { (\$/MWh) } \\
\text { Market }\end{array}$ & $\begin{array}{c}\text { 2.32-MW Land-Based } \\
\text { Turbine } \\
\text { (\$/MWh) } \\
\text { GPRA }\end{array}$ \\
\hline Rotor module & 317 & 6.9 & 7.5 \\
\hline Blades & 203 & 4.4 & 4.8 \\
\hline Pitch assembly & 66 & 1.4 & 1.6 \\
\hline Hub assembly & 48 & 1.1 & 1.1 \\
\hline Nacelle module & 539 & 11.8 & 12.7 \\
\hline Nacelle structural assembly & 108 & 2.4 & 2.6 \\
\hline Drivetrain assembly & 211 & 4.6 & 5.0 \\
\hline Nacelle electrical assembly & 184 & 4.0 & 4.3 \\
\hline Yaw assembly & 35 & 0.8 & 0.8 \\
\hline Tower module & 237 & 5.2 & 5.6 \\
\hline Turbine capital cost & 1,094 & 23.8 & 25.8 \\
\hline Development cost & 17 & 0.4 & 0.4 \\
\hline Engineering management & 20 & 0.4 & 0.5 \\
\hline Foundation & 65 & 1.4 & 1.5 \\
\hline Site access and staging & 48 & 1.1 & 1.1 \\
\hline Assembly and installation & 49 & 1.1 & 1.2 \\
\hline Electrical infrastructure & 160 & 3.5 & 3.8 \\
\hline Balance of system & 360 & 7.8 & 8.5 \\
\hline Construction financing cost & 60 & 1.3 & 1.4 \\
\hline Contingency fund & 97 & 2.1 & 2.3 \\
\hline Financial costs & 157 & 3.4 & 3.7 \\
\hline Total capital expenditures & 1,610 & 35.1 & 38.0 \\
\hline
\end{tabular}

Because of CapEx variability among projects, estimates for the turbine component costs were established using the NREL 2015 CSM. BOS costs were estimated using NREL's Land-Based Wind BOS model, which relies on scaling relationships and costs derived from detailed data obtained through a major engineering, procurement, and construction firm active in the wind industry to characterize costs. Construction financing was estimated assuming a 3-year construction duration distributing the capital and interest over the 3 years using the same methodology as NREL's 2018 ATB for land-based wind (NREL's Annual Technology Baseline and Standard Scenarios web page). Project contingency is estimated at 6\% of CapEx, which is consistent with industry reporting. Total installed project CapEx for U.S. projects in 2017 came in at $\$ 1,610 / \mathrm{kW}$ (Wiser and Bolinger 2018), which is a slight increase from last year's cost report of $\$ 1,590 / \mathrm{kW}$ as a result of the data collected for projects installed in 2017.

\subsection{Land-Based Technology Characteristics and Annual Energy Production}

\subsubsection{Turbine Parameters}

For the purpose of this report, the turbine parameters are specific to the turbine and independent of the wind resource characteristics. These parameters consist not only of turbine size (such as rated power, rotor diameter, and hub height), but also of turbine operating characteristics (such

This report is available at no cost from the National Renewable Energy Laboratory (NREL) at www.nrel.gov/publications. 
as coefficient of power [Cp], maximum tip speed, maximum tip-speed ratio (TSR), and drivetrain design). Because the three-stage planetary/helical gearbox with a high-speed asynchronous generator-style drivetrain topology dominates the U.S. market, this type of drivetrain was selected for the baseline turbines used in this analysis. The power curve for the 2.32-MW land-based turbine is derived from NREL's SAM (NREL 2010). A summary of the turbine parameters is shown in Table 4. For specific approaches regarding additional turbine parameters (e.g., power curves), see the 2010 Cost of Wind Energy Review (Tegen et al. 2012).

Table 4. Reference Land-Based Turbine Parameters

\begin{tabular}{|lc|}
\hline & Turbine Parameters \\
\hline Turbine rated power $(\mathrm{MW})$ & 2.32 \\
\hline Turbine rotor diameter $(\mathrm{m})$ & 113 \\
\hline Turbine hub height $(\mathrm{m})$ & 86 \\
\hline Maximum rotor tip speed (meters per second $[\mathrm{m} / \mathrm{s}])$ & 80 \\
\hline Tip-speed ratio $(\mathrm{TSR})$ at maximum coefficient of power $\left(\mathrm{C}_{\mathrm{p}}\right)$ & 8 \\
\hline Drivetrain design & Geared \\
\hline Cut-in wind speed $(\mathrm{m} / \mathrm{s})$ & 3 \\
\hline Cut-out wind speed $(\mathrm{m} / \mathrm{s})$ & 25 \\
\hline Maximum coefficient of power & 0.47 \\
\hline
\end{tabular}

\subsubsection{Wind Resource}

The average wind speed can vary from project to project across the United States. The annual average wind speed chosen for the reference project analysis, consistent with prior reports, is 7.25 meters per second $(\mathrm{m} / \mathrm{s})$ at $50 \mathrm{~m}$ above ground level $(7.83 \mathrm{~m} / \mathrm{s}$ at a hub height of $86 \mathrm{~m})$. This wind speed is intended to be generally indicative of the wind regime for projects installed in moderate-quality sites (i.e., average wind power class 4). An elevation of $450 \mathrm{~m}$ above sea level was applied based on this concept of using a representative site that would have a similar altitude to a project located within the interior of the country. A summary of the wind resource assumptions for the 2017 representative site is included in Table 5.

Table 5. Reference Land-Based Wind Resource Assumptions

\begin{tabular}{|lc|}
\hline \multicolumn{2}{|c|}{ Wind Resource Characteristics } \\
\hline Annual average wind speed at a 50-m height (m/s) & 7.25 \\
\hline Annual average wind speed at an 86-m hub height (m/s) & 7.83 \\
\hline Weibull k & 2.0 \\
\hline Shear exponent & 0.143 \\
\hline Turbine elevation (meters above sea level) & 450 \\
\hline
\end{tabular}

\subsubsection{Losses and Availability}

Although some losses can be affected by turbine design or wind resource characteristics, they are treated as independent of any other input in this simplified analysis. Types of losses accounted for here include array wake losses, electric collection and transmission losses (from the

This report is available at no cost from the National Renewable Energy Laboratory (NREL) at www.nrel.gov/publications. 
substation to the point of interconnection), and blade soiling losses, totaling $15 \%$. A wind power plant availability of $98 \%$ is assumed, indicating that the wind project is ready to produce power between wind turbine cut-in and cut-out wind speeds $98 \%$ of the time. Net average AEP is calculated by applying all losses and availability to the gross AEP. As a point of reference, historical net capacity factors have ranged between about 29\% and 50\% (Wiser and Bolinger 2016). Table 6 shows the losses and availability for the land-based reference wind power plant.

Table 6. Reference Land-Based Wind Losses and Availability Assumptions

\begin{tabular}{|ll|}
\hline \multicolumn{2}{|c|}{ Losses } \\
\hline Losses (i.e., array, energy conversion, and line) & $15 \%$ \\
\hline Availability & $98 \%$ \\
\hline
\end{tabular}

\subsubsection{Annual Energy Production}

The AEP for this analysis was computed using SAM (NREL 2010). The model uses an idealized power curve based on the turbine configuration and computes annual energy capture for a wind project that is specified by the wind resource and the wind power plant's assumed losses and availability. The result of these calculations yields a net energy capture of 3,633 MWh/MW/year, which corresponds to a $41.5 \%$ net capacity factor assuming 8,760 hours in a year. A summary of these results is shown in Table 7.

Table 7. Reference Land-Based Wind Plant AEP and Capacity Factor Summary

\begin{tabular}{|lc|}
\hline \multicolumn{2}{|c|}{ AEP and Capacity Factors } \\
\hline Net energy capture (MWh/MW/year) & $7.25 \mathrm{~m} / \mathrm{s}$ at $50 \mathrm{~m}$ \\
\hline Net capacity factor (\%) & 3,633 \\
\hline
\end{tabular}

\subsection{Land-Based Operation and Maintenance Expenditures}

OpEx costs are generally expressed in two categories: 1) fixed O\&M costs (e.g., scheduled plant maintenance or land lease costs) and 2) variable O\&M costs (e.g., unscheduled plant maintenance). For simplicity, annual OpEx can be converted to a single term and expressed as either dollars per kilowatt per year (\$/kW/yr) or dollars per megawatt-hour (\$/MWh). This analysis uses the dollars-per-kilowatt-per-year convention. Currently, and in past years, it is difficult to get actual project-level O\&M costs, especially for projects installed during the previous year (2017 in this case) because of the lack of publicly available data.

Prior publications of this report, including last year's 2016 Cost of Wind Energy Review (Stehly et al. 2017), the total O\&M cost was informed by the Wind Vision: A New Era for Wind Power in the United States (DOE 2015) and considered Bureau of Labor Statistics (BLS) inflation adjustments from the time of the Wind Vision study. For this year's report, the O\&M cost is updated from analysis conducted in the 2017 Wind Technologies Market Report (Wiser and Bolinger 2018). From this analysis, we derived the total O\&M cost (including all operational expenses) estimates from recent industry interviews with developers, wind turbine manufacturers, as well as other available data to obtain a total O\&M cost estimate of $\$ 43.6 / \mathrm{kW} / \mathrm{yr}$. It should be noted that, given the scarcity and varying quality of the data, OpEx may vary substantially among projects, and the data presented here may not fully represent the 
challenges that OpEx present to the wind power industry. A summary of the annual O\&M costs and for the Market and GPRA cases, on an energy basis, is shown in Table 8.

Table 8. Land-Based Wind Reference Project OpEx

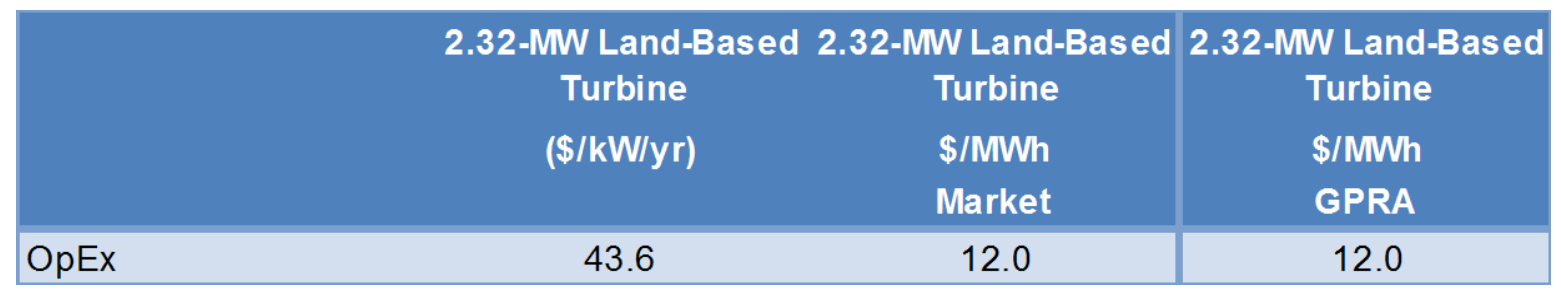

\subsection{Land-Based Finance}

This section describes the financing assumptions for the report's representative land-based wind reference project in the United States in 2017. It is important to distinguish between financing assumptions and financial costs. Financial costs, which are part of CapEx according to the SCBS, include items such as insurance, contingency, and reserve accounts. Financing assumptions, on the other hand, refer to the cost of interest and other carrying charges, corporate taxes, and depreciation (represented by the FCR in this report), applied to the total CapEx. To capture the financing structure and costs, a fixed charge rate, detailed in Section 4.5.2, is used for the LCOE equation.

\subsubsection{Discount Rate}

Typically, various financial terms, such as the cost of debt or equity, are captured in the discount rate, which is in turn used to estimate the cost of energy. For this analysis, the discount rate is calculated as the after-tax weighted-average cost of capital (WACC) and it is presumed that the reported yields for equity are after-tax yields and can be used directly in the WACC calculation. The cost of debt (as a value) is also reported, but because interest on debt is tax deductible, an effective corporate marginal tax rate is used to determine an after-tax cost of debt for the discount rate calculation. The cost of capital data collected by Lawrence Berkeley National Laboratory (Wiser and Bolinger 2018) gives a basis for WACC assumptions for the representative wind project in 2017 and results in a nominal WACC of 7.59\%. This WACC was derived assuming a debt fraction of $46 \%$, nominal debt interest rate of $4.1 \%$, nominal return on equity of $12 \%$, and a $40 \%$ tax rate. ${ }^{9}$ Each actual project, however, has a unique risk profile, financing terms, and ownership structure. For this reason, a single WACC representing the entire fleet of 2017 wind installations should be viewed cautiously and used to illustrate general market trends and conditions only.

Although the data collected from Wiser and Bolinger (2018) are used for calculating a representative WACC for projects installed in 2017, a separate WACC is reported to meet GPRA reporting requirements. This real WACC has been held constant since fiscal year 2015 at $5.68 \%$ and is used for reporting purposes only. The results of this reporting exercise are explained in more detail in Section 4.9 and shown in Table 9.

\footnotetext{
${ }^{9}$ Because these data are derived from installed projects in 2017, they include the impact of the PTC on the debt ratio even though the LCOE estimates do not include the PTC.
} 
In financial modeling, corporate tax rates are often presented as a composite, or effective, tax rate. This rate is calculated from a blend of the highest marginal corporate tax rate of $35 \%{ }^{10}$ and an approximate typical state corporate tax rate. Because state taxes are typically deductible expenses on federal tax returns, the blended rate is represented as $35 \%+7.7 \% \times(100 \%-35 \%)=$ $40 \%$. Wind projects are often organized as disregarded entities for tax purposes (i.e., no taxes are paid by the project entity) and taxes are paid further up the organizational structure at some corporate level.

The inflation rate has been set to $2.5 \%$. This rate aligns with the inflation rate provided in NREL's ATB (NREL's Annual Technology Baseline and Standard Scenarios web page) that is used for future LCOE projections. Discount rates are initially calculated in nominal after-tax USD, and an estimate of inflation is used to calculate a discount rate in real after-tax USD.

Although the PTC is a critical component for wind projects installed in 2017, it is expected to change in the future. ${ }^{11}$ Research has shown that one likely outcome of the termination of the PTC is increased project leverage, which will reduce the higher-cost tax-equity portion of project finance. This shift of capital structure is expected to partially offset the impact of the lack of PTC (Bolinger 2014). For example, assuming that project leverage increases from $40 \%$ to $60 \%$ results in a reduction in nominal after-tax WACC of over 1 percentage point (Mai et al. 2015).

\subsubsection{Economic Evaluation Metrics}

In the economic evaluation of wind energy investments there are two important metrics: the capital recovery factor (CRF) and FCR. The FCR represents the amount of annual revenue required to pay the carrying charge ${ }^{12}$ as applied to the CapEx on that investment during the expected project economic life. ${ }^{13}$ The FCR is based on the CRF but also reflects corporate income taxes and depreciation. The ATB methodology (NREL's Annual Technology Baseline and Standard Scenarios web page) is used to calculate the FCR.

The CRF is defined as "the uniform periodic payment, as a fraction of the original investment cost that will fully repay a loan including all interest, over the term of the loan" (Short et al. 1995). The CRF can be thought of as the recurring fixed payment over the life of a loan common to most types of mortgages. For example, a \$100 loan at 8\% interest amortized over 20 years requires a constant annual payment of $\$ 10.18$ (equivalent to the CRF). Notably, the CRF ignores

\footnotetext{
10 The U.S. tax reform bill passed and signed into law in December of 2017 (Tax Cuts and Jobs Act, H.R. 1) lowers the corporate tax rate from $35 \%$ to $21 \%$; however, the $35 \%$ corporate tax rate is used in this report because final investment decisions for projects commissioned in 2017 would have been made prior to the tax reform.

11 “In December 2015, Congress passed a 5-year phased-down extension of the PTC. To qualify, projects must begin construction before January 1, 2020. In May 2016, the IRS issued guidance allowing four years for project completion after the start of construction, without the burden of having to prove continuous construction. In extending the PTC, Congress also included a periodic reduction in the value of the credit for projects starting construction after 2016. Specifically, the PTC will phase down in increments of 20 percentage points per year for projects starting construction in 2017 (80\% PTC), 2018 (60\%), and 2019 (40\%)” (Wiser and Bolinger 2016).

${ }^{12}$ Carrying charges include the return on debt, return on equity, taxes, and depreciation.

13 The fixed charge rate (FCR) does not allow for detailed analysis of specific financing structures; however, these structures can be represented through the use of a weighted-average cost of capital (WACC) as the discount rate input.
} 
the impact of corporate income taxes, thus is applicable to a no-tax investment scenario, such as from a government investment.

U.S. wind projects in 2017 had the opportunity to benefit from accelerated depreciation (Modified Accelerated Cost Recovery System [MACRS]) and bonus depreciation. Bonus depreciation is ignored based on industry sources, indicating that the bonus is a relatively small benefit and was not taken for many wind projects. A reasonable assumption for land-based wind projects is that 95\% of the project capital cost is eligible for 5-year MACRS depreciation, and the balance of the project capital cost is eligible for 15-year MACRS. In this work, the MACRS assumption is further simplified by assuming that $100 \%$ of the wind project cost basis is eligible for 5-year MACRS.

Table 9 presents the estimated WACC, CRF, and FCR in nominal and real terms using the aftertax WACC discount rate of 7.6\% and 5\%, respectively, a project design lifetime of 25 years, and a net present value depreciation factor of 82\% (assuming a 5-year MACRS depreciation schedule). The nominal and real CRF are estimated at $9 \%$ and $7.1 \%$, respectively. The nominal FCR is estimated at $10.1 \%$ and the real FCR is estimated at $7.9 \%$. As noted in Short et al. (1995), comparisons of two or more capital investments should be on a consistent tax treatment basis (i.e., both investments using a before-tax method or an after-tax method).

DOE reporting has used a common constant FCR first reported in the 2015 Cost of Wind Energy Review (Moné et al. 2017) at 8.57\%, assuming a project design life of 25 years. A summary of the economic metrics for the GPRA case is also shown in Table 9.

Table 9. Summary of Land-Based Reference Project Economic Evaluation Metrics

\begin{tabular}{|lcc|cc|} 
& \multicolumn{2}{c}{ Market } & \multicolumn{2}{c|}{ GPRA } \\
& Nominal & Real & Nominal & Real \\
\hline Weighted-average cost of capital (\%) & $7.6 \%$ & $5.0 \%$ & $8.3 \%$ & $5.7 \%$ \\
\hline Capital recovery factor (\%) & $9.0 \%$ & $7.1 \%$ & $9.6 \%$ & $7.6 \%$ \\
\hline Fixed charge rate (\%) & $10.1 \%$ & $7.9 \%$ & $10.9 \%$ & $8.6 \%$ \\
\hline
\end{tabular}

\subsection{Land-Based Levelized Cost of Energy}

Based on the turbine technology parameters, site conditions, wind resource, and cost estimates, CapEx, FCR, OpEx, and AEP are plugged into the LCOE equation and the LCOE is computed to reflect a 2017 land-based reference wind power plant. Table 10 summarizes the costs for the primary components for the Market and GPRA cases (including their contribution to LCOE). Figure 2 provides a graphical representation of the land-based reference project LCOE by line item for the Market case. 
Table 10. Summary of Inputs and Reference Project LCOE for 2017 Land-Based Installations

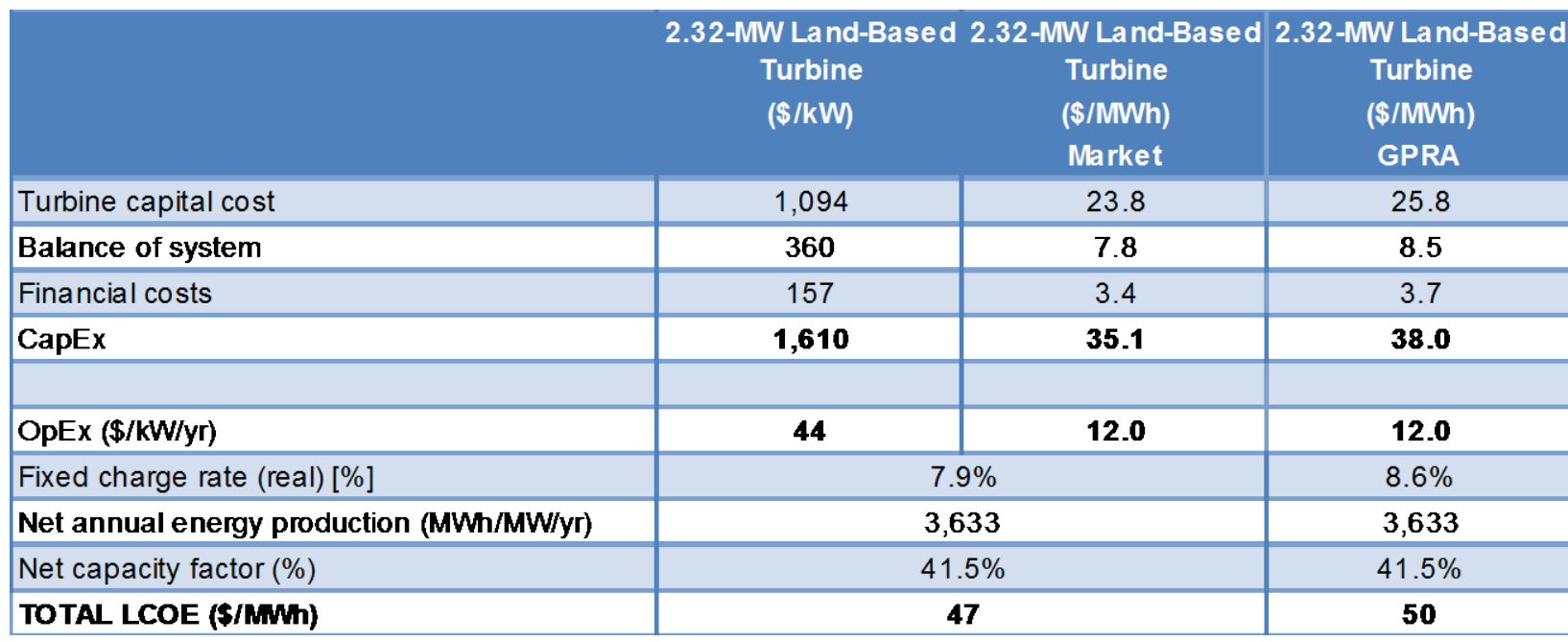

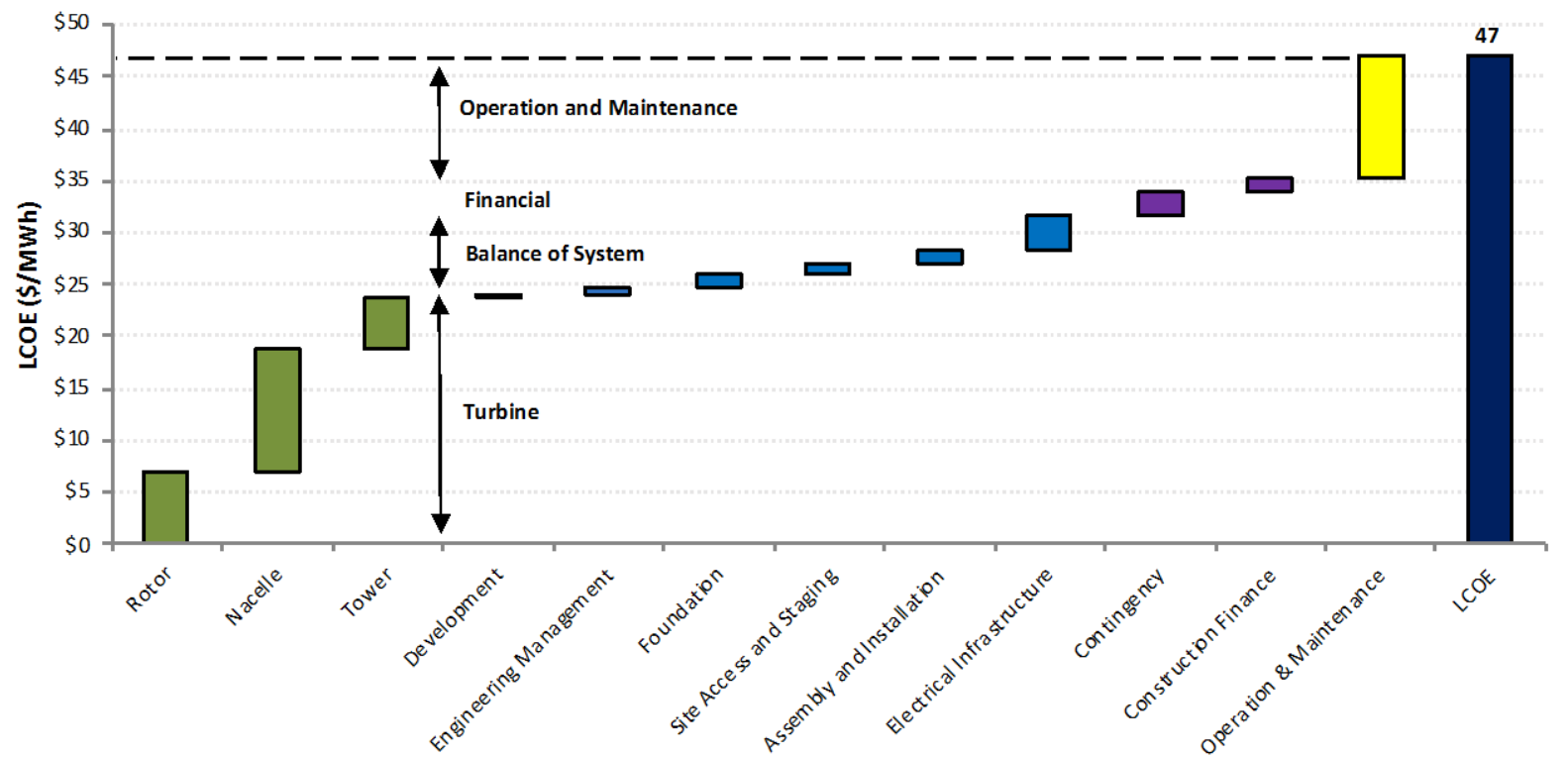

Figure 2. Component-level cost breakdown for the 2017 land-based wind reference project Source: NREL

\subsection{Land-Based Levelized Cost of Energy Sensitivities}

The input parameters described earlier reflect the land-based reference wind project; however, input parameters for a near-term wind project are subject to considerable uncertainty. As a result, it is beneficial to investigate how this variability may impact the LCOE. The sensitivity analysis shown in Figure 3 focuses on the basic LCOE inputs: CapEx, OpEx, capacity factor (a surrogate for AEP), and FCR, which is broken into its principal elements: discount rate and economic operational lifetime. 


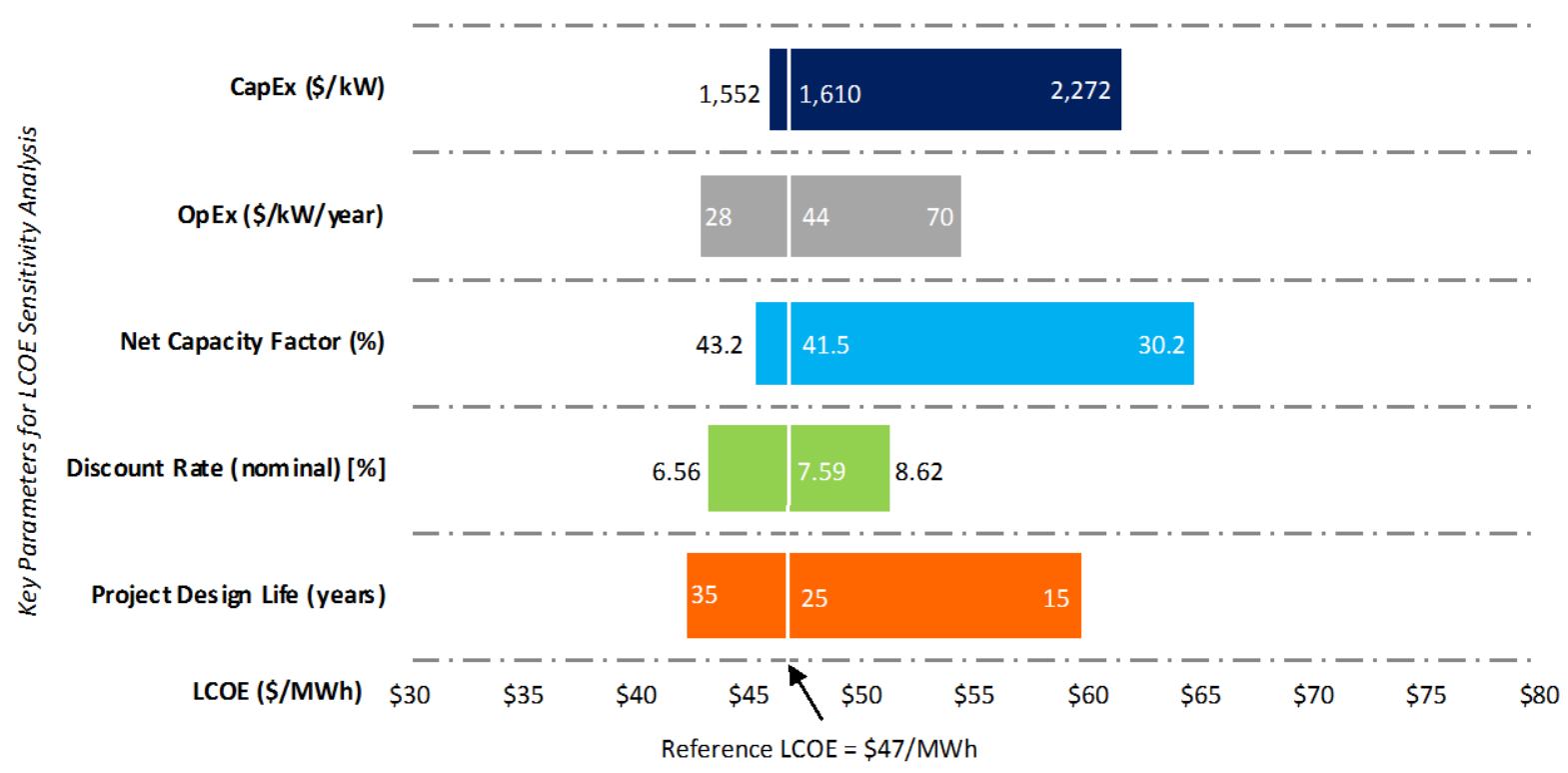

Figure 3. Sensitivity of land-based wind LCOE to key input parameters Source: NREL

Note: The reference LCOE reflects a representative industry LCOE. Changes in LCOE for a single variable can be understood by moving to the left or right along a specific variable. Values on the $\mathrm{x}$-axis indicate how the LCOE will change as a given variable is altered and all others are assumed constant (i.e., remain reflective of the reference project).

Sensitivity analyses are conducted by holding all reference project assumptions constant and altering only the variable in question. Sensitivity ranges are pulled from representative industry data contained in the 2017 Wind Technologies Market Report (Wiser and Bolinger 2018). This selection of ranges provides insight into how real-world ranges influence LCOE. Keeping the same 200-MW project size, the sensitivity analysis yields ranges in LCOE from a low of $\$ 42 / \mathrm{MWh}$ to a high of $\$ 65 / \mathrm{MWh}$ - a low-to-high increase of $\$ 22 / \mathrm{MWh}$. Within the ranges shown, net capacity factor has the greatest impact on land-based wind LCOE followed by impacts from project design life and then CapEx. Project design life appears to have the greatest influence with respect to decreasing the LCOE relative to the reference project.

\subsection{Land-Based Supply Curve}

NREL's land-based supply curve estimates LCOE for over 130,000 locations across the contiguous United States. The LCOE for each of the potential wind power plant locations is computed using a site-specific CapEx and net AEP using a geographic-information-system-based algorithm. The estimated theoretical capacity for the United States is calculated to be over 10,000 gigawatts (GW), assuming a wind power plant density of $3 \mathrm{MW} / \mathrm{kilometer}^{2}$. The range of LCOE calculated for this theoretical capacity ranges from \$32/MWh for the best sites in the United States and extends beyond \$500/MWh for nonideal sites. Figure 4 shows this supply curve. For illustrative purposes, the LCOE is calculated for the land-based wind projects installed in 2017 using the same site-specific methodology for the 130,000 theoretical locations and are shown on the supply curve (marked by green circles). In the figure, most of the installed projects in 2017 are clustered near the left side of the supply curve where LCOE values are lowest, with a few scattered toward the middle of the supply curve with higher LCOE values. 
Also shown is the calculated LCOE for the reference land-based wind project (Market is indicated by the orange diamond), which is based on the 2017 market data from Wiser and Bolinger (2018) and the representative wind site characteristics.

It is important to note that the potential wind power plant capacity available over a range of LCOE varies by geographic region primarily because of the available wind resource characteristics. Incremental costs associated with labor rates, material costs, logistical or siting challenges, and distance to existing transmission infrastructure also contribute to regional differences. This range of costs is illustrated in the supply curve (Figure 4), wherein the cluster of installed wind projects in 2017 is toward the lower LCOE end of the supply curve and reflects projects built in the interior region of the United States where the wind resource is favorable. On the other side of the spectrum, the higher LCOE values on the supply curve reflect sites with a relatively lower quality wind resource and may occur in many regions of the country depending on local meteorological and terrain features.

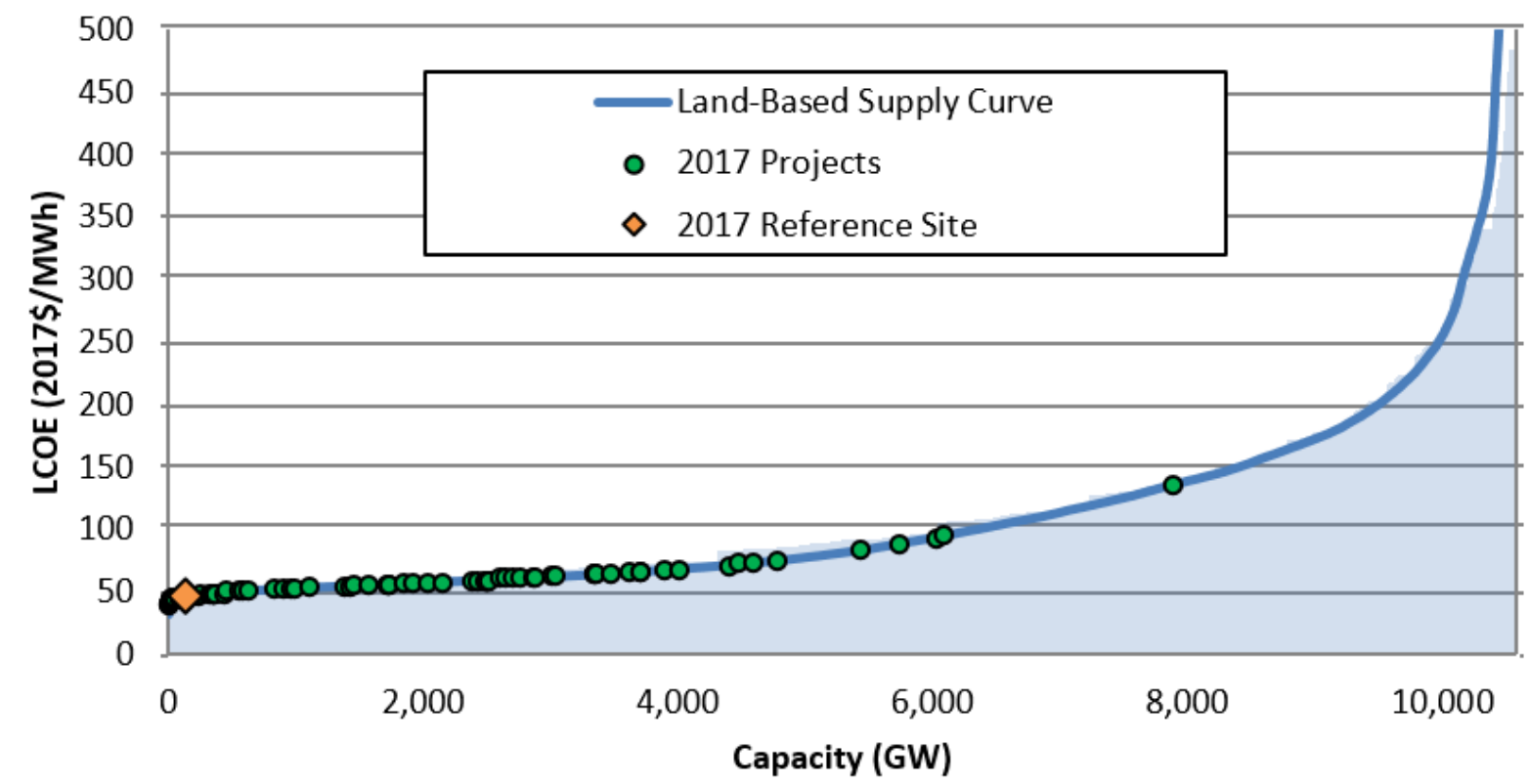

Figure 4. National land-based wind resource supply curve with 2017 U.S. installed projects Source: NREL

\subsection{Land-Based Discussion of Results in Context of DOE Goals}

In this section, we present the official land-based wind GPRA levelized cost of energy end point targets, reported in 2015 USD. The GPRA targets are calculated assuming an annual average wind speed of $7.25 \mathrm{~m} / \mathrm{s}$ at $50 \mathrm{~m}$, a plant life of 25 years, and a real FCR of $8.6 \%$. The updated GPRA targets for 2016 through 2030 are shown in Figure 5. Currently, the end point for the 2030 GPRA target is \$31/MWh in 2015 USD. These trajectories are partially informed by those articulated in the recent study, Enabling the SMART Wind Power Plant of the Future Through Science-Based Innovation (Dykes et al. 2017).

The 2018 GPRA value used for tracking progress against the trajectory is shown in Figure 5. This value is calculated using 2017 market data from Wiser and Bolinger (2018) as well as the 
same 8.6\% real FCR applied for the GPRA trajectory. The resulting LCOE is \$48/MWh in 2015 USD, which is labeled as “Actuals” in Figure 5. The LCOE is converted from 2017 USD to 2015 USD by applying a 96.3\% total inflation adjustment, derived from BLS conversion factors (undated).

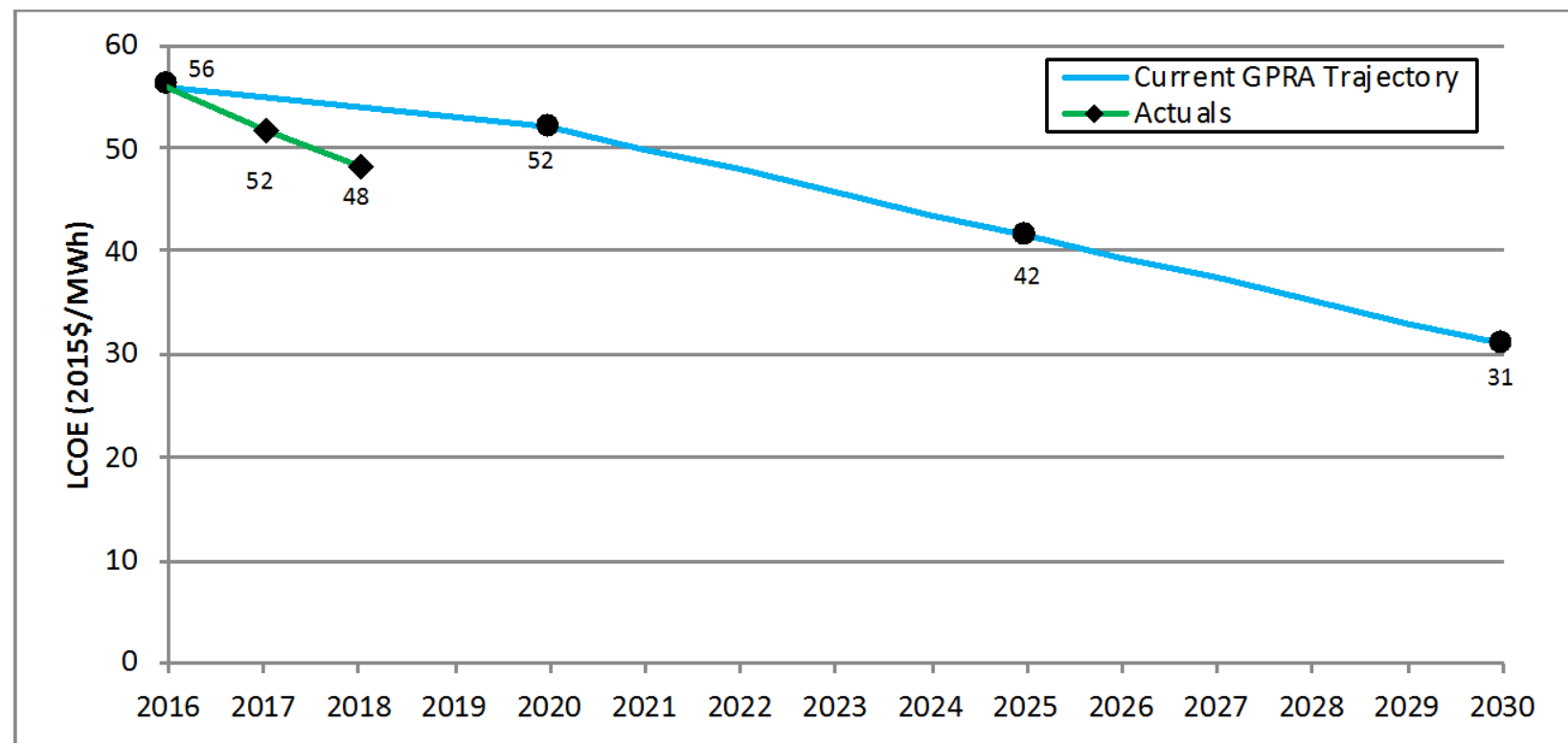

Figure 5. Land-based wind GPRA cost trajectories for LCOE Source: NREL

Note: The GPRA LCOE targets were rebaselined in 2015; therefore, the GPRA trajectory and the actuals are reported in 2015 USD. 


\section{Offshore Wind}

This section explains the methodology and assumptions of calculating LCOE for U.S. offshore wind with each subsection detailing the data at the offshore reference project site. The data from this analysis comes from NREL's internal OWDB, which is populated by global market data and used to analyze market trends for offshore wind costs in Europe to determine cost projections for the United States and inform internal NREL modeling. The analysis uses offshore market research, such as the 2016 Offshore Wind Technologies Market Report (Musial et al. 2017), the 2017 Offshore Wind Technologies Market Update (Beiter et al. 2018), and NREL's 2018 ATB (NREL's Annual Technology Baseline and Standard Scenarios web page) for offshore wind. The reference project site is located in the North Atlantic Ocean at a distance of 30 kilometers from the U.S. mainland. The hypothetical reference site is considered representative of the locations of the first offshore wind projects in the United States. The distance from shore applied in this report is consistent with that used to estimate LCOE in analysis conducted for the National Offshore Wind Strategy: Facilitating the Development of the Offshore Wind Industry in the United States (Gilman et al. 2016) and A Spatial-Economic Cost-Reduction Pathway Analysis for U.S. Offshore Wind Energy Development from 2015-2030 (Beiter et al. 2016).

\subsection{Offshore Reference Project}

The offshore reference project is intended to be representative of near-term offshore wind projects likely to be developed in the North Atlantic region of the United States. This wind power plant consists of 107 wind turbines each rated at 5.64 MW, equating to a 600-MW wind power plant capacity. The offshore reference project assumes that the turbines are oriented in a grid layout and will be operating for 20 years, with no catastrophic O\&M events. The reference project parameters for fixed-bottom versus floating configurations are the same except for the water depth. The fixed-bottom project assumes a water depth of $30 \mathrm{~m}$ and utilizes a monopile substructure, whereas the floating project assumes a water depth of $100 \mathrm{~m}$ and uses a semisubmersible substructure. The array cable system and electrical line that connects to the offshore substation is a 33-kilovolt collection system design. The export cable from the offshore substation that is used to transfer the power to landfall assumes a 220-kilovolt export system. Specific to the floating reference site, cost premiums are applied to the array and export cable systems to account for the use of dynamic cables. The offshore reference project characteristics are summarized in Table 11. 
Table 11. Offshore Reference Project Parameters (Fixed-Bottom and Floating Substructures)

\begin{tabular}{|lc|}
\hline Project Parameters & $\begin{array}{c}\text { Fixed-Bottom/Floating } \\
\text { Substructures } \\
\text { Location }\end{array}$ \\
\hline Turbine rated power (MW) & 5.64 \\
\hline Number of turbines & 107 \\
\hline Wind plant capacity (MW) & 600 \\
\hline Water depth (m) & $30 / 100$ \\
\hline Substructure type & 30 \\
\hline Distance from shore (km) & 20 \\
\hline Project design life (years) & \\
\hline
\end{tabular}

\subsection{Offshore Capital Expenditures}

The various components of the offshore project CapEx for both fixed-bottom and floating substructures were informed by NREL's OWDB, which contains information on 26 offshore wind projects that were approved, under construction, and installed in 2017, and corresponding to 4,844 MW of capacity. The data are obtained by conducting several parallel assessments: analyzing global market data, studying published literature, reviewing recent press statements, and collaborating with industry.

The capacity-weighted average turbine installed globally in 2017 was 5.64 MW with a 140-m rotor diameter. ${ }^{14}$ Given the relatively limited number of U.S. offshore projects, the CapEx estimate is derived from NREL's Offshore Wind Cost Model (Beiter et al. 2016) using the spatial parameters for the reference site (Table 11) for 2017. ${ }^{15}$ The NREL model yields a total installed CapEx value of $\$ 4,536 / \mathrm{kW}$ for an offshore wind power plant with turbines being supported by monopile fixed-bottom substructures. The analysis for floating substructures uses the same methodology and turbine characteristics as for fixed-bottom and estimates installed CapEx to be $\$ 5,605 / \mathrm{kW}$. It should be noted that the CapEx estimates for floating offshore wind in this analysis assume a 5.64-MW turbine and are not necessarily optimized for floating offshore wind applications, therefore, they may negatively impact CapEx estimates. Progression to larger turbines is likely to coincide with deployment of commercial-scale floating wind technologies (Spyroudi 2016).

When reviewing the results, note that all costs are converted to USD from the original reported year exchange rate and then inflated to 2017 USD using the Consumer Price Index. A breakdown of the CapEx for the fixed-bottom offshore reference project is shown in Figure 6. The shades of green represent the turbine cost, shades of blue represent BOS costs, and shades of purple represent financial costs. Further details on the BOS cost breakdown are provided in Maness et

\footnotetext{
14 The capacity-weighted average turbine rating for this analysis was based on data contained in NREL's OWDB as of May 2018. The capacity-weighted average turbine rating in the 2017 Offshore Wind Technologies Market Update (Beiter et al. 2018) presents a different turbine rating because it was based on updated data in the OWDB after May 2018. The difference in turbine rating is anticipated to have a minor impact on the LCOE results for fixed-bottom and floating offshore wind.

${ }^{15}$ A linear interpolation was assumed between the model run years 2015 and 2022 to derive a value for 2017.
} 
al. (2016). The dollar-value component cost breakdown is shown in Table 12. Figure 7 and Table 13 describe the same breakdown for the floating offshore reference project.

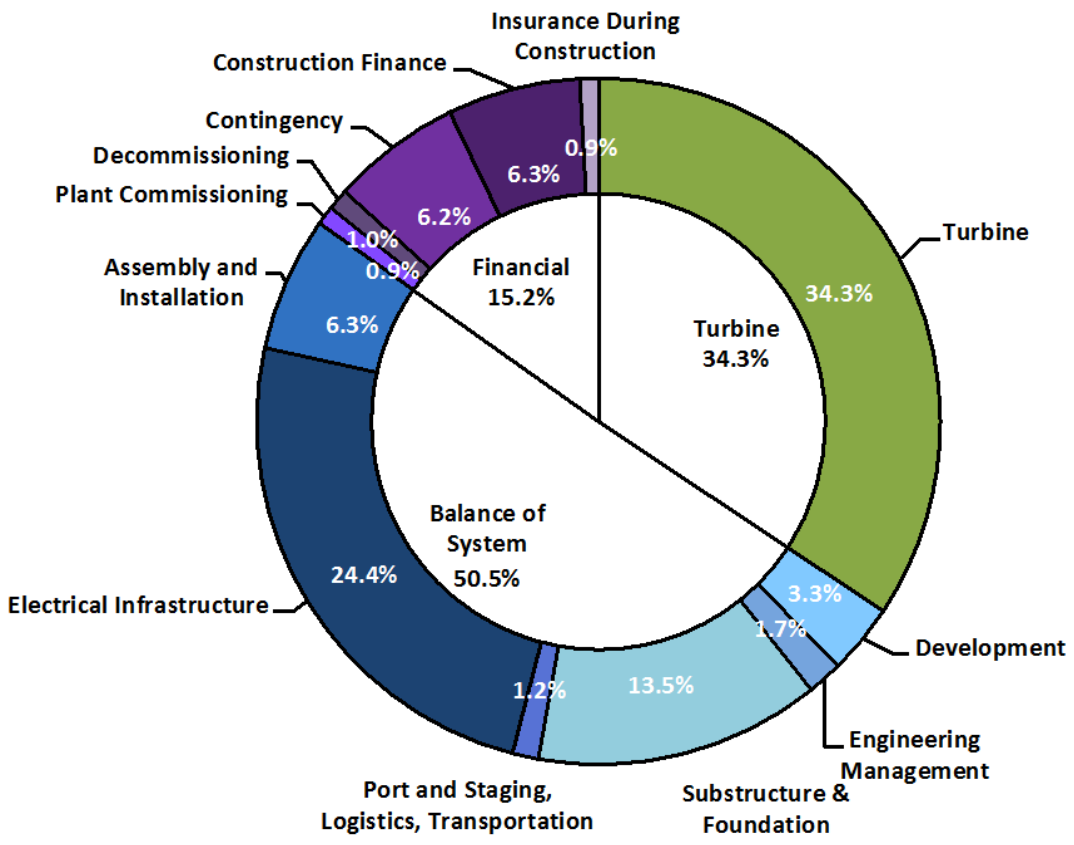

Figure 6. Capital expenditures for the fixed-bottom offshore wind reference project

This report is available at no cost from the National Renewable Energy Laboratory (NREL) at www.nrel.gov/publications. 
Table 12. Fixed-Bottom Offshore CapEx and LCOE Breakdown

\begin{tabular}{|c|c|c|}
\hline & $\begin{array}{l}\text { 5.64-MW Offshore } \\
\text { Turbine } \\
\text { (\$/kW) }\end{array}$ & $\begin{array}{c}\text { 5.64-MW Offs hore } \\
\text { Turbine } \\
\text { (\$/MWh) }\end{array}$ \\
\hline TURBINE CAPITAL COST & 1,557 & 29.2 \\
\hline Deve lopment cost & 150 & 2.8 \\
\hline Project management & 76 & 1.4 \\
\hline Subs tructure and foundation & 613 & 11.5 \\
\hline Port and staging, logis tics, trans portation & 56 & 1.1 \\
\hline Electrical infrastructure ${ }^{\star}$ & 1,106 & 20.8 \\
\hline Assembly and installation & 288 & 5.4 \\
\hline BALANCE OF SYSTEM & 2,289 & 43.0 \\
\hline Insurance during construction & 40 & 0.8 \\
\hline Decommissioning bond & 46 & 0.9 \\
\hline Construction financing & 285 & 5.4 \\
\hline Contingency & 279 & 5.2 \\
\hline Plant commissioning & 40 & 0.8 \\
\hline FINANCIAL COSTS & 690 & 13.0 \\
\hline TOTAL CAPITAL EXPENDITURES & 4,536 & 85.2 \\
\hline
\end{tabular}

Note: The electrical infrastructure cost category includes construction and fabrication costs of both the land-based and offshore substations, and does not include installation costs for the electrical system as they are included in the assembly and installation costs.

This report is available at no cost from the National Renewable Energy Laboratory (NREL) at www.nrel.gov/publications. 


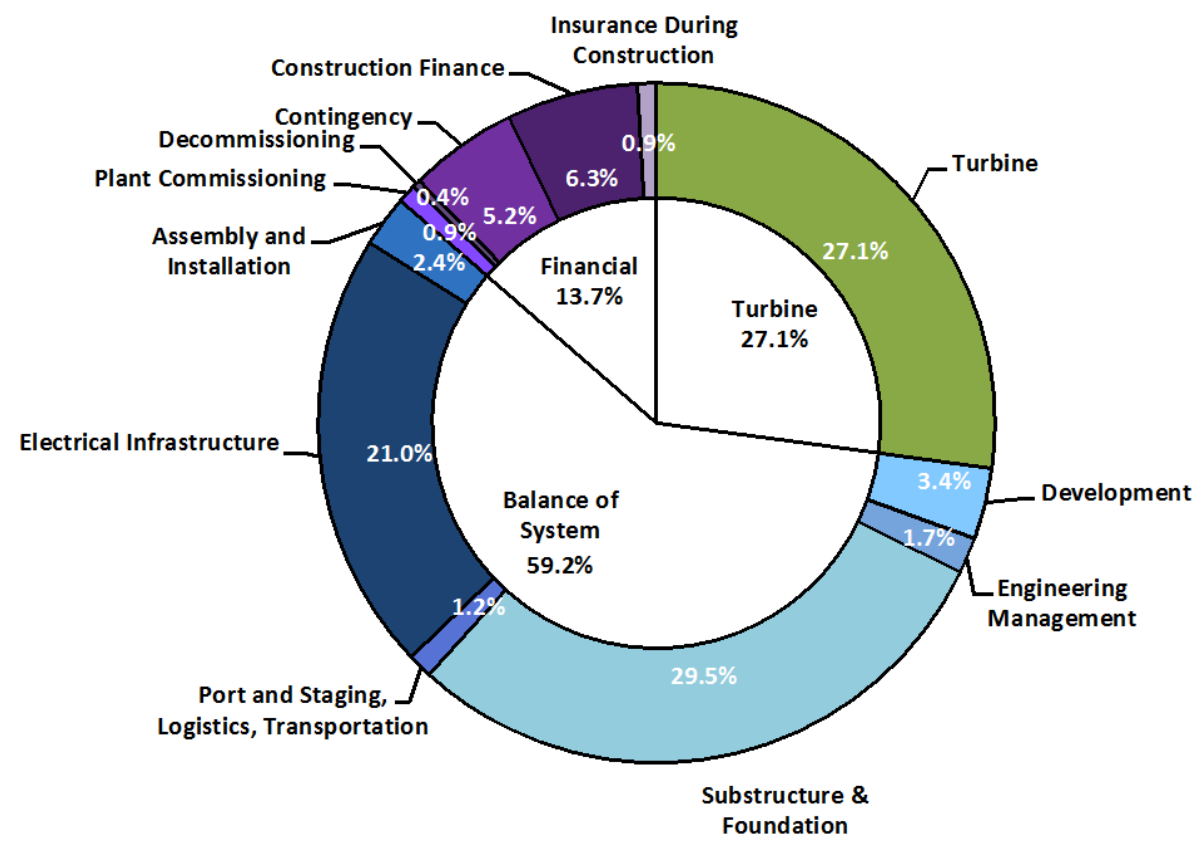

Figure 7. Capital expenditures for the floating offshore wind reference project Source: NREL

This report is available at no cost from the National Renewable Energy Laboratory (NREL) at www.nrel.gov/publications. 
Table 13. Floating Offshore CapEx and LCOE Breakdown

\begin{tabular}{|c|c|c|}
\hline & $\begin{array}{l}\text { 5.64-MW Offshore } \\
\text { Turbine } \\
(\$ / k W)\end{array}$ & $\begin{array}{c}\text { 5.64-MW Offs hore } \\
\text { Turbine } \\
\text { (\$/MWh) }\end{array}$ \\
\hline TURBINE CAPITAL COST & 1,521 & 33.3 \\
\hline Deve lopment cost & 190 & 4.2 \\
\hline Engineering management & 96 & 2.1 \\
\hline Subs tructure and foundation & 1,653 & 36.1 \\
\hline Site access, staging, and port & 67 & 1.5 \\
\hline Electrical infrastructure ${ }^{*}$ & 1,175 & 25.7 \\
\hline Assembly and installation & 137 & 3.0 \\
\hline BALANCE OF SYSTEM & 3,318 & 72.6 \\
\hline Insurance during construction & 51 & 1.1 \\
\hline Decommissioning bond & 22 & 0.5 \\
\hline Construction financing & 352 & 7.7 \\
\hline Contingency & 290 & 6.3 \\
\hline Plant commissioning & 51 & 1.1 \\
\hline FINANCIAL COSTS & 766 & 16.8 \\
\hline TOTAL CAPITAL EXPENDITURES & 5,605 & 122.6 \\
\hline
\end{tabular}

Note: The electrical infrastructure cost category includes construction and fabrication costs of both the land-based and offshore substations; this category does not include installation costs for the electrical system as they are included in the assembly and installation costs.

There is a notable difference between the cost components that make up the land-based and offshore projects. In the land-based project, $68 \%$ of the cost is related to the wind turbine. For the offshore project, the turbine makes up $34 \%$ of the fixed-bottom offshore and $27 \%$ of the floating offshore reference project costs. The substructure and foundation portion of the BOS costs is the primary cause for the cost differences between the fixed-bottom and floating offshore projects because of the increase in steel required for the floating substructure compared to a traditional fixed bottom. The other differences in the BOS and financial costs are related to the empiricallybased scaling relationships_-some of which are a simple percentage of total costs.

\subsection{Offshore Technology Characteristics and Annual Energy Production}

Offshore wind turbines are continuing their upscaling trend. Looking ahead, turbines installed in the coming years are expected to exceed $10 \mathrm{MW}$, as turbine manufacturers are announcing 12MW turbines ready to be shipped in 2021 (GE Renewable Energy 2018). Some offshore wind developers are anticipating 13- to 15-MW turbines to be on the market by 2024 (DONG Energy 2017). Larger turbine sizes are enabled in offshore applications, in part, because there are fewer transportation and installation limits than for land-based projects. Furthermore, incorporating 
larger turbines in a project's design may also reduce the nonturbine balance-of-plant costs and result in fewer turbines to service (Musial et al. 2017).

\subsubsection{Turbine Parameters}

The offshore wind turbine technology characteristics for this analysis are calculated using a capacity-weighted average of the global offshore wind projects installed in 2017. The results of this calculation yield a turbine rating of $5.64 \mathrm{MW}$, rotor diameter of $140 \mathrm{~m}$, and a hub height of $96.2 \mathrm{~m} .{ }^{16}$ These values and more detailed offshore turbine characteristics are summarized in Table 14.

Table 14. Reference Offshore Turbine Parameter Input Assumptions

\begin{tabular}{|l|c|}
\hline \multicolumn{2}{|c|}{ Turbine Parameters } \\
\hline Turbine rated power $(\mathrm{MW})$ & 5.64 \\
\hline Turbine rotor diameter $(\mathrm{m})$ & 140 \\
\hline Turbine hub height $(\mathrm{m})$ & 96.2 \\
\hline Maximum rotor tip speed $(\mathrm{m} / \mathrm{s})$ & 90 \\
\hline TSR at maximum $\mathrm{C}_{\mathrm{p}}$ & 8 \\
\hline Drivetrain design & Geared \\
\hline Cut-in wind speed $(\mathrm{m} / \mathrm{s})$ & 3 \\
\hline Cut-out wind speed $(\mathrm{m} / \mathrm{s})$ & 25 \\
\hline Maximum coefficient of power & 0.47 \\
\hline
\end{tabular}

\subsubsection{Wind Resource}

The wind resource and project design assumes specific site characteristics common to the North Atlantic region of the United States for the reference land-based and floating offshore wind projects. The net AEP is calculated using NREL's Offshore Wind Cost Model, assuming an annual average wind speed of $8.4 \mathrm{~m} / \mathrm{s}$ at $50 \mathrm{~m}(8.97 \mathrm{~m} / \mathrm{s}$ at a $96.2-\mathrm{m}$ hub height), with other typical wind resources characteristics of the North Atlantic Coast (Beiter et al. 2016). The wind resource parameters are summarized in Table 15.

Table 15. Reference Offshore Wind Resource Input Assumptions

\begin{tabular}{|l|c|}
\hline \multicolumn{2}{|c|}{ Wind Resource Characteristics } \\
\hline Annual average wind speed at 50-m height (m/s) & 8.4 \\
\hline Annual average wind speed at 96.2-m hub height (m/s) & 8.97 \\
\hline Weibull k & 2.1 \\
\hline Shear exponent & 0.1 \\
\hline
\end{tabular}

\footnotetext{
${ }^{16}$ The turbine size was derived from preliminary data for the 2017 Offshore Wind Technologies Market Update (Beiter et al. 2018). The turbine size presented in Beiter et al. (2018) is $5.3 \mathrm{MW}$ with a 141-m rotor diameter and hub height of $98 \mathrm{~m}$. This difference in turbine size is anticipated to have limited impact on the LCOE results for fixed-bottom and floating offshore wind.
} 


\subsubsection{Losses and Availability}

The U.S. offshore reference project considers losses from wind power plant array wake impacts, inefficiencies in power collection and transmission, and losses from wind power plant availability. These losses and availability estimates are determined using NREL's Offshore Wind Cost Model (Beiter et al. 2016), which performs calculations based on wind power plant layout and site-specific meteorological ocean conditions. The model outputs for the fixed-bottom total system losses are $15.8 \%$, whereas the floating offshore total systems losses are $16.1 \%$. The differences between these offshore technologies are the additional electrical losses for floating wind in deeper waters (i.e., $30 \mathrm{~m}$ versus $100 \mathrm{~m}$ ) and the difference in availability from dissimilar O\&M strategies (i.e., in situ repair versus tow-to-shore repair). Table 16 summarizes the losses and availability estimates for the fixed-bottom and floating offshore wind technologies.

Table 16. Reference Offshore Wind Total Losses

\begin{tabular}{|l|c|c|}
\hline & $\begin{array}{c}\text { Losses } \\
\text { Fixed-Bottom } \\
\text { Substructure }\end{array}$ & $\begin{array}{c}\text { Floating } \\
\text { Substructure }\end{array}$ \\
\hline Total System Losses (\%) & $15.8 \%$ & $16.1 \%$ \\
\hline
\end{tabular}

\subsubsection{Annual Energy Production}

The net AEP is calculated using the turbine technology parameters and wind resource inputs, and by applying the appropriate losses and availability estimates. The net AEP is calculated for the offshore reference project for both fixed-bottom and floating offshore applications using NREL's Offshore Wind Cost Model. The resulting net AEP for the fixed-bottom configuration is 3,741 $\mathrm{MWh} / \mathrm{MW} /$ year, with a $42.7 \%$ net capacity factor and 3,732 MWh/MW/year for the floating configuration, with a $42.6 \%$ net capacity factor. These values are summarized in Table 17.

Table 17. Reference Offshore Wind Net Annual Energy Production

\begin{tabular}{|lcc|}
\hline \multicolumn{2}{|c|}{ Net Annual Energy Production } & \\
\hline & $\begin{array}{c}\text { Fixed-Bottom } \\
\text { Substructure }\end{array}$ & $\begin{array}{c}\text { Floating } \\
\text { Substructure }\end{array}$ \\
\hline Net energy capture (MWh/MW/year) & 3,741 & 3,732 \\
\hline Net capacity factor (\%) & $42.7 \%$ & $42.6 \%$ \\
\hline
\end{tabular}

Capacity factors in the United States are expected to vary widely depending on the project location and turbine technology. Improving the performance of offshore wind turbines and arrays has been a continued focus of industry and research activities. More information on the global trends for offshore wind power plant performance can be found in Musial et al. (2017).

\subsection{Offshore Operation and Maintenance Expenditures}

OpEx can vary greatly between projects for a number of reasons but the two largest cost drivers are the distance from the project to the maintenance facilities and the meteorological ocean climate at the site (Maples et al. 2013; Jacquemin et al. 2011; Pietermen et al. 2011). Beiter et al. (2016) evaluated the O\&M for fixed-bottom and floating substructures located at sites with various wave heights, water depths, and distances from ports informed by parametric studies 
using the Energy Research Centre of the Netherlands O\&M Tool. ${ }^{17}$ The North Atlantic fixedbottom and floating offshore reference projects assume the same operational costs (e.g., annual leases and fees) of $\$ 31 / \mathrm{kW} /$ year, whereas the maintenance expenditures differ between the two because they each utilize a different maintenance strategy (i.e., in situ versus tow-to-shore), resulting in $\$ 127 / \mathrm{kW} /$ year for the fixed-bottom project and $\$ 93 / \mathrm{kW} /$ year for the floating project. These O\&M costs in addition to the LCOE component breakdown are shown in Table 18. Note that the GPRA values on an energy basis for fixed-bottom OpEx are the same as the market values.

Table 18. Offshore Wind Reference Project OpEx

\begin{tabular}{|c|c|c|c|c|}
\hline & \multicolumn{2}{|c|}{$\begin{array}{l}\text { Fixed-Bottom } \\
\text { Substructure }\end{array}$} & \multicolumn{2}{|c|}{$\begin{array}{c}\text { Floating } \\
\text { Substructure }\end{array}$} \\
\hline & (\$/kW/year) & (\$/kWh) & (\$/kW/year) & (\$/kWh) \\
\hline Operation & 31 & 8.3 & 31 & 8.3 \\
\hline Maintenance & 113 & 30.2 & 55 & 14.7 \\
\hline OpEx & 144 & 38.5 & 86 & 23.0 \\
\hline
\end{tabular}

\subsection{Offshore Finance}

This section describes the financing assumptions for the report's representative offshore wind (both fixed-bottom and floating) reference projects in the United States in 2017.

\subsubsection{Discount Rate}

Previous evaluations of the discount rate for offshore wind finance have focused on the European experience and the blended discount rates of prior publications of this report (i.e., 2015 Cost of Wind Energy Review (Moné et al. 2017). Although it is evident that an individual project's financing terms will reflect its specific risk profile, new assumptions and ranges of nominal discount rates for offshore wind have been developed that are based largely on observations from the recent European market, assessing theoretical commercial wind projects in the United States, available information about financing for the Block Island Wind Farm in the United States, and NREL's 2018 ATB (NREL's Annual Technology Baseline and Standard Scenarios web page). The resulting nominal WACC is $5.2 \%$ for fixed bottom and $6.6 \%$ for floating substructures, which corresponds to a real WACC of $2.6 \%$ and $4.0 \%$, respectively, assuming a $2.5 \%$ inflation rate. The higher nominal WACC for floating is a result of reduced debt levels because the technology remains relatively new in today's offshore wind market. Underlying assumptions for marginal tax rate and inflation are consistent with those presented in Section 4.5.1.

\subsubsection{Economic Evaluation Metrics}

To determine the LCOE for the 2017 representative offshore wind project, a similar FCR methodology that was used for the land-based representative wind project is applied (see Section 4.5) and informed by the 2018 ATB (NREL’s Annual Technology Baseline and Standard Scenarios web page). The FCR includes the present value of the accumulated depreciation

\footnotetext{
${ }^{17}$ Operation and maintenance costs for offshore wind projects are assumed to include labor, vessels, equipment, scheduled maintenance, unscheduled maintenance, land-based support, and administration.
} 
benefit and ignores bonus depreciation. Assuming a project life of 20 years and discount rates and depreciation benefits as calculated, the offshore reference project nominal and real FCR is $8.8 \%$ and $7.0 \%$, respectively, for fixed bottom substructures and $10.1 \%$ and $8.2 \%$, respectively, for floating substructures. Table 19 presents a summary of nominal and real WACC, CRF, and FCR that is used throughout the offshore analysis. For reporting purposes, the market financials and GPRA financials for the offshore fixed-bottom reference project are equivalent. GPRA does not require reporting for floating offshore wind.

Table 19. Summary of Offshore Reference Project Economic Evaluation Metrics

\begin{tabular}{|lcc|cc|} 
& \multicolumn{2}{c}{ Fixed Bottom } & \multicolumn{2}{c|}{ Floating } \\
& Nominal & Real & Nominal & Real \\
\hline WACC (\%) & $5.2 \%$ & $2.6 \%$ & $6.6 \%$ & $4.0 \%$ \\
\hline CRF (\%) & $8.1 \%$ & $6.5 \%$ & $9.2 \%$ & $7.4 \%$ \\
\hline FCR (\%) & $8.8 \%$ & $7.0 \%$ & $10.1 \%$ & $8.2 \%$ \\
\hline
\end{tabular}

Note: The Market and the GPRA fixed charge rate are equivalent for the offshore fixed-bottom reference project; therefore, we do not include an additional column to report the GPRA values.

\subsection{Offshore Reference Project Levelized Cost of Energy}

Based on the offshore turbine technology parameters, site conditions, wind resource, and cost estimates, the CapEx, FCR, OpEx, and AEP are plugged into the LCOE equation and the LCOE is computed to reflect a 2017 offshore reference wind power plant for fixed-bottom and floating technologies. Table 20 summarizes the fixed-bottom costs for the primary components (including their contribution to LCOE). Figure 8 provides a graphical representation of the fixedbottom offshore reference project LCOE by line item. Table 21 and Figure 11 show the LCOE cost components and their associated graphical representation for the floating project.

Table 20. Fixed-Bottom Offshore Wind LCOE and Reference Projects Cost Breakdown

\begin{tabular}{|c|c|c|}
\hline & $\begin{array}{c}\text { 5.64-MW Offs hore } \\
\text { Turbine } \\
(\$ / k W)\end{array}$ & $\begin{array}{c}\text { 5.64-MW Offs hore } \\
\text { Turbine } \\
\text { (\$/MWh) } \\
\text { Market }\end{array}$ \\
\hline Turbine capital cost & 1,557 & 29.2 \\
\hline Balance of system & 2,289 & 43.0 \\
\hline Financial costs & 690 & 13.0 \\
\hline CapEx & 4,536 & 85.2 \\
\hline OpEx (\$/kW/yr) & 144 & 38.5 \\
\hline Fixed charge rate (real) [\%] & \multicolumn{2}{|c|}{$7.0 \%$} \\
\hline Net annual energy production (MWh/MW/yr) & \multicolumn{2}{|c|}{3,741} \\
\hline Net capacity factor $(\%)$ & \multicolumn{2}{|c|}{$42.7 \%$} \\
\hline Total LCOE (\$/MWh) & \multicolumn{2}{|c|}{124} \\
\hline
\end{tabular}

Note: The market FCR and the GPRA FCR are equivalent for the offshore fixed-bottom reference project; therefore, we do not include an additional column to report the GPRA values. 


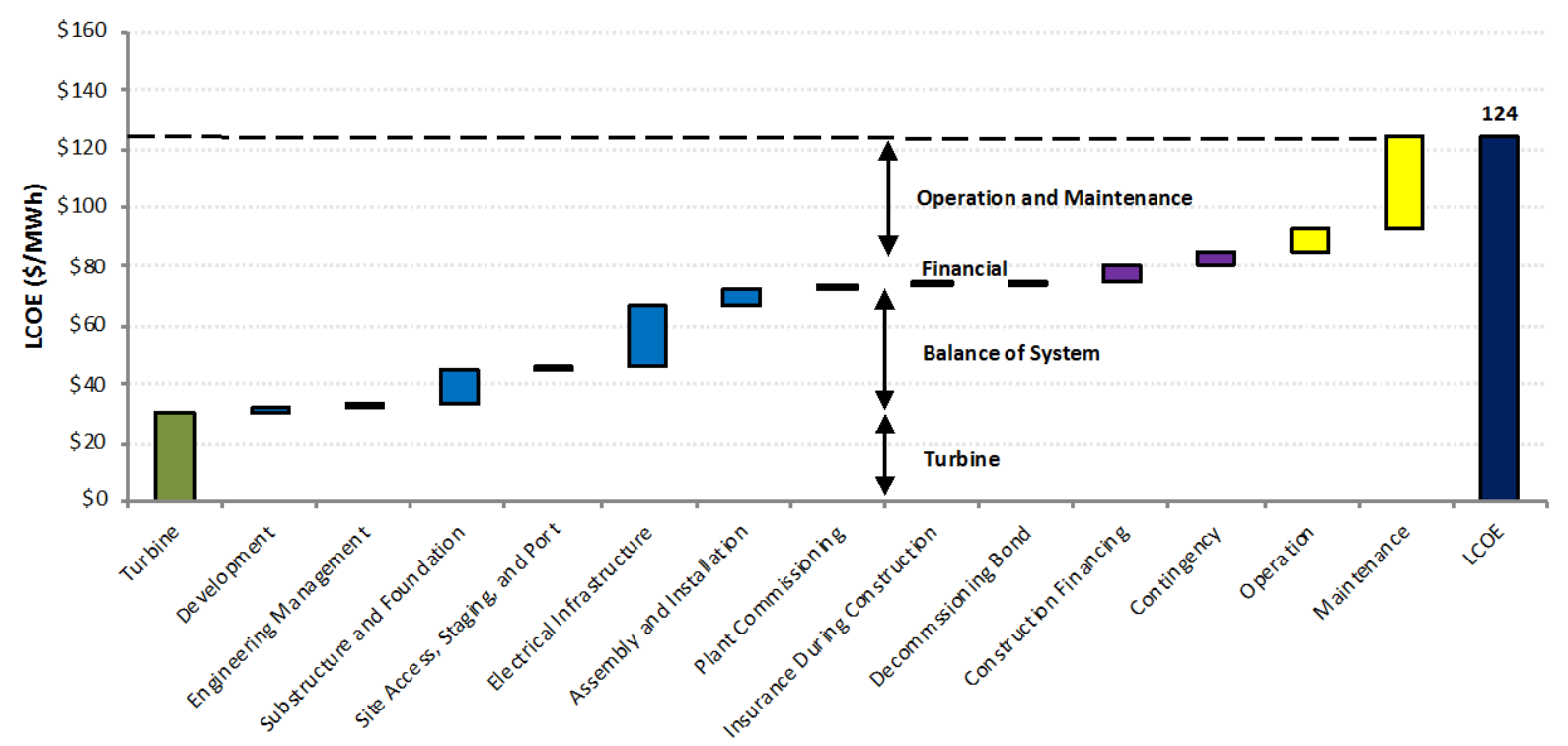

Figure 8. Component-level cost breakdown for the 2017 fixed-bottom offshore wind reference project

Source: NREL

Table 21. Floating Offshore Wind LCOE and Reference Projects Cost Breakdown

\begin{tabular}{|c|c|c|}
\hline & $\begin{array}{l}\text { 5.64-MW Offs hore } \\
\text { Turbine } \\
(\$ / k W)\end{array}$ & $\begin{array}{c}\text { 5.64-MW Offshore } \\
\text { Turbine } \\
\text { (\$/MWh) } \\
\text { Market }\end{array}$ \\
\hline Turbine capital cost & 1,521 & 33.3 \\
\hline Balance of system & 3,318 & 72.6 \\
\hline Financial costs & 766 & 16.8 \\
\hline CapEx & 5,605 & 122.6 \\
\hline OpEx $(\$ / k W / y r)$ & 86 & 23.0 \\
\hline Fixed charge rate (real) [\%] & \multicolumn{2}{|c|}{$8.2 \%$} \\
\hline Net annual energy production (MWh/MW/yr) & \multicolumn{2}{|c|}{3,732} \\
\hline Net capacity factor $(\%)$ & \multicolumn{2}{|c|}{$42.6 \%$} \\
\hline Total LCOE (\$/MWh) & \multicolumn{2}{|c|}{146} \\
\hline
\end{tabular}

Note: GPRA values are not reported for floating technology; hence, they are not included for the floating offshore reference project.

This report is available at no cost from the National Renewable Energy Laboratory (NREL) at www.nrel.gov/publications. 


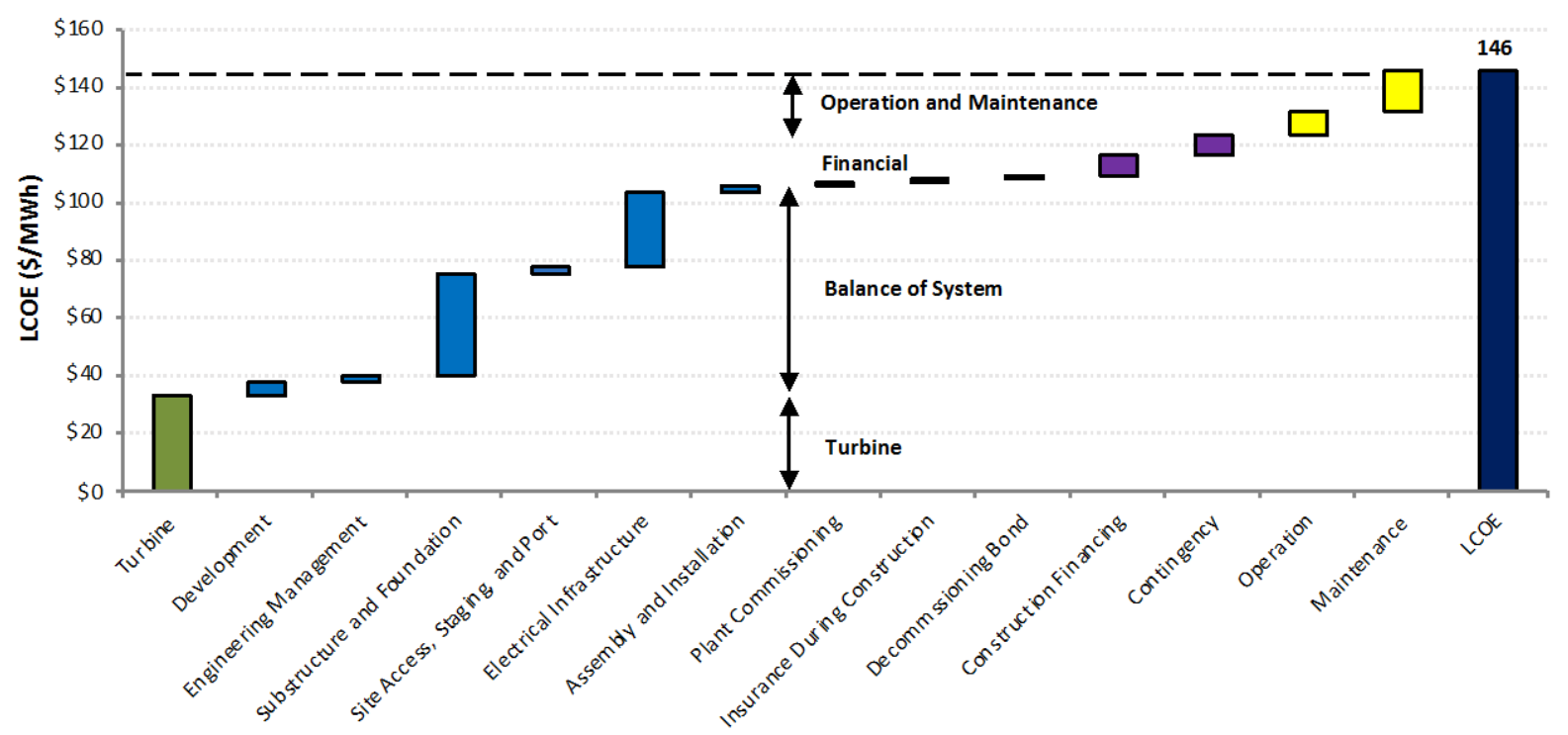

Figure 9. Component-level cost breakdown for the 2017 floating offshore wind reference project Source: NREL

\subsection{Offshore Levelized Cost of Energy Sensitivities}

The input parameters described earlier reflect the fixed-bottom and floating offshore reference wind project; however, input parameters for a near-term wind project are subject to considerable uncertainty. As a result, it is beneficial to investigate how this variability may impact the LCOE. The sensitivity analysis shown in Figure 10 (for the fixed-bottom substructure) and Figure 11 (for the floating substructure) focuses on the basic LCOE inputs: CapEx, OpEx, capacity factor (a surrogate for AEP), and FCR, which is broken into two principal elements: discount rate and economic operational lifetime.

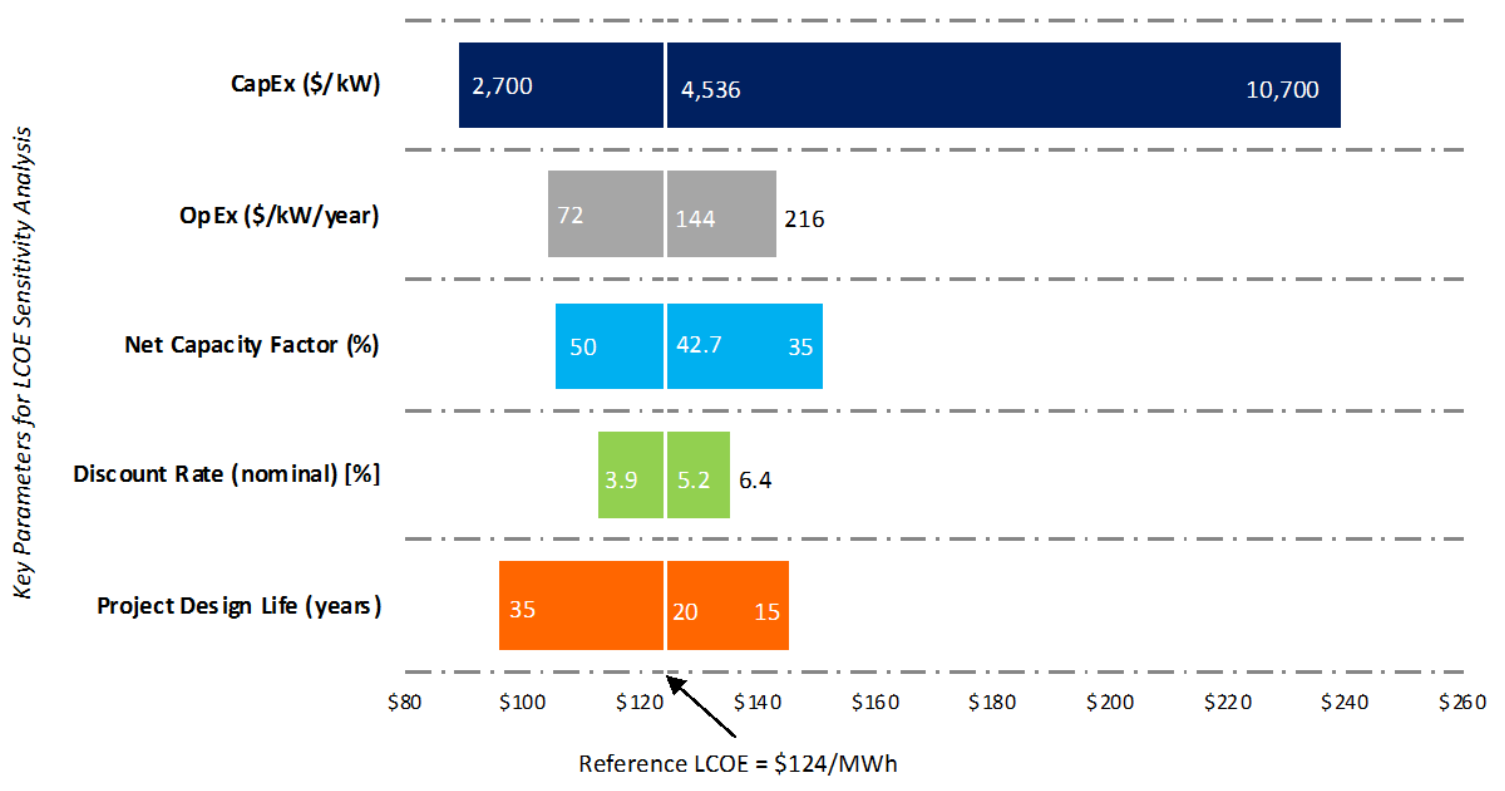

Figure 10. Sensitivity of fixed-bottom offshore wind LCOE to key input parameters Source: NREL 


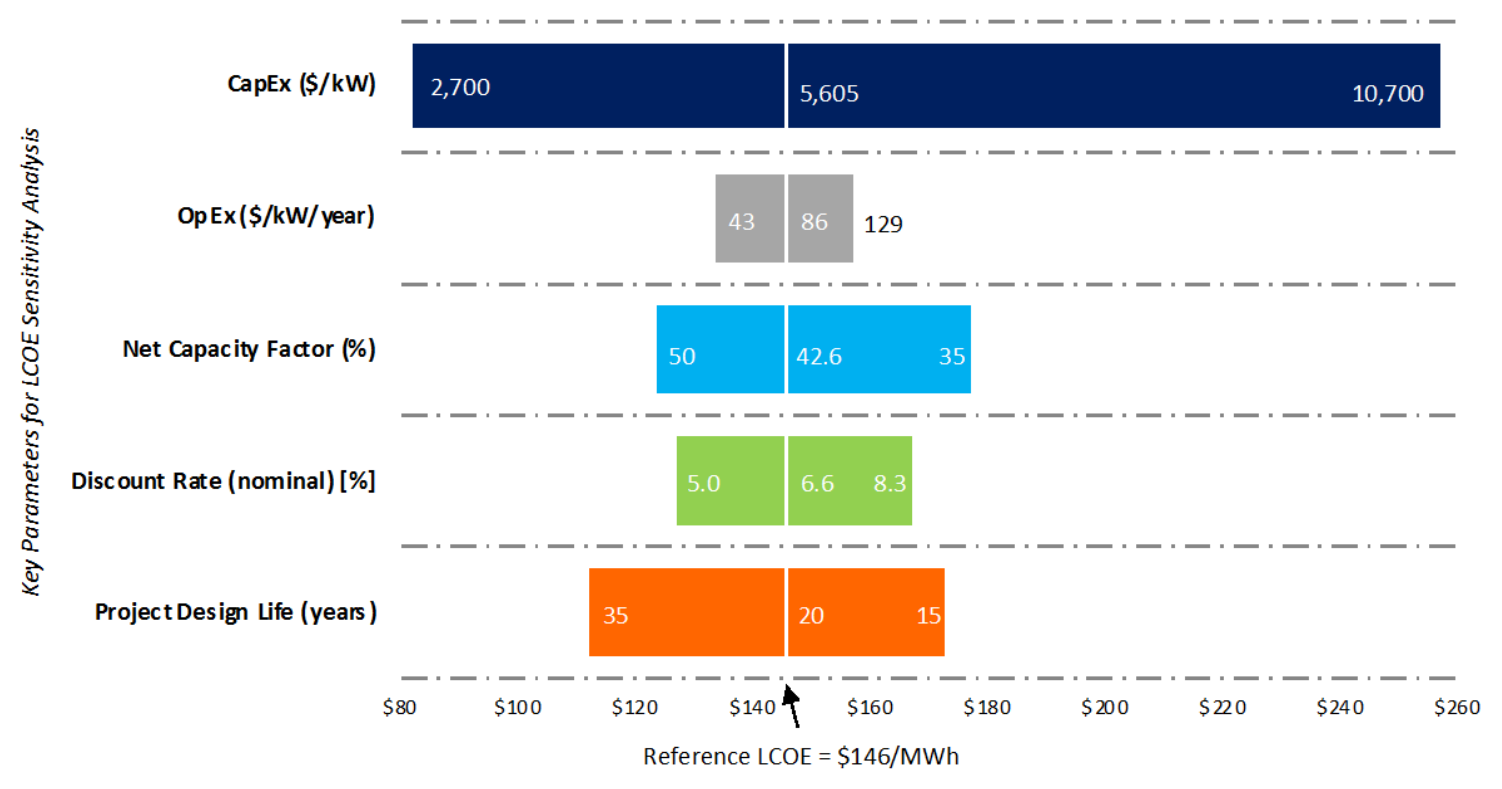

Figure 11. Sensitivity of floating offshore wind LCOE to key input parameters Source: NREL

Note: The reference LCOE reflects a representative industry LCOE. Changes in LCOE for a single variable can be understood by moving to the left or right along a specific variable. Values on the x-axis indicate how the LCOE will change as a given variable is altered and all others are assumed constant (i.e., remain reflective of the reference project).

Sensitivity analyses are conducted by holding all reference project assumptions constant and altering only the variable in question. Sensitivity ranges are selected to represent the highs and lows observed in the industry and from the data in the 2017 Offshore Wind Technologies Market Update (Beiter et al. 2018). This selection of ranges provides insight into how real-world ranges influence LCOE. Keeping the same 600-MW project size, the sensitivity analysis yields ranges in LCOE from a low of \$89/MWh to a high of \$239/MWh for fixed-bottom configurations (Figure 10), and a low of \$82/MWh to a high of \$257/MWh for floating configurations (Figure 11). Within the ranges shown, CapEx and project design life are the two factors that are shown to have the greatest impact on offshore wind LCOE and the greatest influence on decreasing LCOE relative to the reference project.

\subsection{Offshore Supply Curve}

A total of approximately 2,060 GW of offshore wind technical resource potential is estimated by Musial et al. (2016) for all major U.S. coastal regions (excluding Alaska). The LCOE for each of the potential wind power plant locations is computed using a site-specific CapEx and net AEP using a geographic-information-system-based algorithm that is used in the economic potential report for offshore wind (Beiter et al. 2017). The range of LCOE calculated for this theoretical capacity ranged from $\$ 122 / \mathrm{MWh}$ to $\$ 423 / \mathrm{MWh}$ in $2017 .{ }^{18}$ Figure 12 illustrates this supply curve and shows the location of the 2017 fixed-bottom offshore reference site (marked with an orange

${ }^{18}$ LCOE calculations of the theoretical supply curve for 2017 are estimated by interpolating between the modeled LCOE estimates between 2015 and 2022. 
diamond) based on the market data in the 2017 Offshore Wind Technologies Market Update (Beiter et al. 2018), analysis using the NREL Offshore Wind Cost Model (Beiter et al. 2016), and the representative offshore site and wind characteristics presented in Section 5.3.

Note that the potential wind power plant capacity available over a range of LCOE varies by offshore geographic region primarily because of the available wind resource, distance from port, and water depth. Incremental costs associated with labor rates, material costs, logistical or siting challenges, and distance to existing transmission infrastructure also contribute to regional differences.

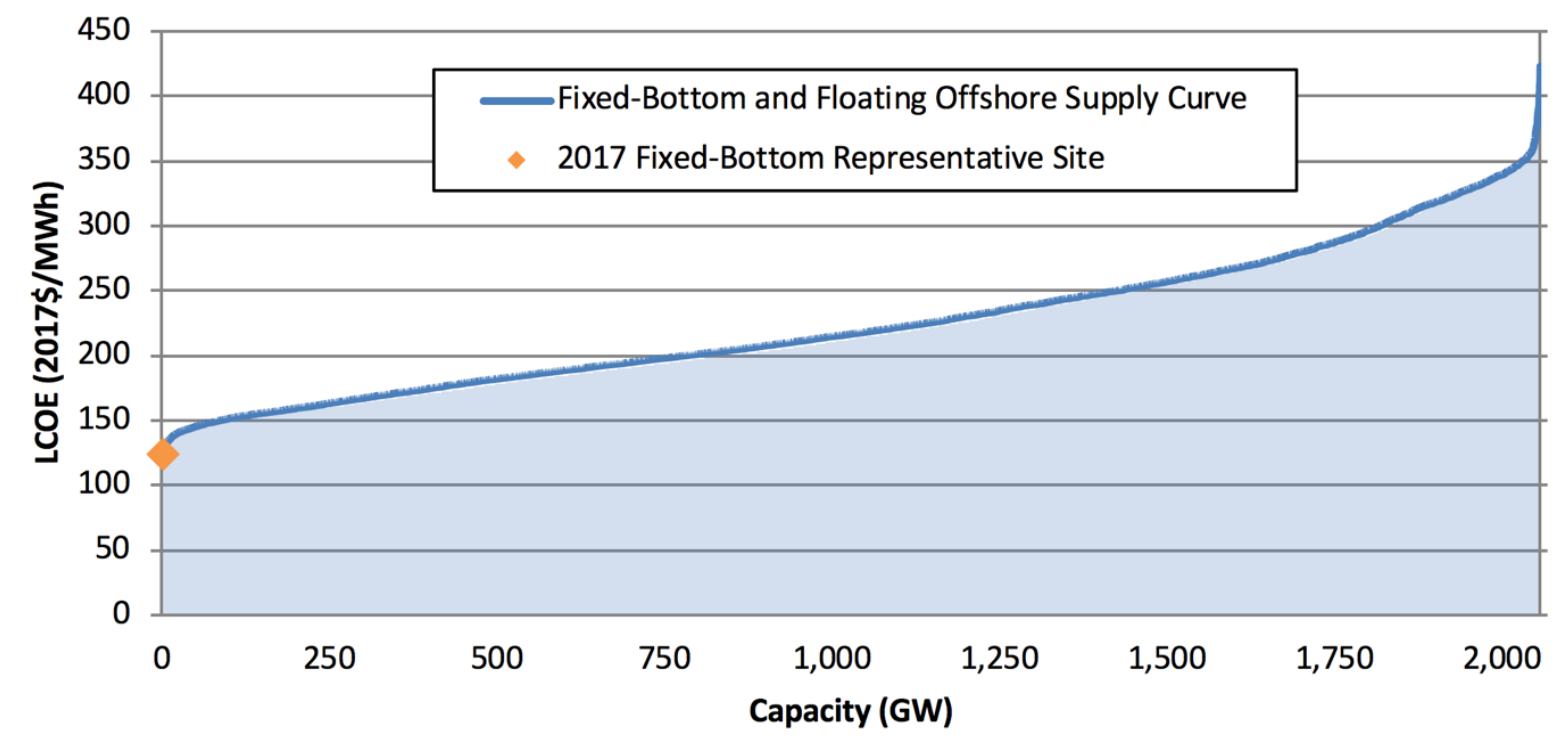

Figure 12. National fixed-bottom and floating offshore wind supply curve Source: NREL

\subsection{Offshore Discussion of Results in Context of DOE Goals}

In this section, we present the official offshore wind GPRA levelized cost of energy end point targets, reported in 2015 USD. For offshore wind, the LCOE targets are only reported for fixedbottom technologies. The GPRA targets are calculated assuming an annual average wind speed of $8.4 \mathrm{~m} / \mathrm{s}$ at $50 \mathrm{~m}$, power plant life of 20 years, and a real FCR of 7.0\%. The updated GPRA targets for 2016 through 2030 are shown in Figure 13. Currently, the end point target for the GPRA 2030 target is $\$ 93 / \mathrm{MWh}$ in 2015 USD. These trajectories are informed by technology innovations considered in the spatial economic analysis by Beiter et al. (2016). The reported LCOE value for 2018 is calculated using 2017 offshore wind market data from Beiter et al. (2018) and updated financial assumptions from NREL's 2018 ATB (NREL's Annual Technology Baseline and Standard Scenarios web page) to arrive at a real FCR of 7.0\% to achieve the \$119/MWh in 2015 USD. In Figure 13, this value is labeled as "Actuals.” The LCOE is converted from 2017 USD to 2015 USD by applying a 96.3\% inflation rate derived from BLS conversion factors. 


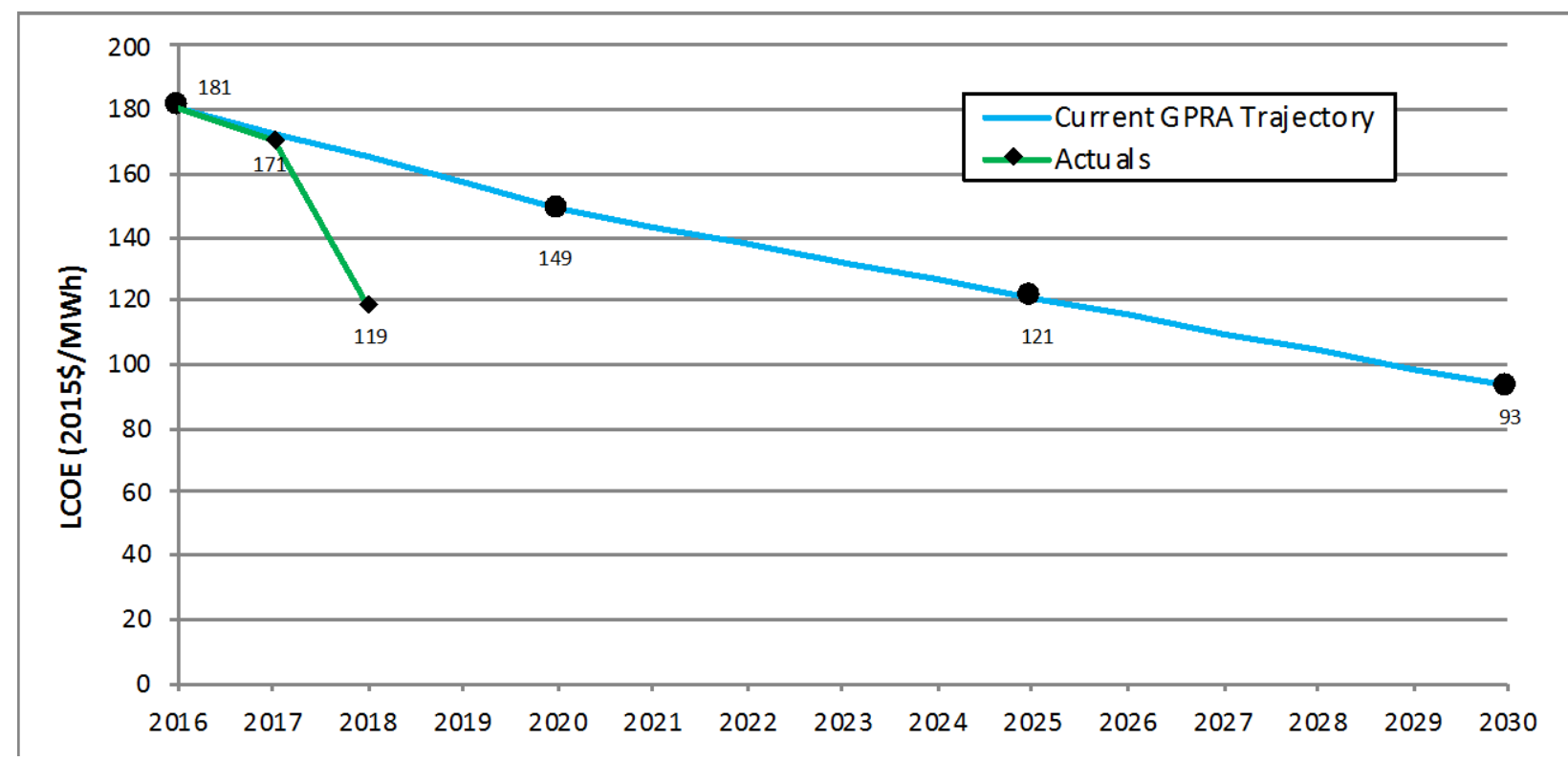

Figure 13. Fixed-bottom wind GPRA cost trajectories for LCOE Source: NREL

Note: The GPRA LCOE targets were rebaselined in 2015; therefore, the GPRA trajectory and the actuals are reported in 2015 USD. 


\section{Conclusions and Future Work}

This analysis presents a picture of the levelized cost of land-based and offshore wind energy using empirically derived and modeled data representative of 2017 market conditions. Scenario planning and modeling activities often focus on one number (or cost) for land-based LCOE and one for offshore LCOE. In reality, the cost of land-based wind energy varies greatly across the United States and offshore wind LCOE varies significantly across Europe and Asia (Table 22).

Notably, the LCOE analysis presented in this report is only one way to measure the cost of wind energy. It does not include other costs and price issues that influence a given wind project's viability, such as transmission, environmental impacts, military constraints, or other areas of consideration (e.g., public policy, consumer costs, energy prices, or public acceptance). In addition, these LCOE estimates do not reflect the value of electricity, incentives, or other policy mechanisms (such as production tax credits or investment tax credits) that affect the sales price of electricity produced from wind projects

Table 22. Range of LCOE for U.S. Land-Based and Offshore Wind in 2017

\begin{tabular}{|c|c|c|c|c|}
\hline & \multicolumn{2}{|c|}{ Land-Based Wind Projects } & \multicolumn{2}{|c|}{ Offshore Wind Projects } \\
\hline & Low & High & Low & High \\
\hline CapEx $(\$ / k W)$ & 1,552 & 2,272 & 2,700 & 10,700 \\
\hline OpEx (\$/kW/year) & 28 & 70 & 72 & 216 \\
\hline Net capacity factor (\%) & $30 \%$ & $43 \%$ & $35 \%$ & $50 \%$ \\
\hline Discount rate (nominal) [\%] & $6.6 \%$ & $8.6 \%$ & $3.9 \%$ & $6.4 \%$ \\
\hline Operational life (years) & 15 & 35 & 15 & 35 \\
\hline LCOE (\$/MWh) & 42 & 65 & 82 & 257 \\
\hline
\end{tabular}

The analysis and findings in this report helped generate the following conclusions:

- LCOE estimates continue to show a downward trend from the 2010 Cost of Wind Energy Review (Tegen et al. 2012) to 2017. Land-based and offshore technologies have shown similar cost reduction trends.

- The reference project LCOE for land-based installations are observed to be \$47/MWh; the full range of single-variable, land-based sensitivity estimates covers $\$ 42-\$ 65 / \mathrm{MWh}$.

- $\quad$ The reference offshore LCOE project estimates are \$124/MWh for fixed-bottom substructures and \$146/MWh for floating substructures, with a single-variable sensitivity range of $\$ 82-\$ 257 / \mathrm{MWh}$. This range is mostly caused by the large variation in CapEx $(\$ 2,700-\$ 10,700 / \mathrm{kW})$ reported by project developers, and is in part a function of differences in water depth and distance to shore. Offshore wind cost reductions show a steep reduction through 2017 and are showing alignment more with recent European project bids or "strike prices" and might suggest continued significant reductions in the coming years.

- The sensitivity analysis shows that LCOE can vary widely based on changes in any one of several key factors. The largest effect on LCOE for land-based wind is net capacity factor followed by project design life, then CapEx. The largest effect on LCOE for fixed- 
bottom and floating offshore wind is CapEx followed by project design life, then net capacity factor.

- The range of LCOE calculated for the more than 10,000 GW of theoretical land-based wind capacity ranges from $\$ 32 / \mathrm{MWh}$ to beyond $\$ 500 / \mathrm{MWh}$, with an estimated LCOE range of $\$ 42-\$ 65 / M W h$ for the projects installed in 2017. For fixed-bottom and floating offshore wind technology, an LCOE range between \$122/MWh and \$423/MWh is estimated for approximately 2,060 GW of theoretical capacity for all major U.S. coastal regions (excluding Alaska). The fixed-bottom representative offshore site is on the lower end of this range at $\$ 124 / \mathrm{MWh}$.

- The 2018 GPRA target for land-based wind is \$54/MWh compared to the actual LCOE estimate of \$48/MWh in 2015 USD. For fixed-bottom offshore wind, the GPRA target for 2018 is $\$ 165 /$ MWh compared to the actual LCOE estimate of \$119/MWh in 2015 USD.

NREL continues to work to gain a better understanding of costs associated with many components of wind turbines and their related systems. Ongoing collaboration with industry, growing data sets, and enhanced modeling capabilities are expected to continue to lead to better insights and increased awareness of current and future wind power system and component costs.

Future updates to this report are anticipated to help maintain a perspective on costs that are grounded in real-time market changes and to offer greater insight into the costs and performance of individual components related to the wind electric generation system. In addition, these reports are intended to provide greater clarity regarding wind energy costs and the effects of changes in specific variables on LCOE. The data and tools developed from this work will be used to help inform projections, goals, and improvement opportunities. As the industry evolves and matures, these data provide current representative project costs and LCOE estimates for scenario planning, modeling, and goal setting.

Future work entails three primary objectives: (1) continuing to enhance data representing marketbased costs, performance, and technology trends to reflect actual wind industry experience, (2) enhancing the fidelity of bottom-up cost and performance estimation for individual wind plant components, and (3) understanding sensitivities to factors, such as regional differences, site characteristics, and technology choices. In 2019 and going forward, NREL will continue to work with industry and national laboratory partners to obtain project-specific data to validate and improve models. 


\section{References}

Beiter, P., W. Musial, A. Smith, L. Kilcher, R. Damiani, M. Maness, S. Sirnivas, T. Stehly, V. Gevorgian, M. Mooney, G. Scott. 2016. A Spatial-Economic Cost Reduction Pathway Analysis for U.S. Offshore Wind Energy Development from 2015-2030 (Technical Report), NREL/TP6A20-66579. National Renewable Energy Laboratory (NREL), Golden, CO (US). https://www.nrel.gov/docs/fy16osti/66579.pdf.

Beiter, P., W. Musial, L. Kilcher, M. Maness, A. Smith. 2017. An Assessment of the Economic Potential of Offshore Wind in the United States from 2015 to 2030 (Technical Report), NREL/TP-6A20-67675. National Renewable Energy Laboratory (NREL), Golden, CO (US). https://www.nrel.gov/docs/fy17osti/67675.pdf.

Beiter, P., P. Spitsen, J. Nunemaker, T. Tian, W. Musial, E. Lantz. 2018. 2017 Offshore Wind Technologies Market Update. U.S. Department of Energy, Washington, D.C. (US). https://www.energy.gov/sites/prod/files/2018/08/f54/71709_0.pdf.

Bureau of Labor and Statistics. Undated. “CPI Inflation Calculator,” Accessed September 2017. https://www.bls.gov/data/\#calculators.

Bolinger, M. 2014. An Analysis of the Costs, Benefits, and Implications of Different Approaches to Capturing the Value of Renewable Energy Tax Incentives. Lawrence Berkeley National Laboratory. https://emp.lbl.gov/sites/default/files/lbnl-6610e.pdf.

DONG Energy (Orsted). 2017. "DONG Energy awarded three German offshore wind projects." Accessed December 2017. http://www.dongenergy.com/en/media/newsroom/companyannouncements-details?omxid=1557851.

Dykes, K., M. Hand, T. Stehly, P. Veers, M. Robinson, E. Lantz. 2017. Enabling the SMART Wind Power Plant of the Future Through Science-Based Innovation (Technical Report), NREL/TP-5000-68123. National Renewable Energy Laboratory (NREL). Golden, CO (US). https://www.nrel.gov/docs/fy17osti/68123.pdf.

GE Renewable Energy. 2018. GE announces Haliade- $X$, the world's most powerful offshore wind turbine. Accessed June 2018. https://www.genewsroom.com/press-releases/ge-announceshaliade-X-worlds-most-powerful-offshore-wind-turbine-284260.

Gilman, P., B. Maurer, L. Feinberg, A. Duerr, L. Peterson, W. Musial, P. Beiter, J. Golladay, J. Stromberg, I. Johnson, D. Boren, A. Moore. 2016. National Offshore Wind Strategy: Facilitating the Development of the Offshore Wind Industry in the United States. DOE/GO-102016-4866. U.S. Department of Energy, Washington, D.C. (US). http://energy.gov/sites/prod/files/2016/09/f33/National-Offshore-Wind-Strategy-report09082016.pdf.

Jacquemin, J., D. Butterworth, C. Garret, N. Baldock, A. Henderson. 2011. WindspeedInventory of location specific wind energy cost. Intelligent Energy Europe. EIE/07/759/S12.499460. http://www.windspeed.eu/media/publications/WINDSPEED_D2_2_revised_May_2011.pdf. 
Mai, T., W. Cole, V. Krishnan, M. Bolinger. 2015. "Impact of Federal Tax Policy on UtilityScale Solar Deployment Given Financing Interactions.” NREL/PR-6A20-65014. National Renewable Energy Laboratory (NREL), Golden, CO (US). http://www.nrel.gov/docs/fy16osti/65014.pdf.

Maness, M., B. Maples, and A. Smith. 2016. NREL Offshore Balance-of-System Model (Technical Report). TP-6A20-66874. National Renewable Energy Laboratory (NREL), Golden, CO (US). http://www.nrel.gov/docs/fy17osti/66874.pdf.

Maples, B., G. Saur, M. Hand, R. van de Pietermen, T. Obdam. 2013. Installation, Operation, and Maintenance Strategies to Reduce the Cost of Offshore Wind Energy (Technical Report). NREL/TP-5000-57403. National Renewable Energy Laboratory (NREL), Golden, CO (US). http://www.nrel.gov/docs/fy13osti/57403.pdf.

Moné, C., A. Smith, B. Maples, and M. Hand. 2015a. 2013 Cost of Wind Energy Review (Technical Report). NREL/TP-5000-63267. National Renewable Energy Laboratory (NREL), Golden, CO (US). http://www.nrel.gov/docs/fy15osti/63267.pdf.

Moné, C., T. Stehly, B. Maples, and E. Settle. 2015b. 2014 Cost of Wind Energy Review (Technical Report). NREL/TP-6A20-64281. National Renewable Energy Laboratory (NREL), Golden, CO (US). http://www.nrel.gov/docs/fy16osti/64281.pdf.

Moné, C., M. Hand, M. Bolinger, J. Rand, D. Heimiller, J. Ho. 2017. 2015 Cost of Wind Energy Review (Technical Report). NREL/TP-6A20-66861. National Renewable Energy Laboratory (NREL), Golden, CO (US). https://www.nrel.gov/docs/fy17osti/66861.pdf.

Musial, W., P. Beiter, D. Heimiller, and G. Scott. 2016. 2016 Offshore Wind Energy Resource Assessment for the United States (Technical Report). NREL/TP-5000-66599. National Renewable Energy Laboratory (NREL), Golden, CO (US). http://www.nrel.gov/docs/fy16osti/66599.pdf.

Musial, W., P. Beiter, P. Schwabe, T. Tian, T. Stehly, P. Spitsen. 2017. 2016 Offshore Wind Technologies Market Report. DOE/GO-102017-5031. U.S. Department of Energy, Washington, D.C. (US). https://energy.gov/sites/prod/files/2017/08/f35/2016\%20Offshore\%20Wind\%20Technologies\%2 0Market\%20Report.pdf.

National Renewable Energy Laboratory (NREL). (Internal, undated). Offshore Wind Database.

NREL. (Internal, undated). Land-Based Wind Balance of System Model.

“Annual Technology Baseline and Standard Scenarios.” National Renewable Energy Laboratory (NREL), Golden, CO (US). Accessed August 2018.

http://www.nrel.gov/analysis/data_tech_baseline.html.

“Renewable Resource Data Center.” National Renewable Energy Laboratory (NREL), Golden, CO (US). Accessed August 2017. http://rredc.nrel.gov/wind/pubs/atlas/tables/1-1T.html. 
"System Advisor Model (SAM).” National Renewable Energy Laboratory (NREL), Golden, CO (US). Accessed August 2017. Published on April 5, 2010. https://sam.nrel.gov/.

Pietermen, R., H. Braam, T. Obdam, L. Rademakers, T. van der Zee. 2011. Optimisation of maintenance strategies for offshore wind farms. Energy research Centre of the Netherlands. http://www.ecn.nl/docs/library/report/2011/m11103.pdf.

Short, W., D. J. Packey, and T. Holt. 1995. A Manual for the Economic Evaluation of Energy Efficiency and Renewable Energy Technologies (Technical Report). NREL/TP-462-5176.

National Renewable Energy Laboratory (NREL), Golden, CO (US).

http://www.nrel.gov/docs/legosti/old/5173.pdf.

Spyroudi, A. 2016. Cost Modelling Analysis of Floating Wind Technologies: Assessing the Potential of TLPWIND. Offshore Renewable Energy Catapult.

https://ore.catapult.org.uk/app/uploads/2017/12/SP00006-Cost-Modelling-Analysis-of-FloatingWind-Technologies.pdf.

Stehly, T., D. Heimiller, G. Scott. 2017. 2016 Cost of Wind Energy Review (Technical Report). NREL/TP-6A20-70363. National Renewable Energy Laboratory (NREL), Golden, CO (US). https://www.nrel.gov/docs/fy18osti/70363.pdf.

Tax Cuts and Jobs Act, H.R. 1., 115 ${ }^{\text {th }}$ Cong. (December 22, 2017), H.R.1 - An Act to provide for reconciliation pursuant to titles II and $V$ of the concurrent resolution on the budget for fiscal year 2018. https://www.congress.gov/bill/115th-congress/house-bill/1.

Tegen, S., M. Hand, B. Maples, E. Lantz, S. Schwabe, A. Smith. 2012. 2010 Cost of Wind Energy Review (Technical Report). NREL/TP-5000-52920. National Renewable Energy Laboratory (NREL), Golden, CO (US). http://www.nrel.gov/docs/fy12osti/52920.pdf.

Tegen, S, E. Lantz, M. Hand, B. Maples, A. Smith, P. Schwabe. 2013. 2011 Cost of Wind Energy Review (Technical Report). NREL/TP-5000-56266. National Renewable Energy Laboratory (NREL), Golden, CO (US). http://www.nrel.gov/docs/fy13osti/56266.pdf.

U.S. Department of Energy (DOE). 2015. Wind Vision: A New Era for Wind Power in the United States. DOE/GO-102015-4557. DOE Office of Energy Efficiency and Renewable Energy. Washington, D.C. (US). http://www.energy.gov/sites/prod/files/WindVision_Report_final.pdf.

Wiser, R. and M. Bolinger. 2016. 2015 Wind Technologies Market Report. U.S. Department of Energy, Office of Energy Efficiency and Renewable Energy. Washington, D.C. (US). http://energy.gov/sites/prod/files/2016/08/f33/2015-Wind-Technologies-Market-Report08162016.pdf.

Wiser, R. and M. Bolinger. 2018. 2017 Wind Technologies Market Report. U.S. Department of Energy, Office of Energy Efficiency and Renewable Energy. Washington, D.C. (US). https:/emp.lbl.gov/sites/default/files/2017_wind_technologies_market_report.pdf. 


\section{Appendix A. Land-Based Wind 30-Year Financial Life Sensitivity}

The financial life is the period in which a project achieves the requisite cash flow it needs to recover its initial capital expenditures (CapEx) and meet investors' internal rate of return threshold. In basic levelized cost of energy (LCOE) analysis, this is the period in which capital is recovered at a specified rate of return, with a composite implied internal rate of return threshold based on the project's weighted-average cost of capital. Historically, prior versions of this report assumed financial life of a land-based wind power plant has been 20 years but recently the financial life has been increased to 25 years (Stehly et al. 2017). The 25-year financial life assumption was derived from the period associated with engineering certification processes and procedures. This appendix includes a calculation of the sensitivity of a longer land-based wind power plant financial life of 30 years and reports its impact on the cost of energy. We consider this extended financial life based on data from direct engagements with wind power plant owners. For this sensitivity analysis, we change the plant's financial life from 25 to 30 years. All other wind power plant assumptions (i.e., CapEx, operational expenditures [OpEx], and net annual energy production remain the same as the analysis provided in the main body of this report. A summary of the financial parameters impacted by increasing the plant life to 30 years (i.e., capital recovery factor, fixed charge rate, and levelized cost of energy) are shown in Table A1.

Table A1. Summary of Offshore Capital Recovery Factor, Fixed Charge Rate, and Levelized Cost of Energy for 30-Year Useful Life

\begin{tabular}{|lcc|}
\hline & Nominal & Real \\
\hline Capital recovery factor (\%) & $\mathbf{8 . 5 \%}$ & $\mathbf{6 . 5 \%}$ \\
\hline Fixed charge rate (\%) & $9.6 \%$ & $7.3 \%$ \\
\hline TOTAL LCOE (\$/MWh) & \multicolumn{3}{|c|}{$\mathbf{4 4}$} \\
\hline
\end{tabular}

Based on this sensitivity analysis, extending the plant's financial life and assumed period in which the threshold internal rate of return is achieved from 25 to 30 years results in a reduction of LCOE of approximately 6\%-a decrease from \$47/MWh to \$44/MWh. 


\section{Appendix B. Offshore Wind 25- and 30-Year Financial Life Sensitivity}

The same financial life sensitivity analysis conducted for land-based wind in Appendix A was performed for fixed-bottom and floating offshore wind. Historically, the assumed financial life of an offshore wind power plant has been 20 years. The 20 -year financial life assumption was derived from the period associated with engineering certification processes and procedures. This appendix includes a calculation of the sensitivity of a longer offshore wind power plant financial life of 25 and 30 years for fixed-bottom and floating wind facilities and reports its impact on the cost of energy. We consider this extended financial life based on data from direct engagements with wind power plant owners and analysis of European offshore wind power plant lifetime. For this sensitivity analysis, we change the plant's financial life from 20 to 25 and 30 years. All other wind power plant assumptions (i.e., capital expenditures, operational expenditures, and net annual energy production) remain the same as the analysis provided in the main body of this report. A summary of the financial parameters impacted by increasing the plant life to 25 and 30 years (i.e., capital recovery factor, fixed charge rate, and levelized cost of energy [LCOE]) are shown in Table B1.

Table B1. Summary of Offshore Capital Recovery Factor, Fixed Charge Rate, and Levelized Cost of Energy for 25- and 30-Year Useful Life

\begin{tabular}{|c|c|c|c|c|c|c|c|c|}
\hline & \multicolumn{4}{|c|}{ 25-Year Life } & \multicolumn{4}{|c|}{ 30-Year Life } \\
\hline & \multirow{2}{*}{\multicolumn{2}{|c|}{$\begin{array}{l}\text { Fixed-Bottom } \\
\text { Substructure }\end{array}$}} & \multirow{2}{*}{\multicolumn{2}{|c|}{$\begin{array}{c}\text { Floating } \\
\text { Substructure }\end{array}$}} & \multirow{2}{*}{\multicolumn{2}{|c|}{$\begin{array}{l}\text { Fixed-Bottom } \\
\text { Substructure }\end{array}$}} & \multirow{2}{*}{\multicolumn{2}{|c|}{$\begin{array}{c}\text { Floating } \\
\text { Substructure }\end{array}$}} \\
\hline & & & & & & & & \\
\hline & Nominal & Real & Nominal & Real & Nominal & Real & Nominal & Real \\
\hline Capital recovery factor (\%) & $7.2 \%$ & $5.5 \%$ & $8.3 \%$ & $6.4 \%$ & $6.6 \%$ & $4.8 \%$ & $7.8 \%$ & $5.8 \%$ \\
\hline Fixed charge rate $(\%)$ & $7.8 \%$ & $6.0 \%$ & $9.2 \%$ & $7.1 \%$ & $7.2 \%$ & $5.3 \%$ & $8.6 \%$ & $6.4 \%$ \\
\hline TOTAL LCOE (\$/MWh) & \multicolumn{2}{|c|}{111} & \multicolumn{2}{|c|}{130} & \multicolumn{2}{|c|}{102} & \multicolumn{2}{|c|}{119} \\
\hline
\end{tabular}

The increased wind power plant financial life from 20 to 25 and 30 years results in a change of the capital recovery factor, fixed charge rate, and LCOE. Based on this sensitivity analysis, extending the plant's financial life and assumed period in which the threshold internal rate of return is achieved from 20 to 25 and 30 years results in a reduction in LCOE for all cases. Fixedbottom projects can experience an approximate $11 \%$ reduction in LCOE from $\$ 124$ MWh to $\$ 111 /$ MWh for a 25-year life and about a $17 \%$ reduction from $\$ 123 /$ MWh to $\$ 102 /$ MWh for a 30 -year life. Floating offshore projects can experience about a 11\% reduction in LCOE, decreasing from $\$ 146 / \mathrm{MWh}$ to $\$ 130 / \mathrm{MWh}$ for a 25 -year life and around an $18 \%$ reduction, or a decrease from \$146/MWh to \$119/MWh for a 30-year life. 


\section{Appendix C. Summary of Assumptions for 2017 Reference Projects}

Table C1. Land-Based Wind Reference Project

\begin{tabular}{|c|c|c|c|}
\hline Assumption & Units & Value & Notes \\
\hline \multicolumn{4}{|c|}{ Wind Power Plant Characteristics } \\
\hline Wind plant capacity & megawatts (MW) & 200 & \multirow{2}{*}{ Representative of commercial-scale projects } \\
\hline Number of turbines & & 87 & \\
\hline Turbine rating & MW & 2.32 & \multirow{3}{*}{$\begin{array}{l}2017 \text { Wind Technologies Market Report (Wiser } \\
\text { and Bolinger 2018) }\end{array}$} \\
\hline Rotor diameter & $\mathrm{m}$ & 113 & \\
\hline Hub height & $\mathrm{m}$ & 86 & \\
\hline Specific power & watts $/ \mathrm{m}^{2}$ & 231 & Calculation \\
\hline Cut-in wind speed & meters per second $(\mathrm{m} / \mathrm{s})$ & 3 & \multirow{2}{*}{ Typical turbine characteristics } \\
\hline Cut-out wind speed & $\mathrm{m} / \mathrm{s}$ & 25 & \\
\hline $\begin{array}{l}\text { Annual average wind speed } \\
\text { at } 50 \text { meters }\end{array}$ & $\mathrm{m} / \mathrm{s}$ & 7.25 & Class 4 wind site \\
\hline $\begin{array}{l}\text { Annual average wind speed } \\
\text { at hub height }\end{array}$ & $\mathrm{m} / \mathrm{s}$ & 7.83 & Power law calculation \\
\hline Weibull k factor & & 2.0 & \\
\hline Shear exponent & & 0.143 & Shear for neutral stability conditions \\
\hline $\begin{array}{l}\text { Turbine elevation above sea } \\
\text { level }\end{array}$ & $\mathrm{m}$ & 450 & \\
\hline Losses & $\%$ & $15 \%$ & \multirow{2}{*}{ Wind Vision (DOE 2015) } \\
\hline Availability & $\%$ & $98 \%$ & \\
\hline Net energy capture & megawatt-hour/MW/year & 3,633 & \multirow{2}{*}{ System Advisor Model calculation } \\
\hline Net capacity factor & $\%$ & $41.5 \%$ & \\
\hline \multicolumn{4}{|c|}{ Capital Expenditures } \\
\hline Total Capital Expenditures & $\$ /$ kilowatt (kW) & 1,610 & $\begin{array}{l}2017 \text { Wind Technologies Market Report (Wiser } \\
\text { and Bolinger 2018) }\end{array}$ \\
\hline Turbine & $\$ / \mathrm{kW}$ & 1,094 & \multirow{11}{*}{2015 Cost and Scaling Model (Dykes et al. 2015) } \\
\hline Rotor module & $\$ / k W$ & 317 & \\
\hline Blades & $\$ / \mathrm{kW}$ & 203 & \\
\hline Pitch assembly & $\$ / k W$ & 66 & \\
\hline Hub assembly & $\$ / \mathrm{kW}$ & 48 & \\
\hline Nacelle module & $\$ / \mathrm{kW}$ & 539 & \\
\hline Nacelle structural assembly & $\$ / \mathrm{kW}$ & 108 & \\
\hline Drivetrain assembly & $\$ / k W$ & 211 & \\
\hline Nacelle electrical assembly & $\$ / \mathrm{kW}$ & 184 & \\
\hline Yaw assembly & $\$ / \mathrm{kW}$ & 35 & \\
\hline Tower module & $\$ / \mathrm{kW}$ & 237 & \\
\hline Balance of system & $\$ / \mathrm{kW}$ & 360 & \multirow{3}{*}{$\begin{array}{l}\text { Land-Based Wind Balance of System Model (NREL } \\
\text { 2010) }\end{array}$} \\
\hline Development cost & $\$ / \mathrm{kW}$ & 17 & \\
\hline Engineering management & $\$ / \mathrm{kW}$ & 20 & \\
\hline
\end{tabular}

This report is available at no cost from the National Renewable Energy Laboratory (NREL) at www.nrel.gov/publications. 


\begin{tabular}{|c|c|c|c|}
\hline Assumption & Units & Value & Notes \\
\hline Foundation & $\$ / \mathrm{kW}$ & 65 & \\
\hline Site access and staging & $\$ / \mathrm{kW}$ & 48 & \\
\hline Assembly and installation & $\$ / \mathrm{kW}$ & 49 & \\
\hline Electrical infrastructure & $\$ / \mathrm{kW}$ & 160 & \\
\hline Soft costs & $\$ / \mathrm{kW}$ & 157 & \\
\hline Construction finance & $\$ / \mathrm{kW}$ & 60 & $\begin{array}{l}2018 \text { Annual Technology Baseline (NREL's Annual } \\
\text { Technology Baseline and Standard Scenarios web } \\
\text { page) }\end{array}$ \\
\hline Contingency & $\$ / \mathrm{kW}$ & 97 & $6 \%$ of total capital expenditures \\
\hline \multicolumn{4}{|c|}{ Operational Expenditures } \\
\hline $\begin{array}{l}\text { Total operational } \\
\text { expenditures }\end{array}$ & $\$ / \mathrm{kW} /$ year & 44 & $\begin{array}{l}\text { Industry interviews with developers, wind turbine } \\
\text { manufacturers, and other available data }\end{array}$ \\
\hline \multicolumn{4}{|c|}{ Financials } \\
\hline Project design life & Years & 25 & Project life for GPRA reporting \\
\hline $\begin{array}{l}\text { Tax rate (combined state } \\
\text { and federal) }\end{array}$ & $\%$ & $40 \%$ & \multirow{6}{*}{$\begin{array}{l}2018 \text { Annual Technology Baseline (NREL's Annual } \\
\text { Technology Baseline and Standard Scenarios web } \\
\text { page) }\end{array}$} \\
\hline Federal & $\%$ & $35 \%$ & \\
\hline State & $\%$ & $8 \%$ & \\
\hline Inflation rate & $\%$ & $2.5 \%$ & \\
\hline $\begin{array}{l}\text { Interest during construction } \\
\text { (nominal) }\end{array}$ & $\%$ & $8.0 \%$ & \\
\hline Construction finance factor & $\%$ & $104 \%$ & \\
\hline Debt fraction & $\%$ & $46 \%$ & \multirow{3}{*}{$\begin{array}{l}2017 \text { Wind Technologies Market Report (Wiser } \\
\text { and Bolinger 2018) }\end{array}$} \\
\hline Debt interest rate (nominal) & $\%$ & $4.1 \%$ & \\
\hline Return on equity (nominal) & $\%$ & $12.0 \%$ & \\
\hline $\begin{array}{l}\text { Weighted average cost of } \\
\text { capital (WACC) (nominal; } \\
\text { aftertax) }\end{array}$ & $\%$ & $7.6 \%$ & \multirow{4}{*}{ Calculation } \\
\hline WACC (real; aftertax) & $\%$ & $5.0 \%$ & \\
\hline $\begin{array}{l}\text { Capital recovery factor } \\
\text { (nominal; aftertax) }\end{array}$ & $\%$ & $9.0 \%$ & \\
\hline $\begin{array}{l}\text { Capital recovery factor (real; } \\
\text { aftertax) }\end{array}$ & $\%$ & $7.1 \%$ & \\
\hline Depreciable basis & $\%$ & $100 \%$ & Simplified depreciation schedule \\
\hline Depreciation schedule & $\begin{array}{l}\text { 5-year Modified Accelerated } \\
\text { Cost Recovery System } \\
\text { (MACRS) }\end{array}$ & $\begin{array}{l}5 \text { year } \\
\text { MACRS }\end{array}$ & Standard for U.S. wind projects \\
\hline $\begin{array}{l}\text { Depreciation adjustment } \\
\text { (net present value [NPV]) }\end{array}$ & $\%$ & $82 \%$ & \multirow{4}{*}{ Calculation } \\
\hline Project finance factor & $\%$ & $112 \%$ & \\
\hline Fixed charge rate (nominal) & $\%$ & $10.1 \%$ & \\
\hline FCR (real) & $\%$ & $7.9 \%$ & \\
\hline Levelized cost of energy & $\$ / M W h$ & 47 & Calculation \\
\hline
\end{tabular}


Table C2. Fixed-Bottom Offshore Wind Reference Project

\begin{tabular}{|c|c|c|c|}
\hline Assumption & Units & Value & Notes \\
\hline \multicolumn{4}{|c|}{ Wind Power Plant Characteristics } \\
\hline Wind plant capacity & MW & 600 & \multirow{2}{*}{ Representative of commercial-scale projects } \\
\hline Number of turbines & Number & 107 & \\
\hline Turbine rating & MW & 5.64 & \multirow{3}{*}{2017 Offshore Wind Technologies Market Update (Beiter et al. 2018) } \\
\hline Rotor diameter & $\mathrm{m}$ & 140 & \\
\hline Hub height & $\mathrm{m}$ & 96.2 & \\
\hline Specific power & $\mathrm{W} / \mathrm{m}^{2}$ & 365 & Calculation \\
\hline Water depth & $\mathrm{m}$ & 30 & \multirow{12}{*}{ Representative characteristics for COE Review } \\
\hline Substructure type & & $\begin{array}{c}\text { Monop } \\
\text { ile }\end{array}$ & \\
\hline Distance from shore & $\mathrm{km}$ & 30 & \\
\hline Maximum rotor tip speed & $\mathrm{m} / \mathrm{s}$ & 90 & \\
\hline Maximum tip speed ratio & & 8 & \\
\hline Cut-in wind speed & $\mathrm{m} / \mathrm{s}$ & 3 & \\
\hline Cut-out wind speed & $\mathrm{m} / \mathrm{s}$ & 25 & \\
\hline $\begin{array}{l}\text { Maximum coefficient of } \\
\text { power }\end{array}$ & & 0.47 & \\
\hline $\begin{array}{l}\text { Average annual wind speed } \\
\text { at } 50 \mathrm{~m}\end{array}$ & $\mathrm{~m} / \mathrm{s}$ & 8.4 & \\
\hline $\begin{array}{l}\text { Average annual wind speed } \\
\text { at hub height }\end{array}$ & $\mathrm{m} / \mathrm{s}$ & 9.0 & \\
\hline Shear exponent & & 0.10 & \\
\hline Weibull k & & 2.1 & \\
\hline Total system losses & $\%$ & $15.8 \%$ & \multirow{5}{*}{ NREL Offshore Wind Cost Model (Beiter et al. 2016) } \\
\hline Gross energy capture & $\begin{array}{l}\mathrm{MWh} / \\
\mathrm{MW} / \mathrm{yr}\end{array}$ & 4,441 & \\
\hline Net energy capture & $\begin{array}{l}\mathrm{MWh} / \\
\mathrm{MW} / \mathrm{yr}\end{array}$ & 3,741 & \\
\hline Gross capacity factor & $\%$ & $50.7 \%$ & \\
\hline Net capacity factor & $\%$ & $42.7 \%$ & \\
\hline \multicolumn{4}{|r|}{ CapEx } \\
\hline Total CapEx & $\$ / \mathrm{kW}$ & 4,536 & \multirow{11}{*}{ NREL Offshore Wind Cost Model (Beiter et al. 2016) } \\
\hline Turbine & $\$ / \mathrm{kW}$ & 1,557 & \\
\hline Rotor nacelle assembly & $\$ / \mathrm{kW}$ & 1,315 & \\
\hline Tower & $\$ / \mathrm{kW}$ & 242 & \\
\hline Balance of System & $\$ / \mathrm{kW}$ & 2,289 & \\
\hline Development & $\$ / \mathrm{kW}$ & 150 & \\
\hline Project management & $\$ / \mathrm{kW}$ & 76 & \\
\hline $\begin{array}{l}\text { Substructure and } \\
\text { foundation }\end{array}$ & $\$ / \mathrm{kW}$ & 613 & \\
\hline Substructure & $\$ / \mathrm{kW}$ & 228 & \\
\hline Foundation & $\$ / \mathrm{kW}$ & 385 & \\
\hline $\begin{array}{l}\text { Port and staging, logistics, } \\
\text { transportation }\end{array}$ & $\$ / \mathrm{kW}$ & 56 & \\
\hline
\end{tabular}




\begin{tabular}{|c|c|c|c|}
\hline Assumption & Units & Value & Notes \\
\hline Electrical infrastructure & $\$ / \mathrm{kW}$ & 1,106 & \\
\hline Array cable system & $\$ / \mathrm{kW}$ & 379 & \\
\hline Export cable system & $\$ / \mathrm{kW}$ & 523 & \\
\hline Grid connection & $\$ / \mathrm{kW}$ & 204 & \\
\hline Assembly and installation & $\$ / \mathrm{kW}$ & 288 & \\
\hline Turbine installation & $\$ / \mathrm{kW}$ & 105 & \\
\hline $\begin{array}{l}\text { Substructure and } \\
\text { foundation installation }\end{array}$ & $\$ / \mathrm{kW}$ & 183 & \\
\hline Soft costs & $\$ / \mathrm{kW}$ & 690 & \\
\hline $\begin{array}{l}\text { Insurance during } \\
\text { construction }\end{array}$ & $\$ / \mathrm{kW}$ & 40 & \\
\hline Decommissioning bond & $\$ / \mathrm{kW}$ & 46 & \\
\hline Construction finance & $\$ / \mathrm{kW}$ & 285 & \\
\hline Sponsor contingency & $\$ / \mathrm{kW}$ & 279 & \\
\hline Procurement contingency & $\$ / \mathrm{kW}$ & 186 & \\
\hline Installation contingency & $\$ / \mathrm{kW}$ & 93 & \\
\hline $\begin{array}{l}\text { Project completions/ } \\
\text { commissioning }\end{array}$ & $\$ / \mathrm{kW}$ & 40 & \\
\hline \multicolumn{4}{|r|}{ OpEx } \\
\hline Total OpEx & $\$ / \mathrm{kW} / \mathrm{yr}$ & 144 & \multirow{3}{*}{ NREL Offshore Wind Cost Model (Beiter et al. 2016) } \\
\hline Operation (pretax) & $\$ / \mathrm{kW} / \mathrm{yr}$ & 31 & \\
\hline Maintenance & $\$ / \mathrm{kW} / \mathrm{yr}$ & 113 & \\
\hline & & & Financials \\
\hline Project design life & Years & 20 & Offshore wind project life for GPRA reporting \\
\hline $\begin{array}{l}\text { Tax rate (combined state } \\
\text { and federal) }\end{array}$ & $\%$ & $40 \%$ & \multirow{7}{*}{$\begin{array}{l}2018 \text { Annual Technology Baseline (NREL's Annual Technology Baseline } \\
\text { and Standard Scenarios web page) }\end{array}$} \\
\hline Federal & $\%$ & $35 \%$ & \\
\hline State & $\%$ & $7.5 \%$ & \\
\hline Inflation rate & $\%$ & $2.5 \%$ & \\
\hline Debt fraction & $\%$ & $70 \%$ & \\
\hline Debt interest rate (nominal) & $\%$ & $3.7 \%$ & \\
\hline Return on equity (nominal) & $\%$ & $12.0 \%$ & \\
\hline WACC (nominal; aftertax) & $\%$ & $5.2 \%$ & \multirow{4}{*}{ Calculation } \\
\hline WACC (real; aftertax) & $\%$ & $2.6 \%$ & \\
\hline $\begin{array}{l}\text { Capital recovery factor } \\
\text { (nominal; aftertax) }\end{array}$ & $\%$ & $8.1 \%$ & \\
\hline $\begin{array}{l}\text { Capital recovery factor (real; } \\
\text { aftertax) }\end{array}$ & $\%$ & $6.5 \%$ & \\
\hline Depreciable basis & $\%$ & $100 \%$ & Simplified depreciation schedule \\
\hline Depreciation schedule & & $\begin{array}{c}5 \text { year } \\
\text { MACR } \\
\text { S }\end{array}$ & Standard for U.S. wind projects \\
\hline $\begin{array}{l}\text { Depreciation adjustment } \\
\text { (NPV) }\end{array}$ & $\%$ & $87.1 \%$ & \multirow[t]{2}{*}{ Calculation } \\
\hline Project finance factor & $\%$ & $109 \%$ & \\
\hline
\end{tabular}




\begin{tabular}{|l|c|c|c|}
\hline \multicolumn{1}{|c|}{ Assumption } & Units & \multicolumn{1}{c|}{ Value } & Notes \\
\cline { 1 - 2 } FCR (nominal) & $\%$ & $8.8 \%$ & \\
\cline { 1 - 2 } FCR (real) & $\%$ & $7.0 \%$ & \\
\cline { 1 - 3 } LCOE & $\$$ MWh & $124 \quad$ Calculation \\
\hline
\end{tabular}

Table C3. Floating Offshore Wind Reference Project

\begin{tabular}{|c|c|c|c|}
\hline Assumption & Units & Value & Notes \\
\hline \multicolumn{4}{|c|}{ Wind Power Plant Characteristics } \\
\hline Wind plant capacity & MW & 600 & \multirow{2}{*}{ Representative of commercial-scale projects } \\
\hline Number of turbines & Number & 107 & \\
\hline Turbine rating & MW & 5.64 & \multirow{3}{*}{$\begin{array}{l}2017 \text { Offshore Wind Technologies Market Update (Beiter et al. } \\
\text { 2018) }\end{array}$} \\
\hline Rotor diameter & $\mathrm{m}$ & 140 & \\
\hline Hub height & $\mathrm{m}$ & 96.2 & \\
\hline Specific power & $\mathrm{W} / \mathrm{m}^{2}$ & 365 & Calculation \\
\hline Water depth & $\mathrm{m}$ & 100 & \multirow{12}{*}{ Representative characteristics for COE Review } \\
\hline Substructure type & & $\begin{array}{c}\text { Semi- } \\
\text { submersible }\end{array}$ & \\
\hline Distance from shore & $\mathrm{km}$ & 30 & \\
\hline Maximum rotor tip speed & $\mathrm{m} / \mathrm{s}$ & 90 & \\
\hline Maximum tip speed ratio & & 8 & \\
\hline Cut-in wind speed & $\mathrm{m} / \mathrm{s}$ & 3 & \\
\hline Cut-out wind speed & $\mathrm{m} / \mathrm{s}$ & 25 & \\
\hline $\begin{array}{l}\text { Maximum coefficient of } \\
\text { power }\end{array}$ & & 0.47 & \\
\hline $\begin{array}{l}\text { Average annual wind } \\
\text { speed at } 50 \mathrm{~m}\end{array}$ & $\mathrm{~m} / \mathrm{s}$ & 8.4 & \\
\hline $\begin{array}{l}\text { Average annual wind } \\
\text { speed at hub height }\end{array}$ & $\mathrm{m} / \mathrm{s}$ & 9.0 & \\
\hline Shear exponent & & 0.10 & \\
\hline Weibull k & & 2.1 & \\
\hline Total system losses & $\%$ & $16.1 \%$ & \multirow{5}{*}{ NREL Offshore Wind Cost Model (Beiter et al. 2016) } \\
\hline Gross energy capture & $\begin{array}{l}\mathrm{MWh} / \\
\mathrm{MW} / \mathrm{yr}\end{array}$ & 4,441 & \\
\hline Net energy capture & $\begin{array}{l}\mathrm{MWh} / \\
\mathrm{MW} / \mathrm{yr}\end{array}$ & 3,732 & \\
\hline Gross capacity factor & $\%$ & $50.7 \%$ & \\
\hline Net capacity factor & $\%$ & $42.6 \%$ & \\
\hline & & & CapEx \\
\hline Total CapEx & $\$ / \mathrm{kW}$ & 5,605 & \multirow{6}{*}{ NREL Offshore Wind Cost Model (Beiter et al. 2016) } \\
\hline Turbine & $\$ / \mathrm{kW}$ & 1,521 & \\
\hline Rotor nacelle assembly & $\$ / \mathrm{kW}$ & 1,315 & \\
\hline Tower & $\$ / \mathrm{kW}$ & 206 & \\
\hline Balance of system & $\$ / \mathrm{kW}$ & 3,318 & \\
\hline Development & $\$ / \mathrm{kW}$ & 190 & \\
\hline
\end{tabular}




\begin{tabular}{|c|c|c|c|}
\hline Assumption & Units & Value & Notes \\
\hline Project management & $\$ / \mathrm{kW}$ & 96 & \\
\hline $\begin{array}{l}\text { Substructure and } \\
\text { foundation }\end{array}$ & $\$ / \mathrm{kW}$ & 1,653 & \\
\hline Substructure & $\$ / \mathrm{kW}$ & 1,305 & \\
\hline Foundation & $\$ / \mathrm{kW}$ & 348 & \\
\hline $\begin{array}{l}\text { Port and staging, logistics, } \\
\text { transportation }\end{array}$ & $\$ / \mathrm{kW}$ & 67 & \\
\hline Electrical infrastructure & $\$ / \mathrm{kW}$ & 1,175 & \\
\hline Array cable system & $\$ / \mathrm{kW}$ & 439 & \\
\hline Export cable system & $\$ / \mathrm{kW}$ & 532 & \\
\hline Grid connection & $\$ / \mathrm{kW}$ & 204 & \\
\hline Assembly and installation & $\$ / \mathrm{kW}$ & 137 & \\
\hline Turbine installation & $\$ / \mathrm{kW}$ & 99 & \\
\hline $\begin{array}{l}\text { Substructure and } \\
\text { foundation installation }\end{array}$ & $\$ / \mathrm{kW}$ & 38 & \\
\hline Soft costs & $\$ / \mathrm{kW}$ & 766 & \\
\hline $\begin{array}{l}\text { Insurance during } \\
\text { construction }\end{array}$ & $\$ / \mathrm{kW}$ & 51 & \\
\hline Decommissioning bond & $\$ / \mathrm{kW}$ & 22 & \\
\hline Construction finance & $\$ / \mathrm{kW}$ & 352 & \\
\hline Sponsor contingency & $\$ / \mathrm{kW}$ & 290 & \\
\hline Procurement contingency & $\$ / \mathrm{kW}$ & 246 & \\
\hline Installation contingency & $\$ / \mathrm{kW}$ & 44 & \\
\hline $\begin{array}{l}\text { Project completions/ } \\
\text { commissioning }\end{array}$ & $\$ / \mathrm{kW}$ & 51 & \\
\hline & & & OpEx \\
\hline Total OpEx & $\$ / \mathrm{kW} / \mathrm{yr}$ & 86 & \multirow{3}{*}{ NREL Offshore Wind Cost Model (Beiter et al. 2016) } \\
\hline Operation (pretax) & $\$ / \mathrm{kW} / \mathrm{yr}$ & 31 & \\
\hline Maintenance & $\$ / \mathrm{kW} / \mathrm{yr}$ & 55 & \\
\hline \multicolumn{4}{|c|}{ Financials } \\
\hline Project design life & Years & 20 & Offshore wind project life for GPRA reporting \\
\hline $\begin{array}{l}\text { Tax rate (combined state } \\
\text { and federal) }\end{array}$ & $\%$ & $40 \%$ & \multirow{7}{*}{$\begin{array}{l}2018 \text { Annual Technology Baseline (NREL's Annual Technology } \\
\text { Baseline and Standard Scenarios web page) }\end{array}$} \\
\hline Federal & $\%$ & $35 \%$ & \\
\hline State & $\%$ & $7.5 \%$ & \\
\hline Inflation rate & $\%$ & $2.5 \%$ & \\
\hline Debt fraction & $\%$ & $55 \%$ & \\
\hline $\begin{array}{l}\text { Debt interest rate } \\
\text { (nominal) }\end{array}$ & $\%$ & $3.7 \%$ & \\
\hline $\begin{array}{l}\text { Return on equity } \\
\text { (nominal) }\end{array}$ & $\%$ & $12.0 \%$ & \\
\hline WACC (nominal; aftertax) & $\%$ & $6.6 \%$ & \multirow{3}{*}{ Calculation } \\
\hline WACC (real; aftertax) & $\%$ & $4.0 \%$ & \\
\hline $\begin{array}{l}\text { Capital recovery factor } \\
\text { (nominal; aftertax) }\end{array}$ & $\%$ & $9.2 \%$ & \\
\hline
\end{tabular}




\begin{tabular}{|c|c|c|c|}
\hline Assumption & Units & Value & Notes \\
\hline $\begin{array}{l}\text { Capital recovery factor } \\
\text { (real; aftertax) }\end{array}$ & $\%$ & $7.4 \%$ & \\
\hline Depreciable basis & $\%$ & $100 \%$ & Simplified depreciation schedule \\
\hline Depreciation schedule & & $\begin{array}{l}5 \text { year } \\
\text { MACRS }\end{array}$ & Standard for U.S. wind projects \\
\hline $\begin{array}{l}\text { Depreciation adjustment } \\
\text { (NPV) }\end{array}$ & $\%$ & $83.9 \%$ & \multirow{4}{*}{ Calculation } \\
\hline Project finance factor & $\%$ & $111 \%$ & \\
\hline FCR (nominal) & $\%$ & $10.1 \%$ & \\
\hline FCR (real) & $\%$ & $8.2 \%$ & \\
\hline LCOE & $\$ / \mathrm{MWh}$ & 146 & Calculation \\
\hline
\end{tabular}

This report is available at no cost from the National Renewable Energy Laboratory (NREL) at www.nrel.gov/publications. 